\title{
Eugène REVERT
}

Docteur ès Lettres

Professeur à la Faculté des Lettres

de l’Université de Bordeaux

\section{1}

\section{La magie antillaise}

Un document produit en version numérique par Mme Marcelle Bergeron, bénévole Professeure à la retraite de l'École Dominique-Racine de Chicoutimi, Québec et collaboratrice bénévole Courriel : mabergeron@videotron.ca

Dans le cadre de la collection : "Les classiques des sciences sociales" dirigée et fondée par Jean-Marie Tremblay, professeur de sociologie au Cégep de Chicoutimi Site web: http://classiques.uqac.ca/

Une collection développée en collaboration avec la Bibliothèque Paul-Émile-Boulet de l'Université du Québec à Chicoutimi

Site web: http://classiques.uqac.ca 


\section{Politique d'utilisation de la bibliothèque des Classiques}

Toute reproduction et rediffusion de nos fichiers est interdite, même avec la mention de leur provenance, sans l'autorisation formelle, écrite, du fondateur des Classiques des sciences sociales, JeanMarie Tremblay, sociologue.

Les fichiers des Classiques des sciences sociales ne peuvent sans autorisation formelle:

- être hébergés (en fichier ou page web, en totalité ou en partie) sur un serveur autre que celui des Classiques.

- servir de base de travail à un autre fichier modifié ensuite par tout autre moyen (couleur, police, mise en page, extraits, support, etc...),

Les fichiers (.html, .doc, .pdf., .rtf, .jpg, .gif) disponibles sur le site Les Classiques des sciences sociales sont la propriété des

Classiques des sciences sociales, un organisme à but non lucratif composé exclusivement de bénévoles.

Ils sont disponibles pour une utilisation intellectuelle et personnelle et, en aucun cas, commerciale. Toute utilisation à des fins commerciales des fichiers sur ce site est strictement interdite et toute rediffusion est également strictement interdite.

L'accès à notre travail est libre et gratuit à tous les utilisateurs. C'est notre mission.

Jean-Marie Tremblay, sociologue

Fondateur et Président-directeur général, LES CLASSIQUES DES SCIENCES SOCIALES. 
Un document produit en version numérique par Mme Marcelle Bergeron, bénévole, professeure à la retraite de l’École Dominique-Racine de Chicoutimi, Québec.

courriel : mailto : marcelle_bergeron@uqac.ca

\section{EUGÈNE REVERT}

Une édition électronique réalisée à partir du texte d’Eugène Revert, La magie antillaise. Paris : Les Éditions Bellenand, 1951, 203 pp.

Polices de caractères utilisés :

Pour le texte : Times New Roman, 12 points.

Pour les citations : Times New Roman 10 points.

Pour les notes de bas de page : Times New Roman, 10 points.

Édition électronique réalisée avec le traitement de textes Microsoft Word 2004 pour Macintosh.

Mise en page sur papier format LETTRE (US letter), 8.5'” x 11'”)

Édition complétée le 4 décembre 2008 à Chicoutimi, Province de Québec, Canada. 


\section{Eugène REVERT}

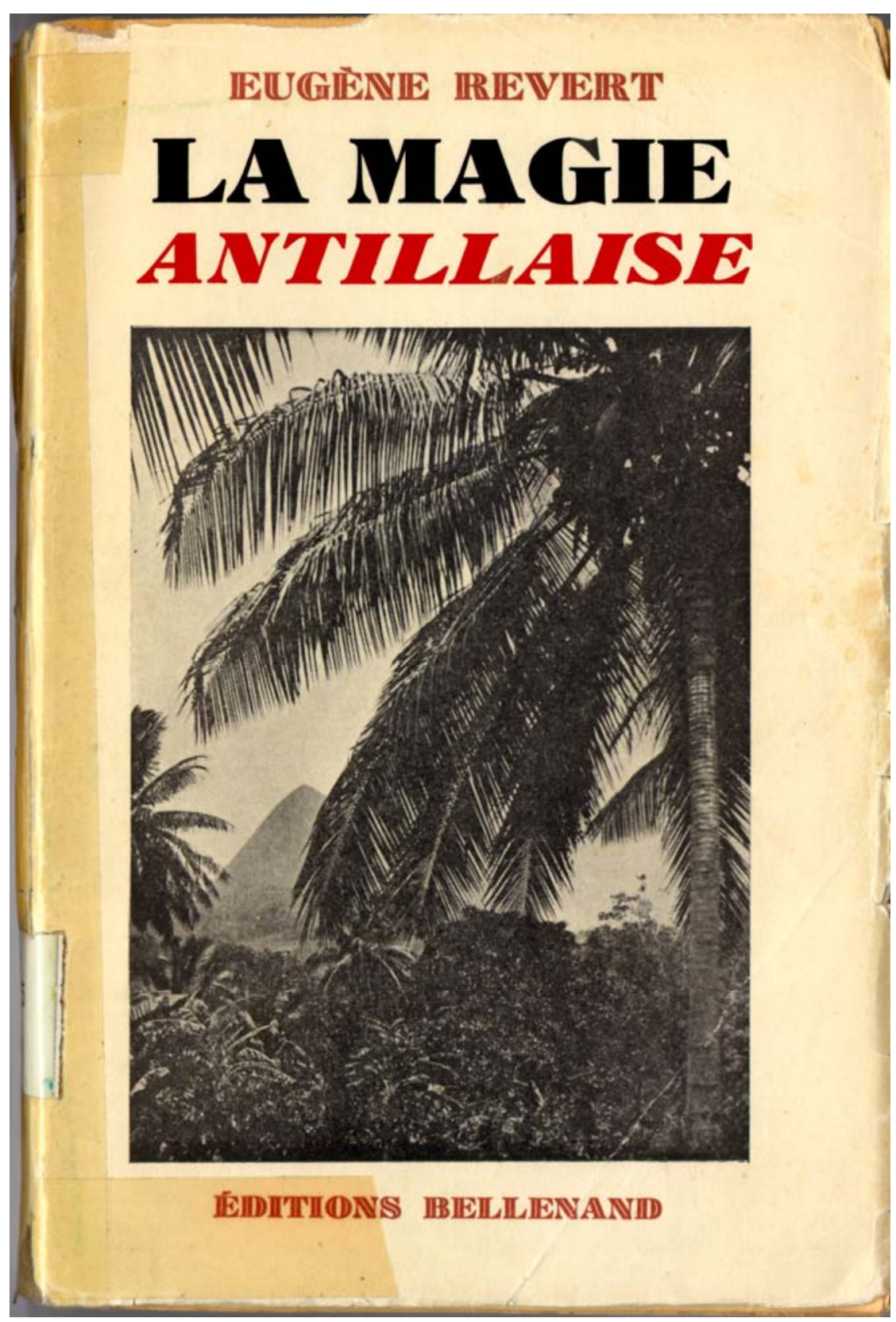


OUVRAGES DU MÊME AUTEUR

La Martinique. Étude géographique. Ouvrage couronné par l'Académie des Sciences. Prix Binoux (Nouvelles Éditions latines, 1949).

La France d'Amérique. Collection «Terres lointaines » (Société d'Éditions géographiques, maritimes et coloniales, 1949).

EN PRÉPARATION :

Le Monde caraïbe.

La dernière éruption de la Montagne Pelée, 1929-1932. 


\section{TABLE DES MATIÈRES}

Chapitre I.

Caractères généraux du folk-lore martiniquais

$\underline{\text { Chapitre II. }}$

Rites et coutumes

Chapitre III.

Remèdes et « charmes »

Chapitre IV.

Charmes et contre-charmes

Chapitre V

Les sorciers et leur organisation

Chapitre VI.

Zombis, Engagés et Vaudou

\section{$\underline{\text { ANNEXES }}$}

Cahier de quimbois

Larsenale (sic) des sorciers

Correspondances

Bibliographie sommaire 


\section{CHAPITRE PREMIER}

\section{Caractères généraux du folk-lore martiniquais}

\section{I. - SA RICHESSE}

\section{$\underline{\text { Retour à la table des matières }}$}

Le folk-lore martiniquais est d'une richesse certaine. Il n'a été l'objet jusqu'ici que d'un nombre restreint d'études désintéressées. Le petit livre de M. Labrousse sur deux vieilles terres françaises, Guadeloupe et Martinique, est, à cet égard, le meilleur que je connaisse. Pour le reste, on est obligé de s'en tenir à des enquêtes personnelles et aux descriptions éparses dans les nouvelles et romans consacrés à la colonie. Quelques-unes sont excellentes, d'autres moins bonnes. Elles ne donnent et ne peuvent donner que des vues fragmentaires.

Les transformations de la vie moderne tendent dans une certaine mesure à modifier ce folk-lore, à en réduire l'importance, moins peut-être qu'ailleurs. Il y aurait urgence néanmoins à recueillir, avant qu'il ne fût trop tard, un certain nombre de traits hérités d'un passé souvent lointain. Les costumes "créoles » existent encore, mais reculent constamment devant les «modes de Paris ». Ce n'est qu'à la campagne et aux jours de fête qu'on peut encore rencontrer des aïeules portant la «jupe », avec de jolies chemises brodées à manches très amples en guise de corsage, le collier chou et les boucles d'oreilles nommées «dahlias ». De même le costume local composé de l'ample peignoir ou " grande robe », du foulard et du madras calandré en forme " tête madras ", devient de plus en plus rare.

Le peuple martiniquais adore la danse. La «Biguine » a conquis droit de cité jusqu'en Europe. Mais il n'y avait plus déjà, lors de mon premier séjour, que les vieilles gens de la campagne pour danser le «Bel é » (Bel air), qui «s'accompagne d'une chanson amoureuse » appelée du même nom. Elle se compose de mouvements "simples et lents qu'on exécute en se tenant la robe de chaque main ${ }^{1}{ }^{\prime}$.

J'ai assisté maintes fois à la danse des coupeuses de cannes, dirigée par un commandeur, et qui s'apparente au « Bombé serré » ou danse du ventre. Mais, à

Labrousse, Deux vieilles terres françaises, p. 9. 
la campagne surtout, d'antiques traditions se perpétuent. " Damier » et « Laghia de la mort » sont des danses pugilistiques africaines, d'après M. Zobel ${ }^{1}$. La seconde dégénère à l'occasion en combat véritable et meurtrier. Un coup de pied dans le ventre abat le plus redoutable des lutteurs, les doigts plantés dans les yeux le rendent aveugle. Le vainqueur a le droit « de piétiner son adversaire à terre, de lui broyer la cage thoracique au son du tamtam, dans le délire des cris des supporters, tandis que s'agitent les torches fébriles ${ }^{2}{ }^{\prime}$. La danse " Mayoumbé », dans la région du Diamant, apparaît plus que lascive et entraîne souvent de véritables scènes de frénésie.

Quant aux conteurs, ils sont légion. Leurs, récits se transmettent par tradition orale, à l'occasion des veillées funèbres, à moins qu'ils ne soient faits par les das ${ }^{3}$ à la ti manmaille qui les écoute avec dévotion. Plus d'un écrivain antillais les a utilisés. Ils n'ont pas encore été recueillis pour eux-mêmes, sans enjolivements littéraires. Il y a place, dans ce domaine, pour plus d'un chercheur.

La présente étude n'a pas la prétention d'embrasser un champ aussi vaste. Elle se restreint aux diverses manifestations de la magie locale ; aux charmes et quimbois ${ }^{4}$, qu'il est parfois difficile de distinguer des remèdes populaires, aux tabous et pratiques irrationnelles de la vie courante. Mais on ne peut dissocier entièrement ces pratiques des croyances qu'elles supposent, ni de ceux qui les appliquent. C'est en fin de compte un monde étrange de sorciers, d'engagés, de revenants, les zombis ou souclians des Antilles, que nous verrons progressivement s'évoquer devant nous.

\section{II - LIMITES ET DIFFICULTÉS D'UNE ENQUÊTE DE FOLKLORE À LA MARTINIQUE}

Dans ce domaine même, le présent travail ne peut avoir la prétention d'être complet, et il faut insister sur les difficultés de toutes sortes que rencontre à la Martinique une étude de ce genre. Beaucoup dans les classes instruites se refusent à répondre ou détournent la conversation, les uns parce qu'ils croient toujours aux revenants, aux " engagés " ${ }^{5}$, à l'efficacité surtout des quimbois et qu'ils ne veulent pas l'avouer, les autres par une sorte de pudeur, de patriotisme de clocher qui les pousse à dissimuler ce dont ils croient qu'un étranger pourrait se moquer. Il est toujours possible, sans doute, d'aller consulter tel guérisseur connu, d'assister à une "séance " moyennant finances. Cela ne conduit pas loin, et les risques d'erreurs ou de tromperie volontaire apparaissent considérables ; il serait facile d'en citer des exemples.

Zobel, Laghia de la mort, p. I.

Tardon, Bleu des îles, p. 58.

Bonne d'enfants.

On ne connaît pas l'origine exacte du terme quimbois. On désigne par là, aux Antilles, les remèdes accompagnés de conjurations, ces conjurations elles-mêmes et, d'une manière plus générale, tous les actes de magie ou de sorcellerie.

« Engagé » : qui a un pacte avec le démon. 
Un Martiniquais seul, connaissant à fond son pays, et dégagé cependant des contingences locales par un long séjour au dehors et des études spécialisées, serait capable de peindre la large fresque dont on est en droit de rêver. Puisse un des nombreux jeunes gens actuellement dans la métropole comprendre l'intérêt de cette tâche et s'y consacrer. Je n'ai d'autre ambition, pour ma part, que de tracer à grands traits une première et incomplète esquisse.

J'ajouterai seulement que mon enquête a commencé dès le lendemain même de mon arrivée à Fort-de-France, en 1927. J'étais à peine débarqué qu'un ami, de passage à la Martinique et que je connaissais de longue date, tomba malade dans des conditions suspectes, et qui ne permettaient pas d'exclure l'hypothèse d'un « quimboisage », qu'on ait voulu se débarrasser d'un gêneur ou qu'il se soit agi d'un " philtre » d'une autre sorte. Quelques mois plus tard, un autre incident attirait de nouveau mon attention sur ces problèmes. J'avais loué, pour les grandes vacances, une maison dans le sud de l'île, au bourg de Sainte-Anne. Des racontars, qu'on ne me rapporta que longtemps après, me firent passer pour indésirable aux yeux de quelques braves pêcheurs. Cela se traduisit d'abord par des bruits sourds, après minuit, autour de ma demeure. Peu après, je fus réveillé par des crissements étranges, analogues à ceux d'une serrure qu'on essaie de forcer. Lever rapide, lumière, exploration, revolver au poing, de l'escalier pour tomber sur un énorme "crabe de terre ", qui passa par la fenêtre plus rapidement qu'on ne l'avait introduit. J'appris seulement par la suite ce qu'était un animal "voyé », c'est-à-dire expédié par sorcellerie. Trois ou quatre jours encore et je trouve au matin, étendu devant mon seuil, le cadavre d'un petit chien, qui appartenait à un vieil instituteur européen, et avec lequel j'avais encore joué la veille. La pauvre bête était dans une position anormale et qui dénotait une intervention humaine. Un coup d'œil me prouva que j'étais épié des maisons voisines. L'agacement, un vague désir aussi d'expérience ou de mystification, me firent considérer gravement l'animal. Je rentrai chercher une canne avec laquelle je traçai à son entour un pentagramme qui pouvait passer pour magique, tout en récitant ce dont je pouvais me souvenir de grec, de finnois ou d'arabe, langues que je supposais inconnues des braves gens qui m'observaient. Après quoi, j'eus la satisfaction de constater que lesdits évitaient soigneusement de passer devant ma porte.

Par la suite, de mauvaises fréquentations me conduisirent dans les milieux politiques de File. Un des Nestors du métier, qui m'avait pris en affection, m'enseigna l'art de me tromper de « punch » dans certains cas, c'est-à-dire de ne pas prendre celui qui m'était ostensiblement offert lorsque je me trouvais en milieu hostile. Un vieux prêtre me répéta qu'il n'autorisait jamais personne à pénétrer dans sa cuisine. Il arrivait que ses ouailles lui offrissent des plats préparés à l'avance. Il acceptait, remerciait chaleureusement, et ne consommait pas. Il avait été témoin de trop de morts rapides et inexplicables.

On pourrait s'étonner de pareilles affirmations si l'on ne savait la prudence extrême, pour ne pas dire plus, avec laquelle la justice locale poursuit de pareils faits. Les magistrats récemment arrivés ne connaissent pas le pays. Les autres peuvent arguer de nombreux cas où les enquêtes n'ont abouti à rien. La situation a été fort bien définie par le P. Delawarde, dans une étude récente et 
inédite dont il a bien voulu me communiquer le manuscrit. "Des vies humaines, y écrit-il, sont livrées aux sorciers habiles à doser les poisons, poisons rapides ou lents, mais toujours sûrs. Après un séjour de dix ans dans le pays, au cours duquel nous nous sommes sans cesse renseignés, nous avons la persuasion que les victimes des quimboiseurs sont encore en nombre appréciable. Nous ne sommes pas seul de cet avis. En avril 1937, notre confrère, le P. de la Brunelière, écrivait, dans les Annales des Pères du SaintEsprit : « ... Les morts par poison sont assez fréquentes. » Et il ajoutait : " Ces crimes demeurent presque toujours impunis. Ceux qui pourraient parler se taisent par crainte des représailles. Interrogés, les voisins et même les parents désolés de la victime répondront aux gendarmes : "Pas z'affaires moins, moin pas save ${ }^{1}$. » En effet, s'ils parlaient, le délinquant serait sans doute arrêté, mais plus tard, remis peut-être en liberté, il viendrait exercer une vengeance certaine et terrible ${ }^{2}$. " Je puis ajouter que plus d'un médecin partage sur ce point l'avis du P. Delawarde et de $\mathrm{M}^{\mathrm{gr}}$ de la Brunelière.

On admettra dans ces conditions les raisons de convenance, pour ne pas dire plus, qui m'obligent à taire le nom de la plupart de mes informateurs demeurés à la Martinique. Je dois beaucoup au P. Delawarde, qui m'a procuré avant tout autre le cahier de quimboiseur reproduit à la fin de ce mémoire, en m’autorisant à le publier ainsi qu'à utiliser l'étude qu'il lui avait consacrée. J'ai fait mes premières enquêtes grâce à $\mathrm{M}$. Legros, instituteur d'origine européenne, établi depuis plus de quarante ans à la Martinique lorsque je l'ai connu, et décédé en 1931. Le chanoine Tostivine, longtemps curé doyen du Lamentin, également disparu, m'a fourni des renseignements non moins précieux, ainsi que mon collègue Boutin, ancien directeur de l'Observatoire, mort pendant la dernière guerre. Que les autres reçoivent ici collectivement le témoignage de cette profonde gratitude que j'ai déjà essayé de leur manifester, lors de mon séjour aux Antilles en 1949. La vieille bande s'était alors retrouvée presque au complet. Je me souviens surtout de certain jour où je m'étais réfugié à l'anse Mitan, pour que nul ne pût m'accuser d'avoir trempé dans je ne sais quel noir complot à l'occasion des élections cantonales. Nous sommes restés longtemps à deviser, dans le soir qui tombait, devant la mer azuréenne du couchant, tandis que les lumières de Fort-de-France commençaient à piqueter dans le lointain la masse sombre des Pitons. Quelques jours plus tard, nous nous retrouvions à l'habitation qui vit naître Joséphine, et là encore le punch du Sud eût tôt fait de délier les langues. C'est à vous, mes vieux camarades, mes complices des bons comme des mauvais jours, que je dois la substance entière de ce petit livre dont je n'ai été que le rassembleur et l'ordonnateur.

J'ai été conduit à n'utiliser en effet que les récits de ceux dont la sympathie agissante excluait toute idée de tromperie. Ils appartiennent pour la plupart, comme il est naturel, à la société de couleur. De même, parmi tous les essais, contes et romans consacrés à la Martinique, je n'ai retenu que ceux, fort peu nombreux, qui se distinguaient par leurs qualités folkloriques et dont il m'était

Ce ne sont pas mes affaires, je ne sais pas.

Delawarde, manuscrit dactylographié, p. I. 
possible de vérifier les détails. Les principaux ont été les Contes et paysages de la Martinique d'A. Thomarel, le Fo-Yal de M. Lucien Nay Reine, les nouvelles et romans de MM. Zobel, et surtout R. Tardon. J'ai trouvé de précieux renseignements dans les monographies demandées en 1935 à tous les directeurs d'école pour le Tricentenaire du rattachement des Antilles à la France, et qui sont demeurées inédites jusqu'à maintenant. Je me suis servi enfin de la presse locale, systématiquement dépouillée. Je n'ajouterai qu'une chose : en dehors des quelques références citées, je pourrais mettre sous chacun des détails que je rapporte une date et un nom. Je me suis efforcé de respecter scrupuleusement les récits de mes interlocuteurs, dont je n'ai été amené à retrancher, par prudence ou discrétion, que certaines caractéristiques de temps et de lieu.

\section{III. - RAPPEL SOMMAIRE DES CONDITIONS HISTORIQUES ET DES GRANDES ÉTAPES DU PEUPLEMENT}

Avant d'entrer néanmoins dans le vif de cette étude et d'exposer les données recueillies, il apparaît nécessaire de rappeler succinctement l'histoire du peuplement martiniquais.

Lorsque les Français ont pris possession de l'île en 1635, ils l'ont trouvée occupée par un millier de Caraïbes environ, eux-mêmes conquérants de fraîche date, qui avaient exterminé leur prédécesseurs Arawaks, les femmes mises à part. Bien que la plupart d'entre eux eussent été expulsés en 1658, ils ont joué dans le peuplement de l'île un plus grand rôle qu'on ne l'admet à l'ordinaire. Ils ont été en contact prolongé avec les nouveaux occupants, et plusieurs de leurs techniques se sont maintenues jusqu'à nos jours. Le gros contingent des colons a été fourni par la Normandie, la Bretagne et le Sud-Ouest. Il n'est pas inutile de préciser que l'immense majorité d'entre eux était de très modeste origine, et, en général, assez peu instruite. Les esclaves affluèrent après 1650, apportant avec eux des habitudes et des croyances que la conversion obligatoire au christianisme n'arrivait que rarement à extirper.

La libération, en 1848, entraîna une crise agricole de quelque gravité, beaucoup des nouveaux citoyens, on le comprend sans peine, ne ressentant qu'une sympathie médiocre pour le travail de la terre. Il fallut leur trouver des suppléants, ce qui entraîna l'immigration de quelque vingt-cinq mille Hindous, d'un nouveau contingent d'Africains et de quelques centaines de Chinois et Indochinois. Tous se sont fondus dans la masse, à laquelle ils ont insufflé une part plus ou moins grande de leurs traditions propres. La Martinique a ainsi été, et continue d'être, un des "melting pot » les plus actifs qu'on connaisse à la surface du globe. 


\section{CHAPITRE II}

\section{Rites et coutumes}

\section{I. - INTERDICTIONS, PRÉSAGES ET OBLIGATIONS DE LA VIE COURANTE}

$\underline{\text { Retour à la table des matières }}$

Il en résulte un ensemble complexe. De très vieilles habitudes se sont maintenues intactes, et la vie de chaque jour apparaît commandée par un très grand nombre de présages, d'interdictions ou de prescriptions. La lune, par exemple, règle toujours les principales opérations de la vie agricole. On ne sèmera ou ne plantera qu'en lune ascendante, un peu avant qu'elle atteigne son plein. Sinon, la récolte serait nulle. On admet de même que les cyclones ne peuvent se produire que dans les deux jours qui précèdent ou qui suivent les pleines lunes de juillet, août, septembre et octobre. On croit, comme partout, à la valeur bénéfique ou maléfique du nombre 13 .

Il existe, de même, des tabous absolus de langage. Il est des mots qu'il faut éviter de prononcer, parce qu'ils porteraient malheur. Dans la région de SainteAnne, on ne connaît que le "bœuf à lait » et on considère comme une incongruité grave le nom de la génisse fécondée. L'expansion du français, que favorise l'école primaire, a conduit à étendre singulièrement la liste des interdits, par un esprit allusif de goût déplorable, mais pris au sérieux par beaucoup de braves gens. Voici, à titre d'exemple, quelques-uns des termes à éviter de manière absolue :
abondamment ${ }^{1}$,
occupé,
impinément (sic),
patate ${ }^{2}$,
manifessetement (sic) ;
converger,
concurremment,
vitalité.

Je n'insiste pas, mais nous aurons l'occasion de retrouver à plus d'une reprise cette obsession quasi permanente des questions sexuelles, qui est l'un des traits les plus frappants du folk-lore antillais. Indiquons seulement, au passage, qu'aussi bien le «sens » créole qu'européen du vocable tabou a été

Bonda : bas-ventre.

Patate désigne vulgairement le sexe de la femme. 
utilisé, grâce à des déviations verbales susceptibles elles-mêmes de devenir, en s'accentuant, génératrices de mythes, ou de pratiques fort peu rationnelles.

Il existe également des interdictions ou des prescriptions alimentaires, passagères ou absolues, que rien, en raison, ne justifie. Aux alentours de l'anse Couleuvre, les pêcheurs considèrent comme une faute grave de ne pas rejeter à l'eau, et surtout de faire cuire, un beau poisson blanc fileté d'or qu'ils appellent le bon Dieu Mayen. Il n'y a que des individus descendus au plus bas degré de l'abjection qui oseraient le faire. Les gombos, qui se consomment un peu à la manière des asperges, encore que plus gluants, conviennent, paraît-il, au beau sexe, mais sont contre-indiqués pour les hommes dont, en vertu du principe des analogies, ils passent pour abattre le courage. Il n'y a pas de doute qu'à la campagne les mâles qui en usent sont tenus en piètre estime par les femmes.

Je n'ai pu découvrir la raison exacte pour laquelle, en quelques endroits de l'île on continue à manger de la terre. J'aurais tendance à y voir, en plus de cas certains de perversion du goût, la survivance de très vieilles habitudes africaines. Le $\mathrm{P}$. Labat parle, en effet, d'un petit nègre du royaume de Mine qui avait ce vice ${ }^{1}$. Dans la région « du Diamant, on consomme encore parfois une argile rouge veinée de blanc. Ailleurs, on m'a parlé de cendres. Mais le cas le plus frappant est celui de ce dépôt brunâtre recueilli dans le bassin d'une source aux hauteurs de Trinité, et qui apparaît comme une friandise gratuite à beaucoup des habitants d'alentour, des femmes et des enfants surtout. Il n'est, en effet, ni insipide ni même désagréable au goût, mais apparaît légèrement poivré, ce qui peu s'expliquer par une proportion considérable de matières organiques. L'analyse faite par M. de Montaigne au laboratoire du Service de l'Agriculture a donné les résultats suivants :

$\begin{array}{lr}\text { Silice totale } & 42,70 \% \\ \text { Fe } 203 & 11,60- \\ \text { A } 1203 & 29- \\ \text { Ca o } & 0,72- \\ \text { Mg o } & 0,79- \\ \text { Perte au feu } & 14,90- \\ \text { Indosés } & 0,29-\end{array}$

La perte au feu correspond évidemment à la teneur en matières organiques. Il faut ajouter que l'usage courant de cette terre entraîne des occlusions intestinales presque toujours mortelles dans un délai maximum de deux ans.

Mais, à l'inverse, on ne verra jamais une blanchisseuse croquer une banane en repassant du linge : elle attraperait à coup sûr une maladie de poitrine. Elle se refusera de même à passer sous le fer chaud une paire de chaussettes : cela donne l'éléphantiasis, ou maladie du gros pied.

Labat, Éd. Duchartre, I, p. 139. 
Le moindre acte, évidemment, prend alors sa signification. Les couverts, fourchettes ou couteaux mis en croix portent malheur. On doit se garder de déposer son chapeau ailleurs que sur les portemanteaux disposés à cet effet. Un verre blanc qui se brise, un parapluie ouvert dans la maison ${ }^{1}$ sont également de détestables présages. Une femme qui, pendant ses époques, marche sur des cosses de pois d'Angole est menacée de coliques violentes. Un commerçant qui, dans sa boutique, commettrait la même imprudence, pourrait être assuré de voir ses marchandises lui rester pour compte ${ }^{2}$.

Mais l'un des pires accidents qui puisse arriver est de faire une tache d'huile. Si l'on veut avoir quelque chance de conjurer le mauvais sort, il faut la couvrir immédiatement de sel et laver le tout avec du vin, en quantité double. Malgré tout, on redoute fort les conséquences de l'accident et j'ai connu une candidate au baccalauréat qui, pour avoir renversé une bouteille d'huile au cours de l'examen, n'alla même pas chercher le résultat, tant elle était sûre d'avance de son échec. Tel autre de mes amis vit ses voisins se lamenter bruyamment sur les malheurs qui l'attendaient parce qu'un jour, au début de la guerre, il eut la malchance de briser une jarre pleine du précieux liquide qui, à cinq ou six litres près, se répandit dans la rue. Les taches d'encre sont également de mauvais présage, encore qu'elles n'aient point la même efficacité. Il en est de même pour une bougie qui éclaire mal.

Une femme qui perd son bas, lorsqu'elle en a un, est persuadée que son ami lui est infidèle. S'asseoir sur la table, manger dans un canari (vase en terre dans lequel on fait cuire les aliments) est signe qu'on vous oublie ${ }^{3}$. Se laver en commun dans un seul récipient doit entraîner une brouille de famille. Une démangeaison à la main droite indique qu'il faudra bientôt payer une vieille dette, à la main gauche c'est, au contraire, l'annonce d'une rentrée imprévue. La grosse mouche qui entre en bourdonnant précède de peu une visite. Il en est de même des aliments tombés de la fourchette. Si, par inadvertance, comme le bon roi de la chanson, on a mis quelque vêtement à l'envers, c'est qu'on est protégé par les puissances invisibles, et l'on a chance de recevoir un cadeau avant que la journée s'achève.

Les oreilles qui tintent ou picotent signalent médisances ou calomnies. Il ne faut entreprendre aucune affaire ou démarche si, en cours de route, on a heurté un caillou du pied gauche. Vous n'y réussirez pas, car « ou congnin mauvais pied » (vous vous êtes cogné le mauvais pied) ${ }^{4}$.

Il en est encore ainsi quand l'on aperçoit de bon matin une personne ennemie. Les heures qui suivent, sinon la journée entière, risquent d'en être gâtées. Il est excellent au contraire d'être bien " étrenné ». Les marchandes ambulantes y tiennent par-dessus tout, et M. Nay Reine rapporte avoir vu l'une d'entre elles, « son tray sur la tête et un coui de tomadoses sous le bras, refuser

Nay Reine, Fo-Yal, p. 9.

Labrousse, Deux vieilles terres françaises, p. 69.

Nay Reine, Fo-Yal, p. 10.

Nay Reine, Fo-Yal, p. 10. 
toutes les acheteuses, ne voulant être étrinin que par un garçon bien chaud, et ce durant toute la journée ${ }^{1}$ ». Il s'agit d'attirer ainsi des rayons bénéfiques et de neutraliser les autres. À l'ordinaire les vendeuses de légumes et de fruits considèrent que pour écouler vite leurs marchandises il leur faut les couvrir de feuilles de ti baume ${ }^{2}$, et garder au fond de leur bourse quelques grains de sel, des gousses d'ail et des feuilles de menthe glaciale.

Les animaux jouent leur rôle en l'affaire. Les chiens et les bœufs qui hurlent ou beuglent à la mort signifient comme partout un deuil rapproché. On peut y ajouter les papillons de couleur sombre ou noire appelés sophies counans, le chant imprévu du coq, des sauterelles, la découverte de gros zagriens (araignées,) et de nids de fourmis dites fourmis cinmitié (cimetière) ${ }^{3}$.

On croit à la valeur des signes corporels : lire dans les lignes de la main n'est même pas regardé comme sortilège. On prête également la plus grande attention aux « envies », ou grains de beauté, et à leur position sur le corps. Il fut prédit à l'un de mes amis qu'il mourrait noyé, parce qu'il porte un de ces signes sous le pied gauche. En contrepartie, il existe, naturellement, de très nombreux moyens pour conjurer le mauvais sort qui menace. L'un des plus employés, et qui remonte aux débuts mêmes de la colonisation, est l'eau bénite. Le P. Labat raconte que "quelque quantité qu'on en fasse le dimanche à la grand'messe, il est rare qu'on en trouve une goutte quand le service est fini. Ils l'emportent dans de petites calebasses et en boivent quelques gouttes en se levant, et prétendent se garantir par ce moyen de tous les maléfices qu'on pourrait jeter sur eux ${ }^{4}$ ». Cela continue à se pratiquer, et il est bien des régions du département où un cultivateur, avant de retourner son champ, commence par l'arroser avec un peu de cette eau prise à l'église.

Un autre procédé consiste à brûler du caoutchouc pour chasser les mauvais esprits. Il est particulièrement efficace le vendredi à quinze heures. Toutefois, pour qu'il donne son plein effet, il est nécessaire que personne ne paraisse s'en apercevoir, et surtout qu'on n'y fasse aucune allusion, sans quoi les mauvais esprits reviendraient.

\section{II. - LES « RITES DE PASSAGE », NAISSANCE, COMMUNION, MARIAGE ET MORT}

De tels rites apparaissent surtout nombreux et impératifs aux changements importants de l'existence. Le P. Delawarde rappelle qu'une femme enceinte, ou même allaitant, ne doit sous aucun prétexte couper un arbre fruitier, car, par une loi d'analogie facile à saisir, on s'imagine que l'enfant en mourrait. Le même auteur a vu, aussitôt après la naissance, enterrer le placenta au pied d'un jeune arbre : cela s'accompagne d'une petite cérémonie où « l'on formule le

Nay Reine, ibid., p. 9. Tray : plateau de charge que l'on porte sur la tête. Coui : récipient de forme ronde, parfois une demi-calebasse.

Croton balsamifer L.

Nay Reine, Fo-Yal, p. 9.

Labat, Éd. Duchartre, II, p. 407. 
souhait que l'enfant vive autant que l'arbre et participe à sa prospérité ». Cela l'enracine dans la vie ${ }^{1}$.

La couvade n'est pas inconnue, encore qu'assez rarement usitée. J'en connais à tout le moins un exemple curieux, parce que le fait d'un homme instruit et de profession paramédicale. Quand sa femme fut pour accoucher de son premier enfant, il lui mit la main sur la bouche pour l'empêcher de crier. Pendant ce temps, lui-même poussait des « hou hou » lamentables et de plus en plus violents, jusqu'au cri final annonçant la délivrance.

La plupart du temps on cherche à faciliter l'opération et, quand celle-ci est particulièrement difficile, on fait ingurgiter à la patiente des mixtures extraordinaires du genre de la suivante :

Du thé la poussièr' quat' coins caye (du thé fait avec de la poussière ramassée aux quatre coins de la case... Étant donné les habitudes locales, il doit s'y rencontrer d'étranges débris...).

Si cela ne suffit pas, on emploie du thé caca male chouval (du thé fait avec du crottin d'étalon). Dans le cas qu'on m'a rapporté, l'effet aurait été immédiat.

Chez les Caraïbes, aussitôt après la naissance, les parents étaient soumis à un jeûne spécialement rigoureux pour l'homme, surtout lorsqu'il s'agissait d'un garçon premier né. Certains s'abstenaient entièrement, « les cinq premiers jours après l'accouchement de leurs femmes, de boire et de manger, et les autres jours jusqu'au dixième ils ne prenaient autre chose que du ouicou ${ }^{2}$ ». Cela se terminait au bout d'un mois ou deux par un festin avant lequel les amis du père « lui découpaient toute la peau du corps avec des dents d'agouti comme avec un couteau jusqu'au sang ». La raison donnée de ce jeûne au P. Breton était que les enfants « auraient mal au ventre ou les membres défectueux comme ceux des animaux que leurs pères mangeraient ${ }^{3}$ ". Il ne semble pas que ces dernières coutumes aient laissé beaucoup de traces. Seuls la mère et l'enfant vont prendre un grand bain au bout de quarante jours, pour se laver de toutes les souillures.

Souvent, d'ailleurs, il est impossible d'observer de telles précautions. Et, plus d'une fois, il est arrivé que les rudes porteuses du Lorrain ou du Morne des Esses aient été saisies par les premières douleurs de l'enfantement, leur tray de légumes sur la tête, et en pleine marche. Elles s'arrêtent alors, cherchent aide et conseil dans une case voisine, à moins qu'elles ne soient obligées de tout faire elles-mêmes sur le bord de la route, et la tradition prétend qu'on en a vu, l'opération terminée, placer l'enfant sur le tray et continuer leur route. L'héritier ou l'héritière, en pareil cas, porte toujours le nom de Chimène, parce que né sur le bord du chemin, transposition à laquelle sans aucun doute Corneille ne songeait guère.

Delawarde, étude dactylographiée, pp. 5-6.

Sorte de bière à base de cassave et de patates fermentées.

Les Caraïbes de la Guadeloupe, relation du P. Breton, Éd. Rennard, pp. 59-60. 
Le choix du prénom est, en effet, commandé par des circonstances que l'on considère comme en partie indépendantes de la volonté des parents. Il est d'usage très général d'appeler les enfants d'après le saint ou la fête du jour : les résultats peuvent alors ne pas manquer de pittoresque. À défaut ou à côté du saint, on choisira un homme important pour que la protection du nom demeure. C'est une des traces les plus durables que laisse à la Martinique le passage d'un gouverneur. Son prénom apparaît avec une fréquence remarquable sur les actes d'état civil pendant son séjour. Et pour que la protection s'étendît à toute la maisonnée, le patronyme a servi plus d'une fois à désigner le chien veillant sur le foyer.

L'enfant est immédiatement déclaré et baptisé, sauf s'il est né en décembre. Dans ce cas, la cérémonie est retardée d'un mois parce qu'on est persuadé que l'on gagne ainsi une année entière de vie. Autrement, il est indispensable que le premier sacrement soit administré dans les trois jours afin de mettre le nouveau-né et toute sa famille à l'abri du démon. Il est fort difficile de conserver des bonnes dans une maison où l'on ne se conforme pas à ces usages, ou, si elles consentent parfois à rester, c'est pour circonvenir l'enfant confié à leurs soins, jusqu'au jour où elles arrivent à l'entraîner à l'église. Toute maladie, toute tare physiologique s'expliquent alors par l'expression consacrée : « Ça, enfant du diable. »

La cérémonie du baptême ne diffère guère de ce qu'elle est en Europe. Le nouveau-né, vêtu de beaux langes, d'une béguine et de chaussons, est porté à l'église par sa $d a$, ou nourrice, dans les familles aisées, qu'accompagnent le parrain et la marraine. Tous trois sont habillés avec recherche. Ils s'appellent compère et commère, et le compère est tenu d'offrir un cadeau à sa commère en même temps qu'un riche présent à son filleul. Le P. Labat soulignait déjà la forte autorité que la tradition locale accorde au parrain.

La nourriture de l'enfant a une grande importance, au début surtout. Le voile qu'il porte à l'occasion sur la tête au moment de la naissance est mélangé à ses aliments, pour le préserver de tout danger. Il sera de même à l'abri du poison si on lui sert à son premier repas de « l'envers caraïbe ${ }^{1}$ ». Pour le rendre intelligent, on lui fera absorber de la mie de pain trempée dans du miel. Au Morne des Esses, on placera sa tête dans un coui, ou moitié de calebasse évidée, afin de le protéger du tonnerre, de tout ce qui peut rendre fou, et de lui permettre plus tard d'aller à l'école, car c'est « l'instruction qui a fait la force des békés ${ }^{2}$ ». De même, le corps du nouveau-né est frotté avec des feuilles de tamarinier, de goyavier et de citronnelle macérées dans du rhum, ce qui a pour but de le rendre fort et vigoureux.

Il existe d'ailleurs des procédés, qu'on prétend éprouvés, pour remédier à certaines malformations. Si un membre, par exemple, ne se développe pas normalement par rapport aux autres, on choisira un ti veau que l'intéressé

Maranta Arundinacea L., l'arrow root des Antilles anglaises.

Blancs créoles. 
remplacera à intervalles réguliers au pis de la vache. Le membre reprendra sa croissance, réglée cette fois sur celle de l'animal, et qu'on arrêtera au moment voulu. Sans quoi, le résultat risquerait d'être trop beau.

L'enfant grandit ainsi sous la surveillance attentive de sa mère, qui le regarde comme son bien presque exclusif. Il arrive même qu'une femme soit capable de déclarer au véritable père qu'il ne l'est pas, afin de conserver son fils pour elle toute seule et d'échapper aux sujétions du mariage.

La première communion semble avoir supplanté définitivement les anciens rites de puberté des "Sauvages" ou des esclaves. On y observe scrupuleusement les prescriptions de 1'Église.

Partout, la maman veille avec soin à la conversation jusqu'au moment où l'enfant s'endort. Aucun mot grossier ne doit être prononcé pendant la retraite. La nourriture est frugale et choisie, la viande demeurant exclue. À la campagne, c'est un peu plus compliqué. Un mois à l'avance, l'enfant a parcouru les quartiers avoisinants pour rendre visite aux alliés et amis. Ce serait manquer gravement aux usages que d'omettre ces démarches. Quatre jours avant la date fixée, les parents, mère, père, sœurs, frères, « cousines proches ou éloignées (les hommes viendront à leur tour, en grande tenue noire, le jour de la solennité) descendent au bourg. Celle-ci porte le panier qui renferme les effets pour l'habillement, celle-là des objets de literie, une autre le tray, qui contient les ustensiles de cuisine et les articles de ménage, une autre les provisions, etc. Tout ce monde s'entasse dans une petite chambre, dans un pied-à-terre que la famille possède au bourg et, durant quatre jours, c'est un va-et-vient continu de gens affairés qui vont de la maison à l'église, de l'église à l'épicerie, de l'épicerie au marché, parlent haut, font du bruit, se couchent tard le soir et se lèvent tôt le matin ». Après la cérémonie, le cortège reprend le chemin de la campagne avec les mêmes fardeaux. Les provisions épuisées sont remplacées par celles qui ont été faites en vue de la réception officielle, car... « toutes ces fêtes s'accompagnent de repas pantagruéliques ${ }^{1}{ }^{\prime}$.

La pratique très généralisée de l'union libre fait que le mariage légal ne s'entoure pas d'un grand nombre de cérémonies. Il n'apparaît même pas toujours aux jeunes filles de la société sous son aspect le plus sérieux : telle y a vu avant tout le moyen d'être plus libre et de pouvoir s'acheter l'après-midi tous les sorbets qu'elle désirait. Ce sont donc les usages importés d'Europe qui, dans l'ensemble, ont prévalu. Le voile de la mariée est jeté au début du bal par l'intéressée, dont les yeux sont bandés, sur les jeunes filles qui l'entourent. Celle qui le reçoit passe à son tour pour devoir convoler en justes noces dans les douze mois. De même que dans la métropole, on garde les fleurs du bouquet porté à cette cérémonie jusqu'à ce qu'elles tombent en poussière. Il est enfin de tradition très généralisée que les nouveaux époux partent avant la fin du bal, accompagnés seulement d'une vieille $d a$, pour une maison de campagne

P. Symphor, Monographie de Rivière Pilote, inédite, écrite à l'occasion du Tricentenaire du rattachement des Antilles à la France. 
éloignée, où ils passent leur lune de miel. De Fort-de-France on se retirera à Sainte-Anne, par exemple. Tous le font dans la classe aisée, qu'il s'agisse des Blancs ou des gens de couleur. Dans le peuple, chaque fois qu'il est possible, les intéressés s'isolent également et empruntent une case écartée qu'il est rare de leur voir refuser.

Quand il s'agit, par contre, d'un -veuf ou d'une veuve qui se remarie, le chalbari, ou charivari, est de rigueur. "Pendant la période de publication des bancs et jusqu'à la célébration du mariage, les gens du quartier et des quartiers avoisinants s'assemblent le soir, à partir de cinq heures, à proximité de la maisonnette de celui des futurs conjoints qui convole en secondes noces. On accourt des points les plus éloignés ; hommes, femmes et enfants, tout le monde y vient, les uns avec des conques de lambis ${ }^{1}$, d'autres avec des débris de chaudrons, des morceaux de tôle ou de fer blanc sur lesquels ils frappent avec frénésie. C'est un tapage assourdissant, un vacarme effroyable, entrecoupé de cris, de huées, de propos souvent injurieux et qui se répercutent de morne en morne, jusqu'aux campagnes les plus reculées. Un instant, le bruit cesse : est-ce la fin ? Non, à peine une accalmie ; c'est le chef de bande qui débite le couplet d'usage, auquel succédera un refrain en chœur, comme s'il s'agissait des passages d'un rituel. Et le tumulte reprend avec plus de violence encore, et cela se prolonge fort avant dans la nuit, avec des alternatives de silence impressionnant et de bruit retentissant.

"Chaque soir amène de nouveaux manifestants. De sorte que, dans les derniers jours, c'est une véritable foule qui assiège la maison de la malheureuse victime, pour la soumettre à cette rude et irritante épreuve. Le jour du mariage, cette cohue accompagne le cortège ou le suit aux abords de la mairie et de l'église, le reconduit à la campagne avec cette musique infernale, et l'on allume des brasiers le long de la route pour effrayer les chevaux... ${ }^{2}$ " On a évidemment perdu de vue la valeur protectrice, à l'origine, de telles manifestations, pour n'y plus voir qu'une occasion de moquerie et d'amusement.

Plus caractéristiques sont les rites et croyances qui entourent la mort, d'autant que celle-ci apparaît rarement comme naturelle, mais qu'on a toujours tendance, même dans certains milieux aisés, à la croire provoquée par un sortilège. Et, naturellement, les sorciers ou quimboiseurs qu'on va consulter sont toujours de cet avis. Parfois, ils désignent nommément l'individu responsable. Ils déclarent, dans d'autres cas, que ce sera par exemple, la première personne rencontrée un matin déterminé, ou celle qui viendra, à un rang qu'ils indiquent, présenter ses condoléances. Il en résulte, à l'occasion, des haines inexpiables entre amis de la veille. Dans tel cas de septicémie porté à ma connaissance, il s'agissait d'un collègue jaloux. En général, on accuse toujours des personnes du même sexe.

Strombus Gigas. La « corne de lambi », percée, sert de trompe à la campagne.

Symphor, Monographie inédite de Rivière Pilote, écrite à l'occasion du Tricentenaire. 
La mort survenue, on arrête aussitôt les pendules et on voile de crêpe toutes les glaces. S'il s'agit d'un homme, on commence, dans beaucoup de campagnes, par le redresser un instant dans la position assise, et lui ingurgiter un demi-litre de rhum avec l'injonction suivante : « Boué, y fout'. Pendant ou té vivant ou té aimé $\mathrm{y}^{1}$. " Un paquet de poivre et quelques feuilles de tabac sont toujours employés pour les femmes. Après quoi commence la toilette du défunt, qu'on revêt de ses plus beaux atours. S'il s'agit d'une femme, on lui passe, quand on le peut, une robe de soie neuve. Il n'est pas rare, à la campagne, que de vieilles mères conservent précieusement, sans la mettre jamais, la robe dans laquelle elles veulent être " exposées ", ainsi que le drap neuf qui doit leur servir de linceul. Souvent même elles ont déjà fait faire leur cercueil, ou à tout le moins conservent-elles des planches d'acajou, ou de tout autre bois précieux et incorruptible, posées à l'ordinaire sur les premières poutres de la charpente et prêtes à être assemblées. Dans d'autres cas, robe et cercueil ne sont exécutés que lorsque la malade se trouve à l'agonie. On commande en même temps les voitures et couronnes pour l'enterrement. On compose s'il y a lieu, et sans plus attendre, l'indispensable oraison funèbre. Tant mieux d'ailleurs si le patient ou la patiente en réchappe ${ }^{2}$.

Puis le mort est entouré de bougies allumées, quatre d'ordinaire, une à chaque coin du lit. Il est arrivé parfois, aux environs de Fort-de-France, qu'on ait fixé, avec un peu de stéarine fondue, deux bougies allumées sur les yeux mêmes du défunt.

Pendant ce temps des « coups de corne », trois par trois ${ }^{3}$, retentissent dans la campagne. Tous savent alors que quelqu'un vient de mourir, et bientôt « le crieur de nos mornes, d'une voix tonitruante, crie à tous vents : «Billet d'enterrement de mussieu Jérémie, Morne Bleu. L'enterrement se fera au bourg demain à quatre heures ${ }^{4}$. »

Avec le soir commence la « veillée », qui se pratique partout à la campagne, mais que la bourgeoisie du chef-lieu n'a pas complètement délaissée. Elle se déroule au milieu d'une grande affluence. Les arrivants vont d'abord voir le défunt et l'asperger d'eau bénite. Après les condoléances à la famille on passe dans la salle voisine, ou plutôt sous la vérandah, lorsqu'il y en a une. Lorsqu'il s'agit d'une simple case, des bancs sont disposés au dehors, éclairés par la lueur fumeuse d'un serbi ${ }^{5}$. Et c'est alors le plus extraordinaire diptyque qu'on puisse imaginer : autour du cadavre, des lamentations, des versets psalmodiés d'un ton plaintif. Dehors, au moins en apparence, la joie la plus bruyante. Des jeux sont à la disposition des visiteurs, surtout dans le Nord, dominos et dés. Parfois, on

Buvez, F.... pendant que vous étiez vivant, vous l'aimiez...

J'ai dû, moi-même, sur ordre et dans une circonstance que je na suis pas près d'oublier, composer l'éloge mortuaire d'un haut personnage alors à l'agonie, mais non encore décédé. C'est un autre, heureusement, qui l'a prononcé.

3 Sorte de trompe formée d'une coquille de lambi (Strombus Gigas) percée à l'arrière, à l'endroit de l'enroulement maximum.

D'après un document communiqué par $\mathrm{M}^{\mathrm{me}}$ Constance N'Dambou.

Serbi : à l'origine torche imbibée de résine, maintenant bouteille de pétrole où trempe une mèche de coton. 
magnifie le disparu par des chants, en le parant de vertus exceptionnelles et d'exploits légendaires ${ }^{1}$. La plupart du temps, le jeu est mené par un chef de file, un conteur de quartier, au bagout renommé, et qui narre les aventures de Compé Lapin, de Maman Diable, de Papa ti poisson.

« Eh cric », crie-t-il à perdre haleine.

« Eh cric », lui répond-on.

« Eh crie », répète-t-il quatre fois de suite.

«Eh crac », lui réplique-t-on encore par six fois ${ }^{2}$.

Cela devient une occasion de tournois d'esprit, où tour à tour les conteurs renommés entrent en lice et cherchent à surpasser leurs rivaux. « Les auditeurs ponctuent de rires, de bravos, d'exclamations convenues: Tim, Misticric, Misticrac, Aboubouba, et de chants nostalgiques, de refrains qui sont de véritables mélopées, de cris gutturaux qui prennent les accents de véritables complaintes ${ }^{3}$. » La famille fait servir des rafraîchissements : café, rhum, etc., et l'on boit, l'on mange, l'on chante, l'on s'amuse ainsi jusqu'à l'aurore, qu'il faut attendre pour échapper aux forces mauvaises de la nuit.

La valeur protectrice de cette bruyante tradition apparaît en pleine lumière si on la rapproche de la peur extrême manifestée par bien des Martiniquais de demeurer seuls la nuit après avoir vu un mort. Il est des hommes faits, appartenant aux classes aisées et instruites de la société, qui, en pareil cas, ont transporté leur matelas et leurs couvertures dans la chambre de leur vieille mère.

Cela s'explique par la crainte, très généralisée dans le pays, d'une sorte de contagion de la mort, redoutable surtout pour ceux qui sont déjà malades. Dans le quartier de la Jossaud, on oblige ces derniers à se lever lorsque passe à proximité un convoi funèbre: sans quoi le leur suivrait à bref délai. Les porteurs eux-mêmes ne sont pas complètement à l'abri, surtout quand le défunt est transporté de son morne au bourg dans un simple drap formant hamac et suspendu aux extrémités d'une longue perche. Les équipes se relaient automatiquement à chaque ponceau du chemin.

Il n'est pas habituel que les femmes de la famille suivent le cortège, mais, pendant les neuf jours qui suivent le décès, elles se réunissent, avec leurs parents et un certain nombre de personnes pieuses, dans la chambre qu'occupait le défunt, pour prier autour du lit funèbre, sur lequel une petite lampe à huile reste allumée huit jours et huit nuits, et dont la flamme est entretenue avec une piété absolue ${ }^{4}$.

Tardon, Bleu des îles, p. 22.

Nay Reine, Fo-Yal, p. 36.

Symphor, Monographie de Rivière Pilote, écrite au moment du Tricentenaire.

Symphor, Monographie inédite de Rivière Pilote, écrite à l'occasion du Tricentenaire. 
Il faut y rattacher à coup sûr les rites de la Toussaint et du jour des Morts. Ils se marquent par l'illumination générale des tombes. À la ville, au " cimetière des riches ", ce sont des guirlandes d'ampoules électriques. Au " cimetière des pauvres ", ainsi qu'à la campagne, ce sont des centaines ou des milliers de bougies à la lueur clignotante. Les familles sont là, près de leurs disparus. On vient leur serrer la main et s'entretenir un peu avec elles. C'est un défilé ininterrompu tandis qu'au dehors se déroule, mais singulièrement amplifiée, la même fête bruyante qu'aux veillées. Cela dure deux soirs, après quoi l'on ramasse les couronnes et croix de perles sorties à cette occasion, que le climat aurait tôt fait d'abîmer, jusqu'à la fois prochaine. Il est explicitement admis que les âmes des trépassés reçoivent, alors, la permission de revenir voir le décor terrestre et de passer quelques heures, de minuit à minuit, dans l'intimité des leurs. Après quoi elles rentrent dans l'au-delà pour une année entière, ce qui n'est pas sans analogie avec les anthestéries athéniennes.

\section{III. - LES FÊTES PÉRIODIQUES ET LEURS TRADITIONS ; LES CHANGEMENTS OCCASIONNELS}

Nous venons d'analyser quelques-uns des rites qui accompagnent les grandes occasions de la vie. Il en existe d'analogues chaque fois qu'intervient un changement, fortuit ou non, de quelque importance.

Il y a d'abord les coutumes observées au moment de certaines fêtes, le premier de l'An, en particulier, et Pâques. Pour la première, les femmes doivent absolument étrenner une robe neuve, et il est désirable que cette robe soit à pois rouges ou roses. Le vert est également admis. Le bleu, au contraire, est sévèrement prohibé, car on ne verrait que du bleu pendant toute l'année, c'est-àdire de la misère, et l'on apparaîtrait comme une dupe facile. À plus forte raison ne faut-il pas de noir. Celui qui s'habillerait ainsi passerait pour souhaiter la mort d'un de ses proches parents dans l'année même. Sous aucun prétexte non plus, et quel que soit l'état de saleté de la maison, on ne doit donner un coup de balai ce jour-là, sous peine de faire disparaître la chance jusqu'à la prochaine Saint-Sylvestre.

On désigne sous le nom de Pangole la coutume en vertu de laquelle, à cette époque, parents et amis se font visite, se déplacent d'un centre à un autre pour se présenter leurs souhaits réciproques. Ce sont, dans les hauteurs du Sud, depuis neuf heures du matin jusqu'à la tombée de la nuit, " de véritables migrations de quartier à quartier, des théories incessantes de gens endimanchés, les hommes de blanc vêtus, le chapeau de feutre posé sur le côté, la pochette bien en évidence, l'œillet ou la rose rouge à la boutonnière, les femmes en organdi brodé et en soieries de toutes nuances, s'arrêtant de porte en porte pour échanger les compliments d'usage, jusqu'au lieu du rendez-vous où elles feront bombance ${ }^{1}$ ". À la Duchêne, c'est même une véritable farandole qui se déroule ainsi tous les jours jusqu'à l'Épiphanie.... « Le cochon fait toujours les frais de

Symphor, Monographie inédite de Rivière Pilote, écrite à l’occasion du Tricentenaire. 
ces ripailles. Chaque maison tue le sien au jour qu'elle a fixé pour sa réception. Le plus pauvre d'entre ces gens se fait un point d'honneur d'abattre son porc. Et il faut être dans une extrême misère, dans une indigence absolue, pour manquer à cette tradition, fort en honneur dans les campagnes de Rivière Pilote. Cela commence le 2 janvier et cela dure une dizaine de jours, et parfois le mois entier. La campagne entière est alors pleine de bruits de voix, de rires, de chants et de danses ${ }^{1}$. »

Laissons de côté le Carnaval trop de fois décrit, devenu depuis longtemps une occasion de s'amuser, et qui se termine le mercredi des Cendres par la cavalcade des Guiablesses, qui parcourent les rues de la ville en traînant derrière elles de vieilles «bombes à pétrole » (gallons de dix-huit litres), et en lançant des poignées de farine à la figure des passants pour annoncer la fin des réjouissances : «Vaval mô, Vaval mô » : Le Carnaval est mort !

La semaine sainte a une importance capitale pour beaucoup de quimbois et de conjurations. L'une des pratiques les plus répandues est celle du Gloria. Le samedi matin, au premier son des cloches « revenues de Rome », tous, grands et petits, se précipitent vers la plus proche fontaine pour se laver le visage à grande eau. Si on le petit, on plonge tête baissée dans un «bassin » de rivière ou dans la mer. Les appontements du Service côtier ou de la Française ${ }^{2}$ au chef-lieu sont noirs de jeune gens qui attendent le signal et qui ne voudraient, pour rien au monde, manquer à la tradition.

Dans les campagnes, après s'être lavé la figure, on sort dans le jardin, où l'on se met à battre les arbres fruitiers pour qu'ils donnent une belle récolte dans l'année. Si le procédé ne réussit pas, c'est que l'on ne s'est pas assez démené. L'année suivante on secoue l'arbre rétif avec une énergie redoublée, ce qui, parfois, le fait crever.

Les autres fêtes ont moins d'importance. Ni la Saint-Jean ni la Noël n'ont cette allure de cérémonies solsticielles dont il reste tant de traces dans les pays du Nord. Mais il existe, aux yeux des «initiés », des jours fastes et néfastes dont ils gardent le secret. Il est rare, par exemple, qu'on entreprenne rien d'important, si ce n'est un quimbois faisant appel aux puissances infernales, un vendredi après-midi.

Les rites propitiatoires sont particulièrement nombreux en cas de changement de résidence, d'installation dans une nouvelle demeure. À la ville et dans les bourgs, il s'agit presque toujours d'une maison louée. On ne se décidera souvent qu'après avoir compté les solives du plafond en répétant pain, vin, misé (misère). On ne fera pas affaire s'il y a trois, six ou neuf solives, parce que la troisième, la sixième et la neuvième correspondent au mot misé ${ }^{3}$. Les gens des mornes s'installent le plus souvent dans une case nouvellement construite ou héritée.

Symphor, Monographie inédite de Rivière Pilote, écrite à l'occasion du Tricentenaire.

Société de gymnastique.

Labrousse, Deux vieilles terres françaises, p. 69. Misé = misère. 
M. Labrousse indique qu'on porte alors, dans la demeure qu'on se prépare à habiter, du sel, qu'on dépose à la cuisine, du vin, dont on asperge toutes les pièces, enfin du pain rassis, qu'on cache dans un endroit où il soit à l'abri des rats. Le sel est nécessaire, parce que sans lui rien n'est mangeable ; le vin est symbole d'abondance ; le pain rassis doit toujours assurer de quoi vivre.

D'un bout à l'autre de l'île, du Diamant à l'anse Couleuvre, on a l'habitude de suspendre au faîtage de la case qu'on va occuper un sachet dans lequel on met toujours de la poussière de charbon, des miettes de pain et des pièces blanches, pour que l'abondance règne dans la maison. Certains y ajoutent du riz et de la farine de manioc. Nouvelle cérémonie au moment où l'on apporte les meubles. Avant de les mettre en place, on entre dans le logis avec du pain, du charbon et de l'argent, qu'on jette par terre et contre les solives du plafond. Toujours dans la même intention, on enterre une poignée de grains mélangés sous la table de la salle commune.

À cela s'ajoutent les précautions prises contre les mauvais esprits ou les malveillants: le "récurage " préalable s'opère avec des herbes choisies écrasées dans de l'eau de mer et additionnées de gouttes d'essence. Vingt-quatre heures avant l'installation, on opère un « lynchage, à l'extérieur à coups de bois d'épineux, et de bois de tamarin à l'intérieur, pour chasser de la demeure tous les esprits malins et la rendre parfaitement saine et habitable ${ }^{1}$ ».

À l'entrée des cases on remarque souvent, en vue d'écarter le malheur et les mauvais esprits, trois petites croix faites à la craie, accompagnées des noms des rois mages : Gaspard, Melchior et Balthazar, toujours disposés dans cet ordre. Parfois, on clouera un Sacré-Cœur sur la porte d'entrée.

On copiera de même sur du « parchemin vierge » - toutes les pharmacies en sont approvisionnées - la prière contre les maladies, qu'on cachera dans le matelas ou le sommier. Toutes les classes de la société en usent et il est rare, lorsqu'on achète un lit d'occasion, qu'on n'en trouve pas une sur un papier plié en triangle, ce qui, paraît-il, serait en rapport avec un signe du Zodiaque.

D'autres formules sont enterrées sous le seuil et à trois pas de la case pour arrêter toutes intentions maléfiques. On demande également au curé de venir bénir les diverses pièces de l'habitation et le lit conjugal, s'il s'agit de nouveaux mariés, sans oublier la cuisine, même quand cette dernière n'est qu'un appentis en bambous. De même, pour assurer la bonne harmonie du ménage qui s'installe, on utilise, dans la région du Diamant, des anses d'Arlets et des TroisÎlets, de petites figurines en terre, grossièrement modelées, qu'on a mises à tremper dans du miel. Plus généralement, quand on désire s'attirer les bonnes grâces de quelqu'un ou fléchir son hostilité, on trempe une figurine de terre cuite à son image dans de l'huile ou du saindoux fondu.

Zobel, Les Jours immobiles, p. 169. Des témoignages oraux me permettent d'affirmer que cette pratique est très généralisée à l'intérieur de l'île. 


\section{CHAPITRE III}

\section{Remèdes et « Charmes »}

\section{I. - PLANTES MÉDICINALES}

$\underline{\text { Retour à la table des matières }}$

L'efficacité attendue de telles pratiques repose sur des données simples de magie sympathique. Elles dominent la vie entière de ceux qui y croient. Il n'y a donc pas à s'étonner si toute la médecine populaire en est profondément imprégnée. Le sorcier, le quimboiseur qui évoque les esprits est en même temps le guérisseur. Ses prescriptions apparaissent souvent comme un mélange de conseils raisonnables et de pratiques qui le sont moins.

Il est incontestable, d'abord, que les plantes médicinales. abondent. Il en est que tout le monde connaît, dont les propriétés ont été maintes fois éprouvées. De vieilles femmes crient dans les rues : "Moin ni la politiqué créole ${ }^{1}$ ", et vendent des choix de fleurs, de feuilles, d'écorces, de racines pour lesquelles elles trouvent de nombreux chalands. Les feuilles d'alloués (aloès) ou de «raquettes » (figuiers de Barbarie) sont employées comme émollients ou contre les brûlures. L'herbe à chattes sert aux femmes en couches ${ }^{2}$. Le piment coolie ou mexicain se vend contre les parasites intestinaux ${ }^{3}$, ainsi que l'herbe à vé (vers) ${ }^{4}$. La véronique soulage la toux, que les hibiscus rouges ou coquelicots guérissent dans les cas les plus rebelles. Le " pompon soldat ${ }^{5}$ » passe pour souverain contre les fièvres et les grippes tenaces. Les marchandes recommandent leur « café zèb piante » (café aux herbes), régénérateur de sang, leur verveine ou "queue rate » contre l'inflammation. Le "thé pays » a son usage dans les maladies d'yeux.

Beaucoup de ces procédés populaires sont efficaces. Il apparaît établi qu'il y a, chez certains quimboiseurs tout au moins, une connaissance empirique assez poussée de la flore et de la faune locales. Ils savent panser, par exemple, et guérir les morsures du trigonocéphale, atténuer et faire disparaître les symptômes extérieurs de la syphilis et de la gonorrhée, qui exercent leurs ravages d'un bout à l'autre de l'île.

La pothiqué, l'apothicaire, les remèdes créoles, Cf. Nay Reine, p. 18.

Hebeclinium macrophyllum.

Capsicum ceralocarpum.

Chenopodium ambrosoides.

Acacia Farnesiana W. 
Ils savent de même procurer à leurs clients, qui en sont friands, les moyens de se montrer à la hauteur en toutes circonstances. Les aphrodisiaques abondent à la Martinique, dont quelques-uns réputés. C'est ainsi qu'il existait naguère sur la route de la Trace, à peu de distance de Fonds-Saint-Denis, un arbre dont les fruits étaient réservés à un grand propriétaire du Nord, qui les envoyait cueillir chaque année, tant il leur trouvait de rajeunissantes et mirobolantes vertus. Cet arbre fut coupé lors de l'élargissement de la route, mais poussa des rejetons dans une savane proche. Un autre fut transplanté au Morne Rouge. Ce sont les graines qui sont efficaces, remarquablement efficaces. On raconte, sous la rose, que de très hauts personnages en essayèrent les vertus au moment du Tricentenaire (1935). Ils se trouvèrent plus que satisfaits et rapportèrent, dit-on, quelques provisions dans la Métropole. Tel maire de l'intérieur, "feu potard » au temps de sa jeunesse, comme il aimait à le rappeler, disposait également d'une «liqueur martiale" dont quelques gouttes suffisaient à relever les courages les plus abattus. Il est vrai que le lendemain les patients faisaient peine à voir. Les accidents, dans ces conditions, ne sont pas rares. Il est de tradition, dans certains mornes, d'aller réclamer au quimboiseur du lieu, avant de se marier, un remède " pour prendre patine pièce ", c'est-à-dire pour ne pas tomber en panne. Les larves de guêpes, le crevin (couvain), passent dans ce cas pour avoir des vertus particulières : "ça renvigor » (ça revigore). Mais il est déjà arrivé plus d'une fois que la dose ait été mal calculée ou que le client, pour plus de sûreté, l'ait dépassée. Dans les hauteurs du Lorrain, on fabrique un aphrodisiaque à base de plantes du pays et d'holoturies qui a déjà expédié à l'hôpital, voire en France, plus d'un jeune ou vieux beau.

Il reste d'ailleurs fort difficile de faire le départ entre les effets réels de ces potions et ceux qu'on attribue aux conjurations qui les accompagnent. Si l'on en croyait la tradition locale, ils seraient dignes du Minotaure, l'expression étant usitée aux Antilles mêmes. En voici deux exemples assez caractéristiques :

Les Martiniquais sont assez facilement vains de leurs exploits. Pour se tenir à la hauteur de leur réputation ils utilisent, dans l'Extrême Nord, le « Viatique du grand coqueur ${ }^{1}$ ", ainsi composé :

On prend les organes génitaux de neuf tortues de mer femelles ou de cinq mâles prélevés à la période du cavalage (accouplement). Il est indispensable d'ailleurs que ces tortues, ou "carets », n'aient, pas été prises au filet ni à la senne. Les organes prélevés doivent être conservés dans du « sirop de batterie $^{2}$ " jusqu'au neuvième jour du mois de Marie, patronne des femmes fertiles. On les met alors à sécher sur une plaque de verre qu'on rentre à la brune, avant la fraîcheur du soir. On pile ensuite, dans un mortier, on réduit en poudre, on ajoute une quantité équivalente de noix de muscade râpée, deux parties de noix d'acajou grillées et également râpées et autant de gingembre. Le tout est versé dans un verre à porto additionné de deux jaunes d'œufs battus avec un zeste de citron. Les effets en sont, paraît-il, extraordinaires, dangereux

Dérivé de coq.

Le sirop de batterie est ce qui précède immédiatement le sucre. Il est obtenu par évaporation du vesou ou jus de cannes dans les chaudières du système « Père Labat ». 
parfois pour les partenaires qui risqueraient l'éventration ou, à défaut, de jumeaux parfaitement constitués, mais venant avant terme.

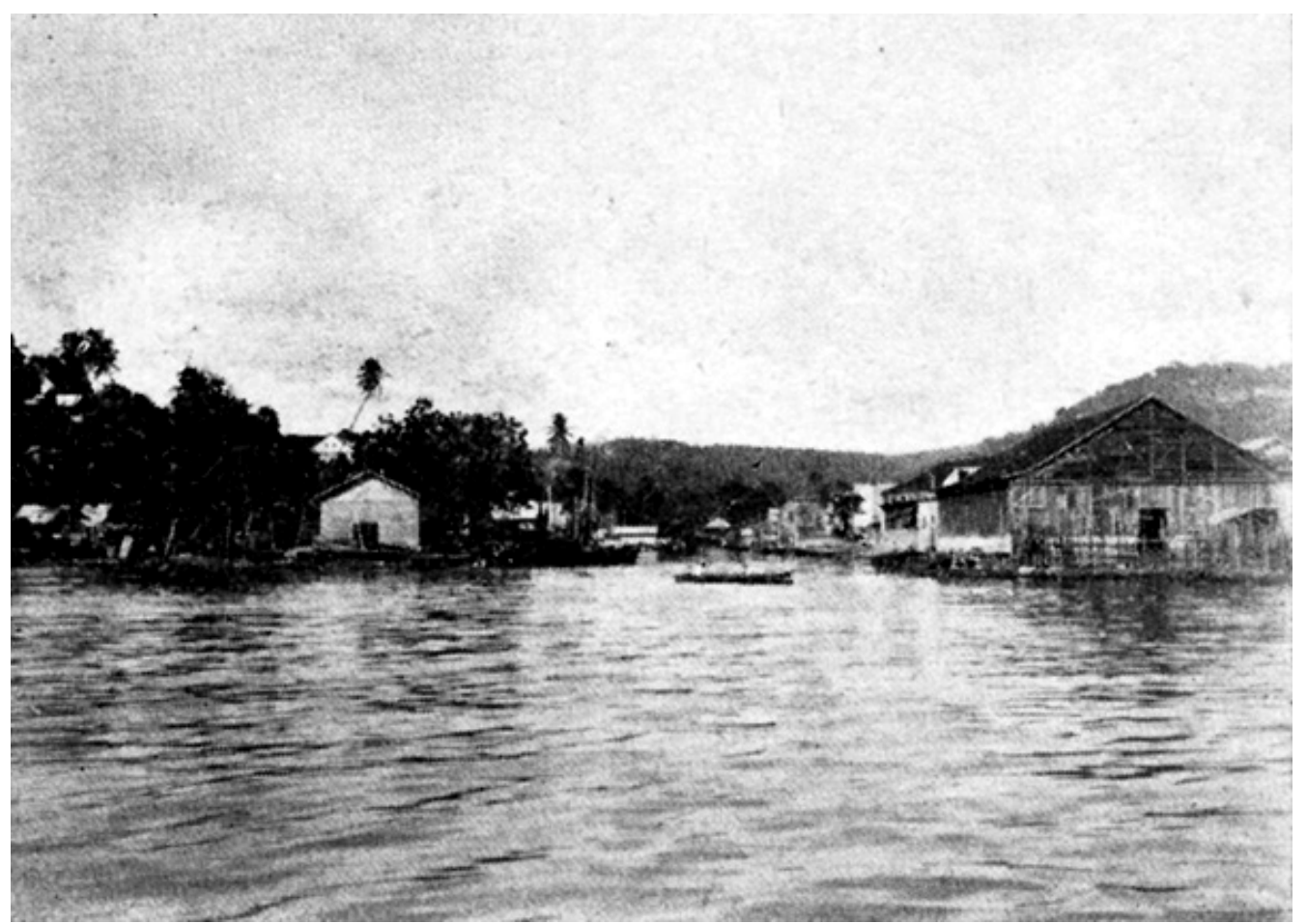

EMBOUCHURE DE LA RIVIÈRE LEVASSOR

Pour recommencer le lendemain les mêmes travaux, il suffit d'en laver l'instrument avec un bol de lait de corossol où l'on a fait macérer du «balai doux ${ }^{1}$ », et qu'on avale après l'ablution. Une bonne sieste sous un gros papayer dont on mange un fruit mûr saupoudré de cannelle râpée, une friction avec un morceau d'orange amère et un peu de miel. Ensuite l'on ingurgite, dans les mêmes conditions que la veille, la moitié de la préparation à base de tortue. En vertu de quoi l'on serait capable de satisfaire une fois encore aux exigences de douze à quinze participantes. Le troisième jour, toutes choses égales par ailleurs, il suffit du tiers de la préparation, le quatrième de la moitié de ce tiers, le cinquième du quart, le sixième on liquide ce qui reste. Le septième, qui doit être un dimanche, on va à la messe, on communie et on remercie le Seigneur d'avoir fait de vous un homme. Il est d'ailleurs indiqué de ne pas dépasser les doses normales. Il est parlé dans le pays d'éclatements comparables à ceux d'un pneu trop usagé ${ }^{2}$.

Corosol Anona muricatal L., balai doux. Scoparia dulcis, plantes «astringentes, stomachiques et béchiques »

2 J'ai reproduit intégralement et sans rien en modifier la formule qui m'a été communiquée, et qui vient de la région du Prêcheur. Mais on éprouve des difficultés de plus en plus grandes à l'appliquer, les tortues de mer ou « carets » étant devenues assez rares aux alentours de la Martinique. Il semble bien que, sur la côte est, on tende à les remplacer par des holoturies, nombreuses sur les fonds sableux et connues localement sous le vocable de « pine carette ", le reste de la composition demeurant identique. 


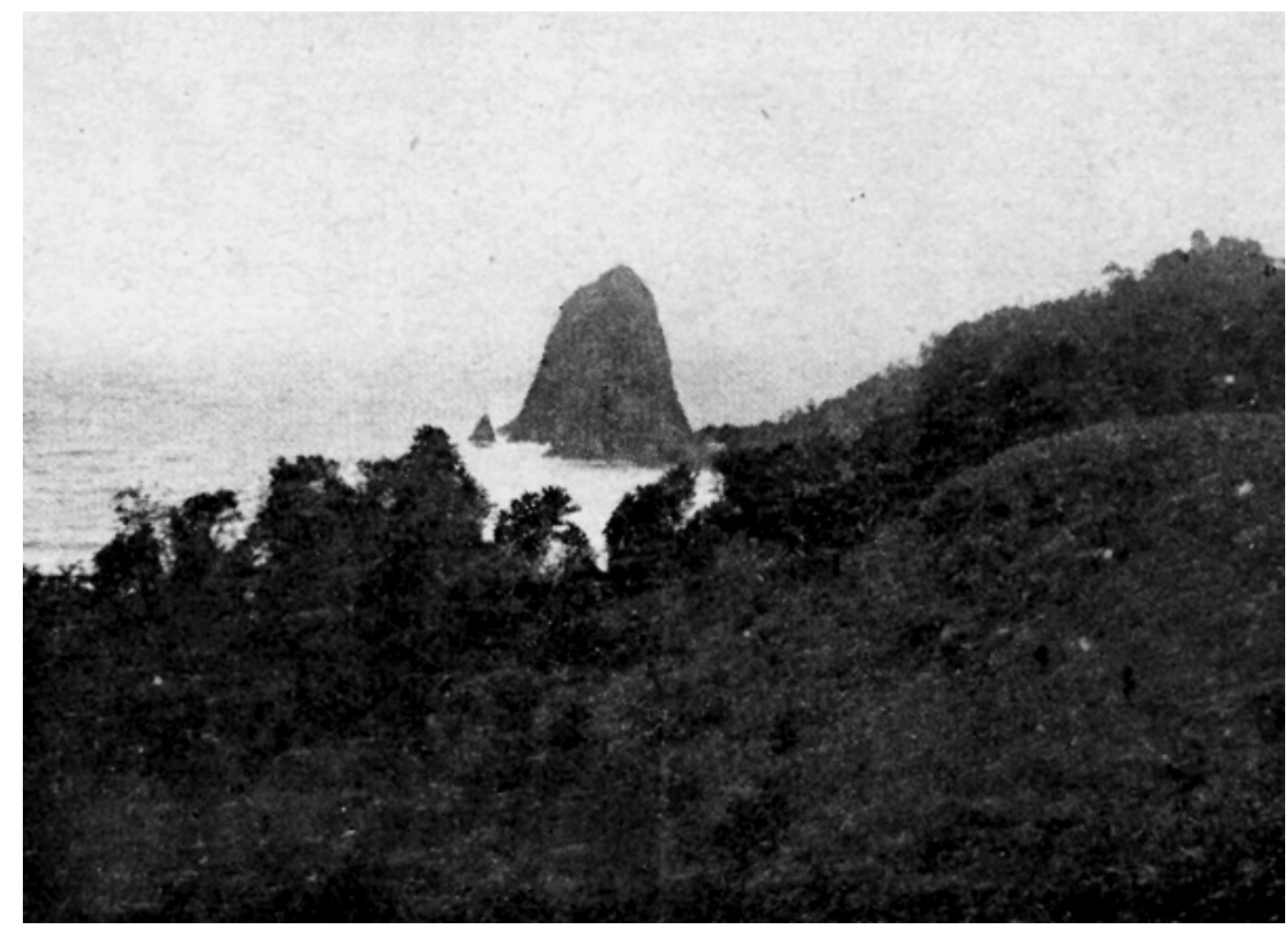

LE PAIN DE SUCRE, ENTRE LE MARIGOT ET SAINTE-MARIE

Il y eut en 1935, au moment du Tricentenaire et des fêtes qui l'accompagnèrent, un incident qui fit quelque bruit et dont les dessous ne purent être élucidés sur le moment même. L'un des plus beaux taureaux du concours agricole, une bête magnifique primée hors concours, et dont le consul d'une République voisine négociait, dit-on, l'achat, fut retrouvé tout sanglant dans la savane où il pâturait, et privé de ses attributs. L'enquête ne donna rien. Je n'ai moi-même appris les dessous de l'affaire que récemment. Peut-être comportaitelle quelques vagues relents d'hostilité politique, mais l'essentiel n'était pas là. Le testicule du taureau, préparé suivant les rites, a des vertus très supérieures encore au viatique du grand coqueur. On se le procure aussi gros que possible, on sale, on poivre sec et on le suspend vingt-sept jours. Malgré l'odeur, il ne faut y toucher ou le remuer sous aucun prétexte. La veille de Pâques, à minuit, on décroche le testicule à peu près sec, on le bat pour l'attendrir avec un manche à balai ou un pilon, puis on le met au four, secrètement. Il est inutile que le voisinage connaisse l'affaire, car il vous croirait livré sans rémission aux puissances des ténèbres. On laisse cuire à feux doux jusqu'au deuxième coq, c'est-à-dire deux heures du matin. Lorsqu'on le retire, le testicule est « aussi plat qu'une cassave de manioc ». Mais pour qu'il ait toute sa vertu, il faut absolument le faire bénir par un prêtre le jour même de Pâques, symbole de résurrection, ensuite de quoi on l'enferme jusqu'au jour de l'Ascension, car alors tout monte, les plantes, les rivières, la lune, la mer, comme NotreSeigneur est monté au ciel. Il faut donc refaire bénir le testicule ce jour-là. Après quoi il ne reste plus qu'à le manger avec du fruit à pain et du cœur de poisson, ce dernier ingrédient indispensable, car, de tous les êtres vivants, les poissons sont les seuls qui puissent se reproduire à des millions d'exemplaires. 




GRAND'RIVIÈRE RENTRÉE DE LA PÊCHE

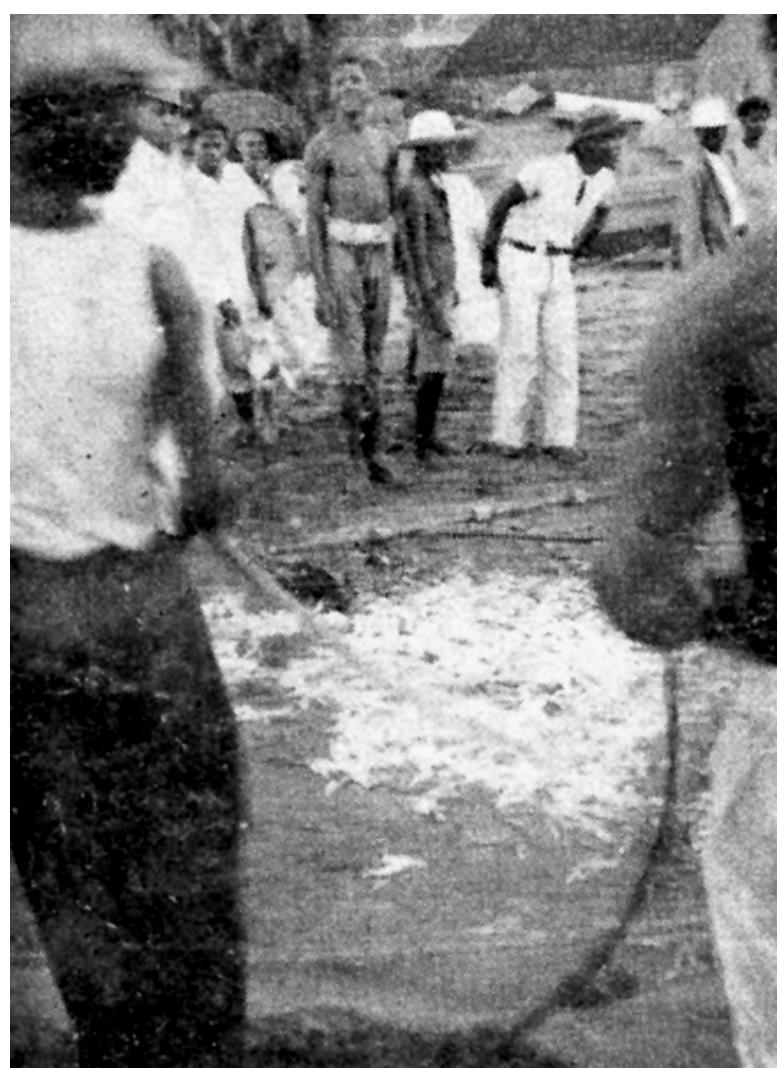

UN COUP DE SENNE. TROIS RIVIÈRES

C'est à cela, très exactement, que servirent les attributs du taureau hors concours. L'auteur du méfait ne fut jamais retrouvé, car il habitait à l'autre extrémité de l'Île. Ses voisins remarquèrent seulement, à l'époque, qu'il 
fréquentait l'église de manière assidue et qu'il communiait fréquemment. Le vieux curé de la paroisse, que je connaissais bien, se félicitait de ce magnifique renouveau de piété. Puis, un beau matin, notre homme se présenta devant le prêtre pour lui demander de bénir le missel qu'il venait d'acheter. Satisfaction obtenue, il part, radieux, rencontre un ami cher, de qui je tiens toute l'histoire, et l'entraîne chez lui : le missel n'était qu'un petit coffret de bois, malgré la croix qui l'authentifiait. À l'intérieur, noirâtre et pestilentiel, le testicule du taureau primé. Et comme l'ami lançait un regard interrogateur : "C'est Pâques aujourd'hui, répartit l'intéressé, ce sera bientôt l'Ascension. »

\section{II. - LES POISONS}

Il est également certain que des produits tirés du monde animal ou végétal peuvent servir à des vengeances de toute sorte. Il est des poisons connus et dont les effets passent pour inévitables. Les poils de bambou dans la soupe entraînent, à des délais plus ou moins rapprochés, suivant la quantité employée, de terribles douleurs intestinales dont l'aboutissement est une péritonite mortelle. Il arrive qu'au lieu de poils de bambou ${ }^{1}$ on utilise des cheveux ou des rognures d'ongles hachés fin comme poivre.

Parmi les toxiques les plus redoutés, on cite à la Martinique le suc extrait des racines de manioc, de pomme rose et surtout de barbadine ${ }^{2}$. C'est avec ce dernier que se pratiquerait l'empoisonnement par le punch, dont le P. Labat a donné une description qui serait toujours valable. Un nègre du sieur SaintAubin, raconte-t-il, étant à l'article de la mort, envoya chercher son maître pour lui demander pardon et lui avouer qu'il était coupable de la mort de plus de trente de ses compagnons. "Il lui dit qu'il se servait pour cela du suc d'une plante qu'on trouve au bord de la mer aux Cabesterres des îles.... Il avait toujours soin d'avoir un de ses ongles plus grand que les autres et lorsqu'il voulait empoisonner quelqu'un il allait gratter avec cet ongle l'écorce de cette plante jusqu'à ce qu'il l'eût rempli du suc épais qui en sortait. Avec cette provision il retournait à la maison et ne manquait pas d'inviter le malheureux, qu'il voulait tuer, à boire un coup d'eau-de-vie. Il buvait le premier, puis il en versait à sa victime de la même bouteille, dans le même coui dont il s'était servi lui-même, mais qu'il tenait d'une manière que son ongle trempait dans l'eau-devie et y répandait le venin dont il était rempli. Il ne se passait jamais deux heures sans que celui qui avait bu ne tombât dans des convulsions horribles qui l'emportaient en peu de moments ${ }^{3}$. » Un autre procédé consisterait à passer sur le bord du verre un doigt légèrement trempé dans le poison. Ce dernier pénétrerait dans l'organisme au simple contact de la muqueuse buccale et produirait plus ou moins rapidement son effet. En général, la victime enfle beaucoup et devient difforme.

On peut remarquer qu'il s'agit là de procédés d'introduction assez récente, puisque bambous, comme pommiers roses, n'ont été apportés à la Martinique que dans la seconde moitié du $\mathrm{XVIII}^{\mathrm{e}}$ siècle.

Pomme rose : Eugenia Jambos L. Barbadine : Passiflora quadrangularis L.

Labat, Édit. Duchartre, II, p. 68. 
Tous ceux qui ont vécu longtemps à la Martinique connaissent des faits de ce genre ou prétendus tels. Peu de temps avant mon départ, un des maires de la colonie me racontait comment, un jour, il avait été victime d'une tentative de cet ordre, pour avoir pris le punch chez un de ses employés. Le liquide à peine avalé, il avait ressenti comme une brûlure intolérable et n'avait échappé que par miracle à la mort, après une longue et douloureuse maladie.

Il est parfois des procédés encore plus subtils. On rapporte qu'un brave cultivateur de Sainte-Marie s'enorgueillissait d'un plant de bananes jaunes magnifique, mais en vain, car chaque fois qu'un régime arrivait à maturité il disparaissait. Notre homme avait quelques raisons de soupçonner son plus proche voisin. Il résolut de se venger et, à cette fin, prépara une décoction bouillie et rebouillie de racines de barbadine et de pommier rose à parts égales. Il en arrosa régulièrement son plant pendant plusieurs mois... Le régime qui poussa dans ces conditions fut encore volé. Le lendemain ou le surlendemain, le voisin mourait.

Dans les régions du Vauclin, Sainte-Anne et Diamant, les pointes d'orphie desséchées servent à la fabrication d'une poudre et d'un venin liquide qui rend inguérissables les blessures faites avec les armes que l'on y a trempées. On peut également répandre des chiques qui entrent dans les chairs et pullulent. La légende prétend que certain gendarme, évidemment peu soigneux, en eut jusque sur la langue.

Mais on ne veut pas toujours la mort du patient. Il peut s'agir, pour une femme, de se faire épouser ou de ne pas être abandonnée par un amant généreux. On fait alors appel aux nombreux aphrodisiaques, tel le fameux bois Bandé, ou Banda ${ }^{1}$, que comporte la pharmacopée populaire. D'autres préfèrent les stupéfiants qui endorment, épuisent ou annihilent la volonté. Il est facile de se faire citer de nombreux cas, réels ou supposés, d'hommes victimes de telles manœuvres et devenus incapables du moindre acte d'énergie. Tel avouait un jour, en ma présence, qu'il n'avait jamais pu retourner dans son pays d'origine parce qu'à chaque fois qu'il se préparait à partir il tombait gravement malade : il avait fini par renoncer au voyage. Il arrive aussi que les stupéfiants ne soient pas exactement dosés et entraînent des accidents graves, paralysies ou dégénérescence. Le salut ne peut venir que d'un contrepoison efficace, difficile à administrer, puisque le danger vient de l'entourage immédiat de la victime, ou d'une fuite précipitée en Europe ou aux États-Unis, s'il en est temps encore. Sinon, le malheureux traîne plus ou moins longtemps, jusqu'au moment où ce que les médecins dénomment affection nerveuse finit par l'emporter.

Les « charmes » assurent donc la force, la puissance de ceux qui « savent », des « Forts », des " Mentors » ${ }^{2}$, et leur permettent d'écraser leurs adversaires, de leur infliger les pires maladies ou les plus cuisantes défaites. Inversement

Richeria Grandis V.

Le terme est réellement employé dans tout le sud et l'est de l'île et trahit ainsi curieusement l'influence de la littérature classique sur les quimbois martiniquais, ainsi que l'extension de ceux-ci dans les milieux les plus aisés et les plus cultivés. 
chacun de nous est environné de dangers qui rôdent autour de lui et qu'il ne peut déceler et vaincre que s'il sait lire les présages et utiliser des contrecharmes appropriés. On sort alors du monde des remèdes proprement dits : poisons ou contrepoisons jouent encore leur rôle, mais à côté d'eux aussi les invocations, les envoûtements, la magie pure.

\section{III. - DE QUELQUES PRATIQUES COURANTES}

On rencontre d'abord toute une série de pratiques médicalement peu contrôlables. Dans la région de Rivière Pilote, lorsqu'un enfant tombe en convulsions, si l'on n'a pas "d'eau chaude ou de manger cochons sur le feu », on arrose le petit malade d'urine fraîche ${ }^{1}$. La guérison se produirait presque instantanément. Il en serait de même pour les écorchures, les blessures légères, voire les piqûres de serpent, s'il faut en croire cette histoire saugrenue, qu'on m'a jurée authentique, d'un agent de police de troisième classe au bourg de la Rivière, disons des Fleurs.... Il était préposé à la surveillance du " gros bois " ou gabarre qui, tous les matins, en pleine nuit, prenait le canal vers la baie de Fort-de-France. Notre homme était volontaire: les mauvaises langues prétendaient qu'il épiait le départ d'un mari. Trois mauvais plaisants s'amusèrent un matin, vers les quatre heures, de contrefaire la voix de celui-ci : «Femme moin là -pa ni vent ce matin » (il n'y avait pas de vent ce matin), drôle de temps. » Tchouk Tchouk Tchouk, c'était l'intrus qui venait de passer par la fenêtre en simple chemise et caleçon, et était tombé dans le marécage connu sous le nom de roseaux Ma Ajax (les roseaux de Madame Ajax). Il fut en un clin d'œil devant son propre domicile, et les trois honnêtes fripouilles qui avaient monté la farce se délectaient à l'entendre : «Louise (c'était sa femme légitime), ouvrez-moi la porte, je vous en prie. Prends le vase urine et verse dans tes mains, frotte moin les fesses. Étais allé roseaux Ma Ajax, serpent piqué moin. » Et comme des rires incoercibles fusaient de la rue : «Faut pas entendre ce qui se passe déro (dehors). Moin en danger mort. »

L'incontinence, cependant, est bien gênante. Au Diamant, lorsqu'un enfant continue à souiller son lit au delà de l'âge normal, on lui attache un gros crapaud dans le cou : l'incontinence cesse immédiatement.

Dans la même région, pour faire passer les «vers », on prend le premier rendu par le patient, on le met à sécher, on le mélange au prochain repas, et puis « cé fini " ${ }^{2}$. Au Prêcheur, on s'imagine que la brise qui vient de la mer, la « risée de terre », parce qu'elle porte vers la côte, fait avorter les femmes enceintes, qui se retirent dans leurs cases dès qu'elle commence à souffler, à moins qu'elles ne désirent se débarrasser de leur fardeau. Au Gros Morne, on se sert à cette dernière fin de fleurs d'ananas trempées dans du sucre, qui constituent, paraît-il, un très puissant emménagogue.

Zobel, Les jours immobiles, p. 163.

Zobel, Les jours immobiles, p. 163. 
La variole, vérette ou petite vérole, a fait longtemps de terribles ravages à la Martinique, et Lafcadio Hearn a laissé une description hallucinante des dernières épidémies de Saint-Pierre. Il était pourtant facile de l'éviter, puisqu'il suffit de porter sur soi trois graines de giromon ${ }^{1}$ et trois de maïs dans un sachet avec des graines odorantes. À Rivière Pilote, un vieux géreur ${ }^{2}$ se plaignait d'une hernie. Un de ses travailleurs lui conseilla de porter dans sa poche un «zyeu bourrique mâle » et un "zyeu bourrique femelle " ${ }^{3}$. La hernie passa, mais, les deux graines ayant été perdues, elle revint, et notre homme dut à nouveau se procurer le «zyeu bourrique mâle» et le «zyeu bourrique femelle » pour recouvrer la santé.

La lèpre, assez fréquente à la Martinique, a la réputation de n'être contagieuse que dans des conditions bien déterminées. On dit pudiquement de ceux qui en sont atteints, mais que leur condition sociale met à l'abri de toute menace d'internement, qu'ils ont une "diathèse ». Ils peuvent alors être pleinement rassurés sur la fidélité de leurs maîtresses, que nul ne songera à leur disputer. S'il arrive cependant qu'un homme sain ait eu des rapports avec une lépreuse et qu'il ait appris dans les vingt-quatre heures la maladie dont la malheureuse est atteinte, il existe un moyen héroïque, d'après les vieux du Nord, pour échapper à la contagion : il faut, le soir même, obtenir les faveurs d'une vierge, le lendemain de deux, la médication devant durer une semaine entière, suivant la même progression, jusqu'à sept par conséquent pour la dernière nuit, et vingt-huit au total.

Tout ce qui vient des parties intimes de la femme est regardé comme ayant des vertus particulières, et on s'en sert à l'occasion comme remède. J'ai vu, sur une plage de l'Est, un jeune enfant piqué par un poisson plat qu'on appelle « crapaud de mer » et qui est fort venimeux. Sa mère trempa le doigt dans son sexe et le passa immédiatement sur la blessure.

\section{IV. - LES « PROTÈGEMENTS »}

Mais on utilise tout autant, sinon davantage, ce que l'on appelle dans le pays des "protègements ». Il en est que tous connaissent et pratiquent. Veut-on, par exemple, se débarrasser d'un visiteur importun? Il n'est que d'installer derrière la porte de la pièce où il se tient un balai renversé avec un grain de sel sous le manche : le visiteur se lèvera aussitôt. S'il résiste, un petit balai à côté du grand aura vite raison de lui. Mais, l'importun éloigné, il faut se hâter de remettre les balais dans leur position normale, sous peine de violente contrariété.

Auprès de la Duchêne s'élève un piton conique d'une cinquantaine de mètres de haut : on l'appelle la Roche Percée, et il a un caractère magique. Aussi tous ceux qui en réussissent la difficile ascension ne manquent-ils jamais de rapporter un morceau du sommet, qu'ils déposent ensuite, comme talisman

Cucurbita Popo.

Le « géreur » dirige les cultures d'une « habitation » de soixante à cent hectares.

Fruit du mucune brûlant, Mucuna urens D. C. C'est une sorte de haricot, avec une cannelure entre deux bandelettes brunes. 
protecteur, au seuil de leur porte. Les gosses de l'endroit considèrent au demeurant qu'ils sont sûrs d'éviter la fessée promise à leurs méfaits s'ils parviennent, de la porte de leur case, à lancer un petit caillou à travers celle d'en face.

Mais, dans la plupart des cas, les protègements sont des bijoux, des médailles accompagnées de chaînes du même métal, c'est-à-dire que, si la chaîne est d'argent, la médaille doit être obligatoirement d'argent, etc. Pour les hommes, on emploie des bagues à chaton.

Le bijou, quel qu'il soit, est acheté sur la prescription d'un sorcier émérite, d'un « Mentor », auquel on a confié l'intention pour laquelle on veut avoir un " protègement». Lorsque le bijou a été acquis, il est remis au Mentor, qui le « monte » suivant les règles de son art et le rend ensuite à son client.

Le protègement peut être également constitué par un sachet contenant des médailles, des amulettes, des herbes séchées ou des poudres diverses. Le tout est enveloppé dans une feuille de parchemin vierge, sur laquelle a été écrite une prière ou tout autre formule fréquemment rédigée en latin macaronique. Le sachet est suspendu au cou par une corde de mahot ${ }^{1}$, parce que cette plante passe pour écarter les maladies : on attachera, par exemple, un chien menacé de la rage avec un collier de ces fibres.

De nombreuses personnes portent séparément des médailles, un scapulaire et un sachet contenant une poudre mystérieuse. Les scapulaires s'achètent dans le commerce, en dehors du clergé. On y joint, à l'ordinaire, des implorations à tel ou tel saint, qui n'est pas toujours en règle avec les canons de l'Église, et qu'on se repasse d'usager à usager. Il existe ainsi de véritables « chaînes de prières ", qu'on ne doit pas interrompre, sous peine des pires calamités. Mais ceux qui les observent échappent à tous les dangers. Parfois, les domestiques en offrent à leurs maîtres, au moment d'un voyage : " Madame, vous la mettez sur vous, et vous n'avez plus rien à craindre. " Il a même été répandu, à la Martinique comme à la Guadeloupe, un Recueil des quarante-quatre prières pour sortir victorieux des luttes de la vie, imprimé à Pointe-à-Pitre en 1939, et contre lequel le clergé a maintes fois cru devoir mettre les fidèles en garde.

On invoque d'abord la Vierge, mais aussi saint Joseph, parce qu'il est le plus grand saint du paradis, saint Antoine de Padoue qui passe, comme partout, pour faire retrouver les objets égarés, et combien d'autres encore. La confiance est telle qu'en certaines communes de la colonie les demandes se font parfois par écrit. Naguère encore, au témoignage formel de M. Legros, il existait dans certaines églises un tronc spécial pour les lettres adressées au saint de l'endroit, et les curés lisaient en chaire celles qui pouvaient l'être. Beaucoup d'entre elles étaient accompagnées d'une petite somme d'argent, avec promesse d'une plus importante "pour le pain des pauvres », au cas où le vœu serait exaucé, ou le

Triumfetta Lappula L. Arbuste des régions sèches dont on tire des cordes très tenaces, ainsi que de nombreux remèdes. 
mariage, car il s'agissait souvent de cela, dûment conclu et célébré. Faut-il rappeler ici que beaucoup des premiers colons venaient de Normandie?

Saint Benoît, représenté debout, lisant son bréviaire, protège contre les mauvais sorts et les accidents de la route. Saint Christophe est, comme en Europe, le patron des chauffeurs, mais on l'invoque spécialement contre l'influence des démons, les épidémies, les calamités publiques, les troubles et séditions populaires, ainsi que contre les fléaux et accidents de toute sorte. Saint Blaise protège des maux de gorge. Le jour de sa fête, aux anses d'Arlets, le prêtre donnait la bénédiction avec deux cierges en croix et l'on raconte qu'une femme, pour s'être moquée de cette dévotion, se réveilla le lendemain avec la gorge démesurément enflée. Sainte Odile et sainte Lucie doivent être invoquées pour les maux d'yeux. Sainte Apolline et saint Pérégrin calment les rages de dents. Saint Georges empêche les mille-pattes de fuir. Sainte Philomène guérit à peu près tout ; saint Michel demeure, comme sur les bords de la Manche, le plus populaire des archanges, ce qui lui vaut d'être spécialement invoqué par les quimboiseurs.

L'obscurité est toute pleine d'embûches et de mauvaises rencontres. Le mieux est à beaucoup près de ne pas se risquer dehors entre minuit et l'angelus du matin. Il est tout de même, quand on est obligé de sortir, quelques moyens de défense éprouvés. L'un des meilleurs est de mettre ses vêtements à l'envers : robe, culotte ou veston. Une femme surprise par une apparition n'a qu'à relever ses jupes au-dessus de la tête. Un procédé plus efficace encore est de se placer une touffe d'herbe sur le crâne et de s'avancer ainsi entre deux terres, dans un domaine inaccessible aux forces de l'au-delà. Par surcroît de précautions, il arrive qu'on place sur la touffe d'herbes une paire de ciseaux grande ouverte : c'est un moyen assuré de couper la mauvaise chance.

\section{V. - BAINS « DE CHANCE », « BAINS DÉMARRÉS » ET RITES PURIFICATOIRES}

On est prêt à tout tenter également pour que celle-ci n'arrive pas jusqu'à la demeure familiale. Si elle y pénètre cependant, on la chassera avec ce que $\mathrm{M}$. Labrousse appelle « trois bains de chance ${ }^{1}$ ». La description qu'il en fournit est complète et précise. La meilleure date pour chacun de ces bains est le premier vendredi du mois. Si l'on est pressé, on peut choisir le premier et le troisième vendredi, ou trois vendredis successifs, voire en une seule semaine le lundi (de préférence le premier du mois, jour du Saint-Esprit), le mercredi, jour de saint Joseph et le vendredi, jour du Saint-Sacrement. Le Saint-Esprit "éclaire ", saint Joseph nourrit et le Saint-Sacrement attire une bénédiction générale. Voici, ajoute M. Labrousse, ce qu'on met généralement dans ces bains : « Un peu de farine de froment, un peu de lait, un flacon de lait d'iris, pour se blanchir aux yeux du patron ainsi qu'aux yeux des gens dont on craint l'opinion ou qui peuvent vous aider, de l'eau de duchesse (pour jouir d'une grande

Labrousse, Deux vieilles terres françaises, p. 64. 
considération), des feuilles d'une plante appelée tabak à Jacquot ${ }^{1}$ (s'il s'agit d'achalander une boutique, de maintenir ou d'augmenter la prospérité d'une entreprise), de feuilles mâles ou femelles de trèfle ${ }^{2}$ (afin d'avoir tout le monde, hommes et femmes pour soi), de l'essence d'acacia (si c'est d'un mulâtre qu'on a besoin d'obtenir l'aide ou de conserver la bienveillance) ou bien de l'essence de verveine blanche ou de verveine rouge, s'il s'agit d'un blanc ou d'un Nègre ${ }^{3}$. »

L'eau du bain sert ensuite à laver toutes les pièces de la maison pour les imprégner de chance. Puis on promène dans les chambres, pendant un ou plusieurs jours, un "canari ", ou récipient en terre, garni de charbons sur lesquels on fait brûler diverses substances: pain, maïs et encens. C'est un symbole des trois rois mages, dont nous avons déjà trouvé les noms inscrits sur la porte de bien des cases. Ils avaient apporté à l'Enfant-Jésus de l'or, de l'encens et de la myrrhe. Comme M. Labrousse l'explique fort ingénieusement, l'or ne brûlant pas, on le remplace par une nourriture essentielle qu'il sert à acheter, et quoi de plus essentiel que le pain ? Le maïs se substitue de même à la myrrhe, et pour écarter plus sûrement les mauvais sorts on ajoute à l'encens du benjoin et du baume du Pérou.

Il est bon, lorsque cette purification a été exécutée, de continuer à veiller soigneusement. Tel maître, que j'ai connu, ne se couchait jamais sans avoir accompli toute une série de rites purificatoires. En particulier, il jetait du sel à larges poignées autour de sa vérandah. Le lendemain, de bonne heure, il chaussait des galoches et arrosait le tout. L'eau salée emportait d'un coup les quimbois qu'on avait pu déposer dans la nuit. Il tenait tellement à cette pratique qu'il n'hésita pas à donner congé à un de ses collègues, auquel il avait cédé une partie de sa demeure, et qui se refusait à l'accomplissement régulier de la cérémonie.

Mais la grande purificatrice demeure la mer. C'est là qu'on va prendre le bain « démarré », dont le but avoué est de " démarrer » ou détacher la déveine persistante. Cela se fait un vendredi, le premier du mois, sauf lorsqu'il y a un vendredi 13 , et à l'aurore. On choisit à l'ordinaire, d'après $\mathrm{M}$. Labrousse, un endroit où la mer est agitée, pour être sûr d'être bien lavé. Avant d'entrer dans l'eau, le patient forme parfois sur le sable une croix avec des bougies allumées. Au choc de la première lame il s'écrie : «Un tel, ou une telle, démarré moin », ce qui signifie : débarrassez-moi de ce qui fait mon malheur en le prenant à votre compte, l'individu ainsi désigné étant, toujours un ennemi, et l'auteur présumé de la déveine.

Pluchea odorata Cass. Arbuste cultivé dans les jardins. On l'emploie dans les bains chauds et en fomentation contre la paralysie.

Elles se distinguent par la forme des lobes.

Labrousse, Deux vieilles terres françaises, pp. 65-66. 


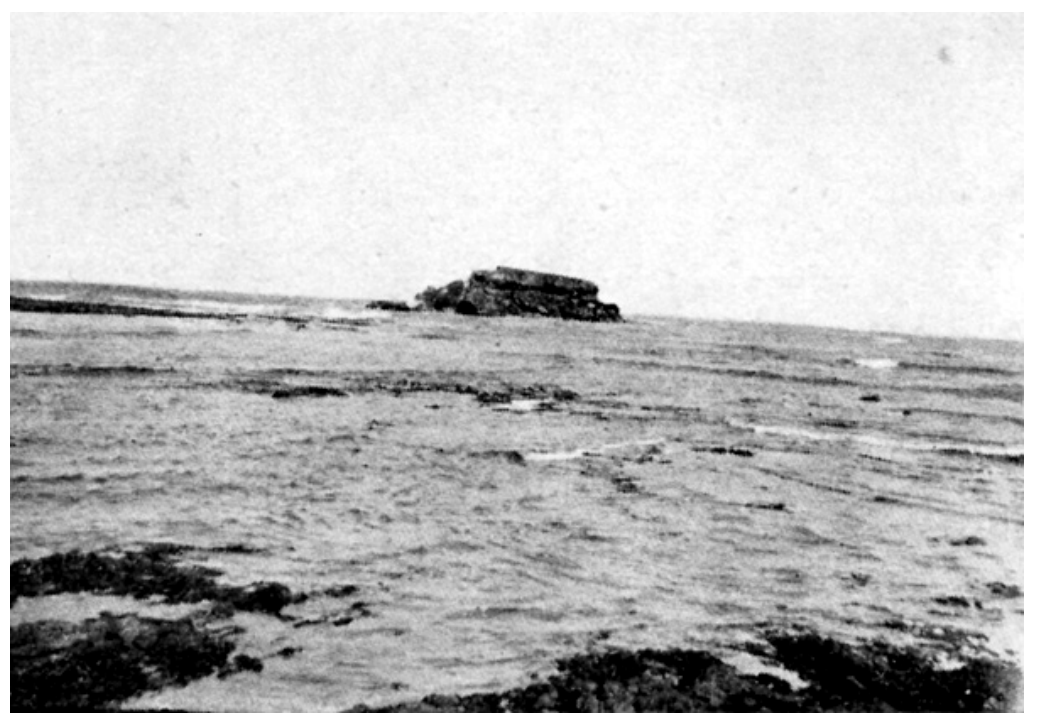

LA TABLE DU DIABLE. SAVANE DES PÉTRIFICATIONS (cliché Veille)



Toujours d'après le même auteur ${ }^{1}$, une fois sorti de l'eau il faut tordre le vêtement avec lequel on s'est baigné et boire quelques gorgées de l'eau qui en coule pour se purifier intérieurement. On ne remet alors que du linge neuf. Puis, au moment du départ, on jette à la mer, pour la remercier, une pièce de monnaie lancée par-dessus l'épaule, sans se retourner.

Labrousse, Deux vieilles terres françaises, Guadeloupe et Martinique, p. 63. 
Il est des lieux particulièrement favorables à de telles opérations et pour cela réputés au loin, même si l'eau, y demeure calme, comme au fonds Cérémaux, près de Trinité, qui passe pour guérir toutes les maladies.

\section{RIVIÈRE PILOTE.}

VOITURE DU GOUVERNEUR

PRÉCÉDÉE DE CAVALIERS
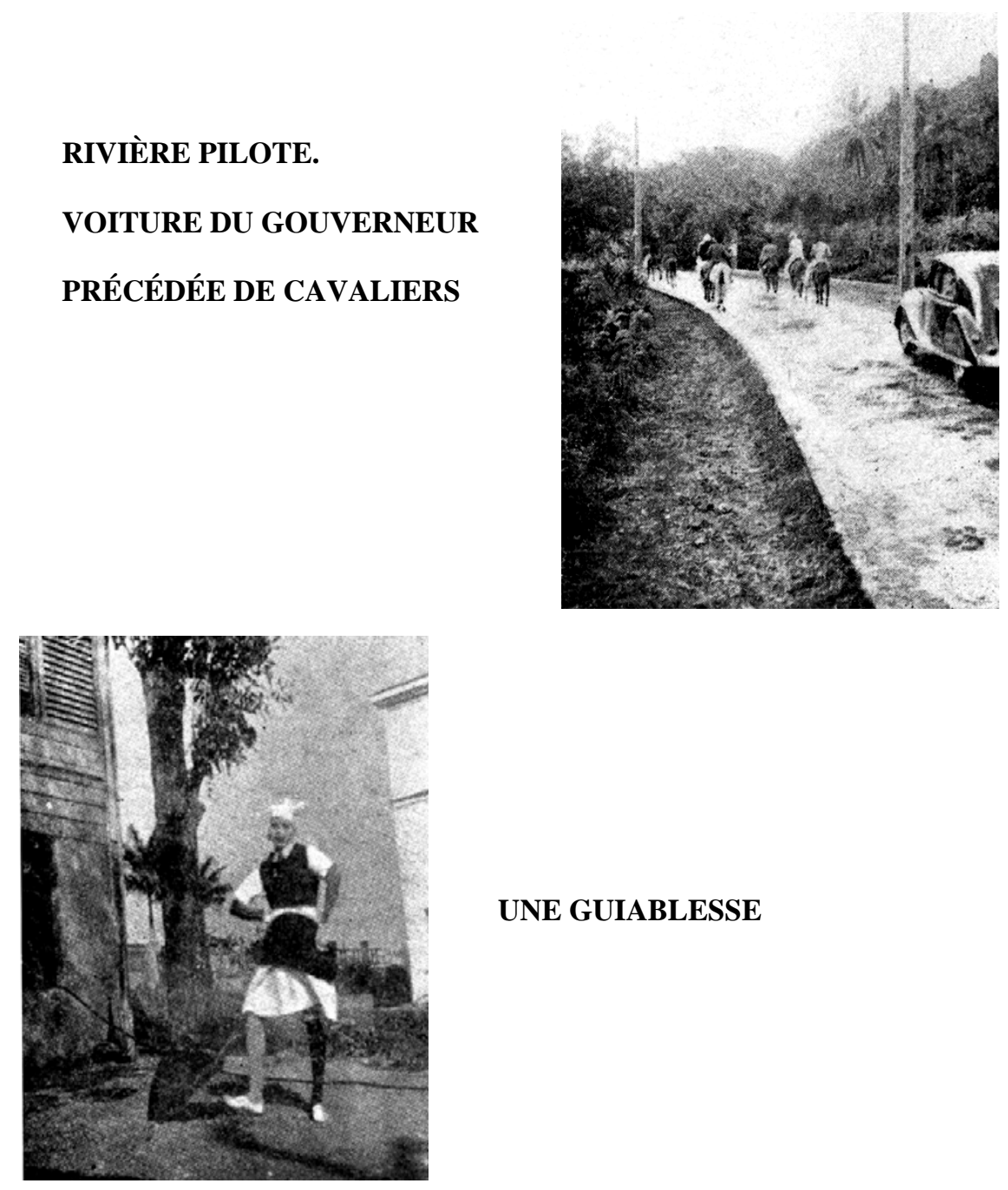

UNE GUIABLESSE

Si l'on ne peut, pour une raison ou pour une, autre, aller jusqu'à la côte, on se baignera chez soi, dans un mélange d'eau de mer, d'eau de pluie et d'eau de rivière, où l'on a fait tremper divers feuillages réunis avec une patience infinie, quand ce ne sont pas les «mille fleurs » de la légende. Les feuilles qui ont servi au bain sont ensuite jetées à l'intersection de deux chemins.

J'ai ramené de mon dernier voyage et je reproduis en annexe une formule de « bain consolidé », d'origine évidemment européenne, mais où les influences locales ont déjà pénétré, puisque la fleur mâle du papayer y voisine avec le lilas et le raifort. On trouvera de même, dans le cahier de quimboiseur que je publie, quelques recettes un peu plus corsées pour se protéger soi-même, acquérir une chance pour toutes choses, se rendre invulnérable aux poisons et faire éclater un verre suspect. 


\section{VI. - RITES D'ACQUISITION ET PORTE-BONHEUR}

La plupart du temps, on poursuit un but bien déterminé. Les pêcheurs, par exemple, désirent prendre le plus de poisson possible. Une tradition tenace prétend que, lorsqu'ils ne ramassent plus rien dans leurs filets ou leurs nasses, lorsque leurs lignes ne mordent plus, ils n'hésitent pas à se servir de chair humaine pour appâter, après l'avoir déterrée dans un cimetière et l'avoir enveloppée d'un bout de chiffon. Cela réussirait surtout avec les dorades, que bien des Martiniquais se refusent à manger pour cette raison. Rien également n'attirerait autant les chalands qu'une friture à l'huile de « cadavres humains ». On se procure la matière première, de nuit, généralement en accord avec un fossoyeur. Parfois on passe simplement commande à celui-ci qui, moyennant une rétribution fixée d'avance, s'engage à fournir la "marchandise ». Les incidents de ce genre, même aujourd'hui, ne sont pas absolument exceptionnels, surtout dans les communes les plus écartées. Les cadavres d'enfants sont particulièrement recherchés. Il en est disparu deux coup sur coup, il n'y a pas très longtemps, de la morgue d'un hôpital.

À l'ordinaire, cependant, on se contente de moins, d'autant que la violation de tombes s'accompagne de conjurations redoutables et qui causent souvent à l'impénétrant une terreur panique. On s'adresse donc au quimboiseur du lieu, qui délivre alors un talisman valable au maximum pour six mois et qu'il est indispensable de renouveler au bout de ce délai. Le prix normal en était de deux cents francs vers 1937, somme considérable si l'on veut bien se rappeler que le salaire d'un manœuvre ne dépassait guère à cette époque douze à quinze francs par jour.

Si le poisson ne mordait pas, c'est que le talisman ne valait rien. Il fallait changer de quimboiseur. Mais les hommes de science ne possèdent-ils pas des formules aussi magiquement puissantes ? C'est pourquoi un pharmacien connu reçut un beau matin la visite d'un pêcheur de Bellefontaine, venu lui réclamer le «bâton magique " à prendre le poisson, son fournisseur habituel l'ayant odieusement trompé. Notre homme refusa une première, une seconde, une troisième fois. Mais le pêcheur revenait constamment à la charge. Pour s'en débarrasser, le pharmacien finit par prendre un tube de verre de moyenne grosseur, qu'il scella aux deux bouts, après l'avoir rempli de gélatine colorée en rouge vif. Il donna le tout au brave homme, non sans lui recommander de ne montrer son talisman à personne sous peine de le voir perdre tout pouvoir. Il n'eut plus de scrupules à avoir accepté les deux cents francs rituels lorsqu'il vit son client revenir quelques semaines plus tard et le remercier chaleureusement, tant le bâton rouge avait fait merveille.

On admet à l'anse Couleuvre que toutes les pêches de l'année se décideront le vendredi saint. La veille, tous les pêcheurs assistent à la procession qui se déroule jusqu'à l'anse des Galets, non sans avoir pris la précaution de se procurer un échantillon de tous les poissons qu'ils désirent capturer dans l'année. 
En ce qui concerne les poissons de rivière et les grosses écrevisses « z'habitants », ils les exposent à l'aube sur la « maîtresse roche d'un maître bassin ", même s'il faut, pour le trouver, remonter très haut vers la montagne. À six heures, au premier coup de la cloche de l'habitation, et au son du tam-tam, ils partent tous en file indienne vers le bassin. Une fois arrivés, ils forment cercle autour de la grosse roche et, s'adressant à "Maman d'leau », ils lui disent: «Maman d'leau, fais-nous prendre gros z'habitants comme cela.» Chacun répète la formule consacrée en touchant l'« habitant» exposé sur la roche. Puis on recommence pour chacun des poissons.

Cette première cérémonie terminée, on revient vers le rivage et chaque équipage monte à bord de son "gommier ». À une centaine de mètres au large est mouillé, un canot vide de rameurs, qu'un jeune garçon, le matin même, a poussé à la nage, mais à l'intérieur duquel se trouve un échantillonnage complet des poissons de mer comestibles.

Les autres gommiers s'alignent à quelque distance, tous les rameurs debout, le barreur seul demeurant assis. Un vieux pêcheur retraité, c'est-à-dire qui ne pratique plus, prend dans ses mains deux grosses pierres et les frappe trois fois l'une contre l'autre. Au dernier coup, les rameurs plongent et filent aussi vite qu'ils le peuvent vers le canot échantillonneur. Le premier arrivé choisit son ou ses poissons, s'il a le temps, les touche et les rejette à la mer. Le suivant l'imite et ainsi de suite. On est persuadé, à l'anse Couleuvre, qu'un poisson rejeté à l'eau, ou plus exactement son espèce, ne peut être pêché en abondance, pendant l'année qui vient, que par celui qui a touché l'échantillon exposé. Les derniers sont considérés comme devant avoir la guigne douze mois de suite, tandis que les deux premiers deviennent les «majors » du lieu, avec tous les avantages et privilèges que cela peut comporter.

En bien des endroits, un des meilleurs porte-chance que l'on puisse imaginer est une tête de mort placée dans un " canari » neuf, et enterrée sous le seuil de la case ou de la boutique. Il est tel bourg de la Martinique où, il y a de cela une trentaine d'années, de nombreux commerçants payèrent cinq cents francs à un "Mentor » pour qu'il plaçât ce genre de talisman sous leur porte. C'était un personnage à grande barbe et qui répétait à qui voulait bien l'entendre qu'un menton pareillement orné aurait dû lui valoir, à lui seul, une place importante au "gouvernement». Il entendait au demeurant que ses conjurations lui fussent exactement payées. Une de ses clientes, qui tenait boutique, ayant refusé de verser le prix convenu, il alla retirer nuitamment la bouteille magique qu'il avait placée le goulot en bas, sous le seuil de la dame, qui fit rapidement faillite.

On obtient encore des résultats remarquables en utilisant comme lampe une tête de mort. Cela se pratique toujours et, le $1^{\mathrm{er}}$ août 1946, on découvrait, à Fort-de-France même, sous un ponceau, près de la Croix de Bellevue, un crâne dont les parois étaient brûlées par endroits, ce qui ne pouvait laisser aucun doute sur l'usage qui en avait été fait. Au demeurant, une bougie éteinte gisait à proximité. 


\section{CHAPITRE IV}

\section{Charmes et contre-charmes}

\section{I. - L'ANTICRI ET LES ANIMAUX « VOYÉS »}

$\underline{\text { Retour à la table des matières }}$

Il n'a été parlé jusqu'à présent que de charmes d'une portée générale et qui n'impliquent pas la subordination d'une volonté à une autre, ou un maléfice nuisible à une personne déterminée. De tels charmes et leurs antidotes sont évidemment d'un usage fort répandu. Ils exigent, dans la très grosse majorité des cas, l'intervention d'un sorcier ou quimboiseur spécialisé.

La première condition à remplir pour qu'un charme ait chance de réussir, c'est de connaître le véritable nom du patient. C'est une des raisons pour lesquelles il y a tant de surnoms à la Martinique, fort pittoresques d'ailleurs en général, mais qui servent à dissimuler le patronyme aux mal intentionnés. De même, il faut autant que possible se procurer un objet ayant appartenu à la personne qu'on veut charmer, et plus l'objet sera intime, plus on aura de chances de réussir. Ongles et cheveux sont particulièrement prisés à cet égard. Beaucoup de campagnards, lorsqu'ils se font couper ces derniers, les ramassent soigneusement et s'en vont les enterrer dans un lieu secret. Ils font de même pour leurs rognures d'ongles.

À défaut, on se contentera d'un mouchoir, d'un bas, d'un soulier, de préférence sale; c'est ce qu'on appelle le "rapport», sur lequel on « travaillera» ou fera «travailler». Si l'individu visé se méfie, pour quelque raison que ce soit, on essaiera de l'atteindre grâce à un animal « voyé », c'est-àdire envoyé par le sorcier.

Le plus remarquable de tous est l'Anticri (sans doute l'Antéchrist). On donne ce nom, à la Martinique, à de minuscules homuncules, capables de prendre lorsqu'ils le veulent, une forme animale, d'ordinaire celle d'un oiseau, et qui sont au service absolu de ceux qui les possèdent.

Pour s'en procurer un, il faut prendre le premier œuf d'une poule noire pondu le vendredi saint et le mettre à couver sous son aisselle. Après l'incubation normale, sort l'Anticri, qui accomplit tout ce qu'on lui commande. On s'en sert pour aller chercher des bouts de linge appartenant aux personnes qu'on désire ensorceler. Il peut même les frapper directement. L'Anticri, sous sa 
forme d'oiseau, passe à travers les persiennes les mieux closes et demeure insensible aux coups. Bien qu'il ne dépasse jamais la taille d'un pigeon, six hommes unissant leurs efforts sont incapables de l'arrêter. Il suffit que la personne contre laquelle on a envoyé l'Anticri soit heurtée ou simplement frôlée par lui pour tomber sans force, paralysée et incapable de parler. Telle brave femme racontait ensuite qu'elle entendait ce qu'on lui disait, mais ne pouvait répondre.

Une autre serait devenue folle du coup et aurait dû être transportée d'urgence à l'asile.

M. Labrousse ne connaît pas le nom d'Anticri, que j'ai rencontré au Gros Morne et dans l'extrême Nord. Il ignore de même le rôle actif du "petit monstre ", mais le considère comme un porte-bonheur pour la personne, et la personne seule, qui le possède. Il ajoute cependant à la tradition que j'ai recueillie une variante de quelque intérêt : le petit monstre vit sous le lit de son propriétaire et doit être uniquement nourri avec de la viande crue. «On ne l'entend crier, mais alors sans arrêt, que lorsqu'il a faim, lorsqu'on a laissé passer l'heure de son repas. Pour le faire taire, il faut vite lui donner son morceau de viande ${ }^{1}$. »

Pour M. Tardon le «petit monstre, mi-homme mi-poulet », éclos dans les conditions déjà rapportées, demeure invisible à tous, sauf à son maître, qui doit le garder constamment sur son épaule. Son rôle est de rapporter chaque jour autant d'argent que peut en contenir une boite d'allumettes. Il n'est pas interdit de faire choisir les gros billets. «En échange de tels services, le patron père nourricier du petit monstre devait le soigner précautionneusement et ne pouvait le quitter sous aucun prétexte, sous peine des pires calamités. Il devait tout d'abord lui assurer une nourriture saine, principalement des légumes cuits à l'eau, sans sel (on peut remarquer l'opposition de cette variante avec celle rapportée par $\mathrm{M}$. Labrousse), cet ingrédient constituant un poison mortel. De même, il était interdit au maître, sous peine de mort, de plonger quand il se baignait à la mer ${ }^{2}$. »

Il est beaucoup d'autres animaux dont on peut se servir, les crabes en particulier et les Bernard l'Ermite. Quand on en aperçoit à proximité de sa demeure, c'est qu'un «quimbois » menace. C'est aussi la raison pour laquelle on ne recueillera que rarement une bête inconnue. Les Européens et les personnes cultivées s'y risquent parfois, au risque de complications domestiques. Un chat roux, aux trois quarts sauvage, avait trouvé asile de la sorte dans une maison proche de Fort-de-France. Il attaquait et dévorait tous les chatons mâles du voisinage. " Ça, disaient les bonnes, c'est un moûn gagé ${ }^{3}$ ", et elles le poursuivaient à grands coups de coutelas. L'animal, remarquablement leste, échappait toujours. On le vit une fois sauter du deuxième étage, ce qui ne fit qu'accroître la terreur qu'il inspirait.

Labrousse, Deux vieilles terres françaises, p. 37.

Tardon, Bleu des îles, Pour l'amour d'Héléna, pp. 44-45.

Une personne engagée, c'est-à-dire qui a un pacte avec le démon. 
Dans un autre cas, les domestiques refusèrent de donner à manger à un chat maigre et efflanqué qui venait miauler désespérément autour de la demeure. La patronne le recueillit cependant, encore qu'on lui répétât sur tous les tons que c'était un chat « voyé » qui pouvait devenir la cause de beaucoup de malheurs. Il fut alors décidé de sauver les maîtres malgré eux. Le chauffeur glissa un jour l'animal dans le coffre de la voiture et s'en alla le perdre au loin.

\section{II. - PHILTRES ET CHARMES AMOUREUX}

L'amour, tout au moins dans ses réalités charnelles, occupe une très grande place à la Martinique. Il n'est donc pas étonnant que j'aie trouvé côte à côte des modèles de déclaration ou de demande en mariage pour les différents cas qui peuvent se présenter, et, des formules de philtres et de « charmes » qui, dans ce domaine, apparaissent d'un emploi très généralisé. Au demeurant, la différence de nature entre les uns et les autres est peut-être moins grande qu'on ne l'imagine de prime abord, et j'ai reproduit aux annexes une lettre dont je possède toujours l'original et qui, dans son indiscutable pittoresque, témoigne également du pouvoir quasi magique que l'on reconnaît là-bas aux grands mots. Quant au cahier de quimboiseur que je publie, il renferme les formules d'un charme à l'odeur, d'un charme pour les femmes, d'un autre pour faire venir une femme chez soi et d'un quatrième pour se faire aimer. Toute recette, dans ce domaine, a de nombreux amateurs.

Un des procédés les plus fréquemment employés, quand une femme désire prendre ou conserver un amant, est de lui faire absorber, sans qu'il s'en aperçoive, un peu d'elle-même. Certaines commencent par placer au contact du plus intime de leur être le bifteck ou le « morceau viande » qu'elles se préparent à servir à l'élu de leur cœur. D'autres mélangent un peu de sang menstruel au café ou au cacao du matin. C'est un des procédés qui laissent le moins de traces. Cependant, lorsque la dose est trop forte, la victime est prise d'incoercibles vomissements. Plus souvent cela s'ajoute aux sauces épicées, souvent relevées d'aphrodisiaques, qu'on sert aux repas principaux. Qui soulèverait à l'improviste le couvercle des marmites où mijote la soupe du soir y ferait à l'occasion d'étranges découvertes. À défaut de sang on peut employer de la sueur, de la crasse corporelle. Une chemise longtemps portée produit encore un effet appréciable.

Il est à remarquer d'ailleurs que le procédé vaut dans tous les domaines de la sympathie. Il est de tradition, dans les mornes de la Martinique, qu'après une réunion électorale, qui se tient toujours à la tombée de la nuit, on offre le punch aux braves gens venus écouter et applaudir leur candidat. Les supporters ont apporté les dames-jeannes de rhum indispensables. Mais, pour donner à ce dernier une vertu supplémentaire et obliger les consommateurs à voter convenablement, il est arrivé qu'on y ait fait macérer au préalable les chaussettes sales de l'impétrant. Le dit d'ailleurs et ses principaux lieutenants devaient, naguère encore, satisfaire aux très nombreuses bonnes fortunes qui s'offraient alors à eux et qui, dans certains mornes éloignés, prenaient l'allure d'une sorte de communion à laquelle participait une bonne partie de la population féminine. Cela n'offusquait d'ailleurs personne. J'ai entendu telle 
accorte matrone se vanter d'avoir bibliquement connu tous les leaders du parti auquel elle appartenait. Il est arrivé également que des mères de famille aient présenté, à un homme politique connu leurs filles non encore nubiles, en précisant qu'elles lui en réservaient les prémices. Et, parlant d'un des plus authentiques héros de la Libération, une brave femme s'écriait, sur la savane de Fort-de-France, le 7 mai 1945 : « Ah ! Moin aimé homme ta la. Moin ka senti moin cé foute y un iche à crédit ${ }^{1}$. "

Inversement, quand on possède un objet ayant été en contact avec la peau de la femme désirée, un bas par exemple, pris par un crabe «voyé » (envoyé), d'ordinaire un crabe blanc, on peut disposer d'elle presque à coup sûr, sauf si un contre-charme intervient à temps. Une jeune fille du François crut entendre un crabe marcher dans sa chambre pendant son sommeil. Lorsqu'elle se réveilla, il lui manquait un bas et elle se mit aussitôt à souffrir violemment de la tête. Celle-ci enflait rapidement. Mais la jeune fille savait que quelqu'un désirait sa main, bien qu'elle l'eût déjà refusée. Elle alla rapidement trouver une sorcière experte qui la fit s'envelopper de linges chauds en compresses. Pendant plus de trois heures de l'eau serait sortie en abondance du crâne de la patiente, mais le soir même elle était guérie.

Le quimboiseur donne naturellement des recettes aussi compliquées que possible. Il s'agit souvent de potions préparées où entrent à doses diverses des plantes, des produits pharmaceutiques, des parfums, et surtout des poudres d'animaux desséchés, crapauds, lézards, oiseaux ou poissons.

Les anolis (petits lézards verts) jouent un grand rôle dans beaucoup de cas. Deux d'entre eux, liés tête à tête avec des herbes de "cabouya ${ }^{2}$ ", et mis à bouillir dans le lait ou la soupe qu'ils doivent consommer, suffisent à lier deux amants de manière indissoluble. Souvent aussi on les fait dessécher et on les glisse, toujours liés, dans le matelas ou l'oreiller de la personne qu'on veut charmer. Toutefois, ils ne sont plus alors attachés avec du cabouya, mais, suivant les prescriptions toujours très minutieuses du quimboiseur, avec des fils de couleur et de longueur différentes, et suivant un ordre déterminé. Les mercières de la campagne en conservent toujours un large assortiment et, lorsqu'on vient leur en acheter, elles n'ont pas le moindre doute sur ce qui est en train de se préparer. Quand on ne dispose pas d'anolis ou que, pour une raison ou pour une autre, on ne veut pas y toucher, ou utilise des crabes qu'on attache, non plus avec des fils, mais avec des «faveurs » de couleurs variées.

Un des procédés les plus courants pour hâter la conclusion d'un mariage est celui des "repas montés », où l'ordre et la composition, des plats ont été réglés par un quimboiseur. On y sert comme boisson une eau "préparée ", d'apparence laiteuse et mélangée souvent à de l'eau de coco. L'effet passe pour infaillible, et l'on cite de nombreuses unions qui en ont été la conséquence. Mais l'on prétend aussi que le «quimbois » ainsi employé n'a pas un effet

1 Ah ! que j'aime cet homme-là ! Je sens que je lui donnerai un enfant à crédit, c'est-à-dire à distance.

Sporobolus Indicus R. B. 
éternel. Le jour arrive où son efficacité diminue. L'homme qui en fut la victime désire venger sa défaite et plus d'une fois rosse sa femme comme plâtre, même dans la bonne société. À tout le moins, un tel mariage n'apporte pas le bonheur : la Martinique en connaît et en cite de très nombreux exemples.

Cela n'empêche pas les vieilles concubines de continuer à «doser » leurs partenaires pour se faire épouser, à moins qu'avec la complicité du quimboiseur, et parfois du médecin, elles n'emploient des procédés dignes de la plus pure comédie. Telle, depuis longtemps en ménage, tombe gravement malade, si gravement qu'elle réclame à la fois guérisseur et curé. Le premier sort gravement de la chambre et déclare à l'homme inquiet qu'il ne sait pas trop ce que c'est, mais que c'est grave et qu'il faut s'attendre bientôt à un événement. Le curé arrive, confesse l'égrotante, qui pleure et déclare qu'elle ne voudrait pas paraître devant Dieu en état de péché mortel. L'homme s'attendrit, le curé est déjà là, on fait venir d'urgence l'officier de l'état civil. Le mariage est célébré, la malade rejette ses draps, esquisse un entrechat, lève la jambe et, déclare à l'intéressé : « Maintenant tu es « fait » et je te tiens. »

Les cadeaux offerts à certaines occasions, et préparés dans les règles, sont censés posséder des vertus analogues. La pépite d'or vierge de Guyane est assez recherchée. Je connais un cas où il a été offert un sachet vert pâle cousu de fils d'or, à l'intérieur duquel il y avait de la poudre d'or et une autre poudre de composition inconnue, l'intention matrimoniale étant évidente. Le zircon, « monté » par un quimboiseur à la façon d'un diamant sur une bague en or, passe pour particulièrement efficace dans ce domaine, mais si l'intéressé, prévenu, le passe au feu, il perd alors tout son pouvoir.

\section{III. - PRIÈRES ET FORMULES MAGIQUES}

Il est rare cependant qu'une intrigue puisse se dérouler sans obstacles. Il y a des rivales à écarter.

L'on en arrive alors à un type de magie offensive et défensive, qui déborde d'ailleurs infiniment le cadre des seules relations amoureuses.

Deux jeunes personnes, par exemple, aimaient un jeune instituteur. L'une d'elles est allée chez le quimboiseur, qui lui prépara un « petit travail » à placer sous la nappe de l'autel, dans l'église du village. Les résultats en furent, paraîtil, remarquables, puisque la rivale quitta la colonie sans espoir de retour. Le mariage eut lieu, et jusqu'ici tient bon.

Souvent l'aventure se termine moins heureusement. Un jeune prêtre, aimé de plusieurs de ses paroissiennes, aurait été assailli un beau matin par un serpent « voyé » dissimulé dans le tabernacle. On prétend qu'il en serait devenu fou.

Lorsqu'on veut jeter la discorde dans un ménage, on symbolise fréquemment chacun des époux par une rose, rouge pour un Noir, jaune pour un mulâtre, blanche pour un créole ou un Européen, qu'on suspend à une 
persienne exposée au vent, en compagnie d'un petit paquet de plantes desséchées mêlées à une poudre de composition plus ou moins extraordinaire. De même, si l'on arrive à soudoyer une bonne, on fera mélanger aux aliments de ceux qu'on veut brouiller certaines décoctions de plantes, auxquelles on ajoute des excréments de canard.

Ce jeu, si c'en est un, se répète à toutes les occasions de la vie. On a une bonne place, on tient à la garder, à s'y « clouer ». C'est par une recette à cette fin, à base d'ongles coupés trempés dans de l'eau bénite, que commence le cahier du Lorrain, signe évident qu'elle était une des plus demandées. M. Labrousse en rapporte une autre qui ne manque pas d'originalité, et qui était employée par un sorcier de la Dominique qu'on venait consulter tant de la Guadeloupe que de la Martinique. Il se plaçait devant l'impétrant avec un fusil légèrement chargé et lui logeait quelques grains de plomb dans le gras du bras. Tant que ces plombs demeuraient en place, l'intéressé pouvait être assuré de garder la sienne ${ }^{1}$. Inversement, il existe de nombreux moyens de " déplacer » quelqu'un que l'on considère comme gênant pour sa propre carrière.

Il est normal encore que des candidats à un examen désirent être reçus et tiennent à s'assurer, pour ce faire, du maximum d'atouts. Récemment on a découvert à la Guadeloupe, chez une sorcière réputée, la liste d'un grand nombre de professeurs (depuis le chef de service de l'enseignement public, jusqu'au professeur de gymnastique) examinateurs au brevet élémentaire ${ }^{2}$.

L'un de mes anciens élèves m'a raconté comment, lorsqu'il était candidat au baccalauréat, il y a de cela une vingtaine d'années, il était allé consulter, avec cinq ou six de ses camarades, une vieille «coolie» (hindoue d'origine) surnommée Chacha, qui habitait, au quartier Sainte-Thérèse, une petite case en bois. Introduits dans la salle des oracles, où se trouvait une statue de la Vierge avec sa petite lampe allumée devant, ils se virent demander ce qui les amenait. La " voyante » mit alors une bougie allumée dans une assiette et, fit asseoir devant elle chacun des impétrants à son tour. Suivant l'aspect de la flamme, elle lui annonçait qu'il passerait "raide comme balle ", ou au contraire qu'il éprouverait de sérieuses difficultés. Mais elle eut soin d'ajouter que pour dix francs de plus par tête elle se chargeait de conjurer sans faute le mauvais sort. Elle indiqua alors à chacun des candidats la toilette très compliquée à laquelle il devait se livrer le matin même de l'examen. Il fallait se laver d'abord dans de l'eau additionnée de deux gouttes de «lavande double rouge », la jeter, recommencer jusqu'à dix gouttes en augmentant chaque fois la dose. Les jeunes gens exécutèrent scrupuleusement les ablutions prescrites, sans confiance exagérée néanmoins, car ils avaient remarqué comment la vieille sorcière avait réservé ses plus brillants pronostics à ceux dont les parents occupaient un rang élevé dans la société locale. Les refusés s'adressèrent ailleurs pour la session suivante et se présentèrent à la première composition les cheveux graissés, si l'on peut s'exprimer ainsi, avec des excréments de chat. L'odeur était telle qu'ils

Labrousse, Deux vieilles terres françaises, p. 59.

R. Fortuné, Quelques croyances populaires, Revue Guadeloupéenne, janvier 1946, p. 40. 
durent, au bout de quelques instants, solliciter la permission de sortir et aller se laver à grande eau.

Il s'agit parfois d'obtenir la confiance d'une assemblée rétive. Dans un cas récent, qui intéressait le conseil municipal d'une commune importante, il avait été recommandé par le sorcier consulté de placer, aux quatre coins de la salle où la séance devait se tenir, autant d'«écrevisses " ${ }^{1}$ trempées dans du vifargent. L'histoire fut connue parce que les intéressés coururent toutes les pharmacies du chef-lieu pour se procurer le mercure nécessaire à leur quimbois.

Dans bien des cas, cependant, il suffit d'une formule récitée sous certaines conditions et où l'on fait appel aussi bien aux démons qu'aux saints du paradis, quand il ne s'agit pas de termes incompréhensibles. Le quimboiseur du Lorrain en utilisait deux principales, dont une prière à saint Joseph et une oraison pour se battre. La dernière est un article très demandé et qui comporte de nombreuses variantes. En voici deux originaires de l'extrême Nord et qu'utilisait un « major » de quartier, authentiquement surnommé Félé la Force, pour triompher de ses adversaires :

La première doit être répétée trois fois avant d'engager le combat :

"O Lid Vavanda, Gran Vavanda, Gran let Isabet, Gran Lucifer ; battezmoi cet homme et donnez-moi la force ! »

La seconde, beaucoup plus efficace, paraît-il, n'a besoin d'être récitée qu'une seule fois. Elle est d'ailleurs d'inspiration nettement biblique et peut venir de la Dominique, colonie anglaise de religion protestante, avec laquelle les pêcheurs du Nord sont en relations constantes, ne fût-ce que pour la contrebande.

«Voici Dieu, pacy Dieu, Ici a passé Saül et Aman, livides, voici Saül et les ennemis pour passer le pont, avec le destin. Battez-moi cet homme ou donnezmoi la force ! »

Il existe des oraisons du même ordre, à saint Expédit, pour qu'il termine rapidement les affaires qui intéressent l'impétrant, voire qu'il expédie ses adversaires dans l'autre monde, à saint Bouleverse ou Bouleversé (c'est le vocable haïtien) pour qu'il bouleverse, c'est-à-dire rétablisse une situation désespérée, et à beaucoup d'autres saints auxquels on suppose, par des jeux de mots élémentaires la plupart du temps, des pouvoirs extraordinaires. À cela s'ajoutent les prières de circonstance, lorsque survient un cataclysme naturel, que des inspirés se vantent de pouvoir apaiser par leur bénéfique intervention.

Lors du réveil de la montagne Pelée en 1929, la "mission volcanique », dont je faisais partie, reçut, comme on peut le croire, une foule d'avis et de

Il s'agit de grosses crevettes pêchées dans les marais du Lamentin. 
conseils tous plus désintéressés les uns que les autres. Une dame "Clémence veuve Lernot » nous adressa, dactylographiées ou imprimées, trois prières et déclarations à tout le moins fort caractéristiques d'un certain état d'âme.

La première est une paraphrase de l'Ancien Testament, qui se termine à la plus grande gloire de l'intéressée parce qu'elle « a le pouvoir de frapper la terre par trois fois et d'éteindre le feu, s'il y en a encore qui vient dans le volcan ${ }^{1}$ ». Et il en ressort qu'avec un minimum de neuf jours de " travail » et un maximum de vingt-sept, le mont Pelé pourrait être à tout jamais éteint. Il faudrait seulement " y exercer de temps en temps avec des secrets que j'aurai (sic) pu donner pour après ma vie ».

«Et toi, mont Pelé, que j'appelle mont Saint-Janvier, tu n'es pas un gros joujou et de ma bouche peuvent sortir contre toi des glaives à double tranchant. "

«... À la Martinique, nous sommes un peuple privilégié. Dieu a choisi parmi nous une petite créature et par elle il travaille... »

La seconde oraison, qui s'intitule «Bénédiction des Saints », a de nombreuses vertus.

«Voici, écrit la dame Lernot, l'histoire de cette belle prière : On lit dans un vieux manuscrit de l'histoire de France que, sous le règne de Charles VII, ce prince, étant dans la consternation de voir son royaume accablé par la guerre, ruiné, divisé et sur le point de passer tout entier sous la domination étrangère, eut recours à un Saint Ermite pour se recommander à ses prières. Le Saint Homme lui donna une image de la Sainte Face avec la suivante oraison, qu'il avait écrite sur le revers de l'image, assurant le prince que, s'il la portait dévotement (sic) et la récitait tous les jours, ses affaires et celles de son royaume se rétabliraient, ce qui arriva en effet peu de temps après, d'une manière que l'on peut dire miraculeuse, par le service que lui rendit la petite bergère de Domrémy, Jeanne la Pucelle, qui chassa l'Anglais, sacra le Roy et sauva la France.

« Cette prière a toujours la même efficacité pour se défendre des maux de la guerre, etc., chasser l'étranger, remettre la paix et l'union dans les ménages et les cœurs divisés, terminer les procès et éviter tous désagréments des personnes méchantes :

"Que la paix de Notre Seigneur Jésus Christ soit toujours avec... (la Montagne) ... Par la vertu du prophète Élie, par la puissance et l'efficacité de la Sainte Face de Notre Divin Sauveur et de sa bien aimée Mère, la Bienheureuse Vierge Marie, par le chef de Saint Jean Baptiste et par les douze Apôtres et par les quatre Évangélistes ci, par tous les Saints Martyrs, Confesseurs, Vierges,

Texte intégral aux annexes. 
Veuves et par les Anges, Archanges et toutes les célestes Hiérarchies. Ainsi Soit-il !

«Que cette bénédiction demeure sur le mont Saint-Janvier jusqu'à la fin de (sic) temps. Ainsi soit-il ! (À l'occasion des éruptions volcaniques.)

\section{« Veuve CLÉMENCE LERNOT.»}

La puissance des formules est donc considérée comme immédiate et s'étend aux choses inanimées. Un commissaire de police, en service dans le Sud, avait arrêté un « vaillant quimboiseur », un « Mentor ». Il l'enferma à la " geôle » dont la cour était fermée, comme il convient, par une porte massive et une grosse barre de fer. Mais bientôt celle-ci se mit à ployer et à se courber sans raison apparente. En se retournant le commissaire vit son prisonnier accroupi sur un lit de camp et marmonnant une formule entre les dents. On lui mit le revolver sous le nez - cet instrument, paraît-il, demeure insensible aux « quimbois » - et on l'obligea à s'arrêter. Puis on le fouilla soigneusement et on lui enleva tous les objets qu'il avait gardés sur lui. On se hâta de le transférer le jour même à la prison du Saint-Esprit. Le lendemain, on le trouvait pendu dans sa cellule.

Un autre exemple célèbre et amusant de cette efficience des formules est celui de la course-poursuite, telle qu'elle m'a été racontée à plusieurs reprises. Un brigadier de police, de la police locale s'entend, de ceux qu'on appelle làbas les "gendarmes ti bâton », poursuit un voleur qu'il ne parvient pas à saisir. Il crie au fugitif : "Tombez », et l'autre s'étale, mais se commande à lui-même de se relever, se retourne contre le commissaire, lui ordonne à son tour d'aller au sol et, pendant ce temps, prends le large.

À cela s'apparente l'histoire de Cantinol et les ruses toujours employées par les contrebandiers de l'extrême Nord pour échapper aux douaniers. Ce Cantinol qui vivait, paraît-il, au début du siècle ne subsistait que de rapines et passait pour insaisissable. La frayeur qu'il inspirait était telle que, lorsqu'on signalait son arrivée dans un bourg, beaucoup de personnes plaçaient sur le pas de leur porte ou le rebord de la fenêtre quelques objets, un « ti butin ", à l'intention du voleur, qu'elles espéraient apaiser par cette offrande propitiatoire et détourner ainsi, en, ce qui les concernait, de toute investigation ultérieure. Cependant, Cantinol était accusé de plusieurs meurtres. La tradition prétend qu'on finit par l'arrêter et qu'une foule énorme se pressait aux Assises pour le voir juger. On ajoutait dans le public, que Cantinol aurait déclaré aux magistrats que peu lui importait leur verdict, car il s'évaderait au moment où il le désirerait. Condamné à "Cayenne », c'est-à-dire aux travaux forcés à perpétuité, et comme les gendarmes qui l'encadraient se préparaient à lui passer les menottes, il aurait interpellé le tribunal, puis, tirant un bout de craie de sa poche, dessiné schématiquement un bateau sur la cloison qui lui faisait face. Ensuite de quoi il aurait fait le simulacre d'y monter et serait disparu du coup. Tel est du moins le récit qui court dans le nord de l'île. Depuis lors, les contrebandiers du Prêcheur et de Grand Rivière, lorsqu'ils se voient en danger d'être pris, n'ont de cesse qu'ils n'entraînent les douaniers sur une plage de sable. Ils se hâtent d'y dessiner 
un bateau sur lequel ils espèrent monter pour disparaître à la façon de Cantinol. Mais les douaniers, qui connaissent l'histoire et qui, pour la plupart, y croient, s'efforcent d'empêcher leurs adversaires de terminer le dessin.

\section{IV. - ENVOÛTEMENTS ET CONJURATIONS}

L'histoire de Cantinol suppose un dessin, c'est-à-dire un embryon de support matériel. L'envoûtement, sous toutes ses formes, est de pratique courante. On y emploie, suivant les cas, des figurines de terre ou de cire, à défaut parfois une simple photographie, voire une racine du pays, un igname par exemple, auquel on peut trouver une grossière ressemblance avec une forme humaine. Il peut s'agir également d'animaux, lézards ou lapins enterrés près d'une maison. Les ossements et les conjurations dans les cimetières apparaissent fréquemment. En voici quelques exemples caractéristiques :

Du premier de ces récits pour ne détruire ni sa fraîcheur, ni sa valeur de document original, je n'ai retranché que les noms propres et une localisation trop précise : la scène s'est authentiquement déroulée en 1915 et a eu pour théâtre les hauteurs qui s'étendent entre Trinité et Sainte-Marie. La personne visée, un fonctionnaire, passait ses vacances au bourg. " Un matin de lundi, écrit-il, je vois arriver à cheval mon fils, qui me dit exactement ceci : "Quelqu'un est venu me prévenir avant hier soir que les... ont décidé de vous tuer. Ils lui ont demandé de leur préparer, en tant que charpentier, un cercueil de soixante centimètres dans lequel sera placé un monsieur... (ici le nom de la victime désignée) bien habillé, qu'ils enfouiront sous un des bananiers en bordure de leur terrain face à l'écurie. Je ne suis pas un assassin, mais je ferai mon travail pour les deux cent cinquante francs qu'ils m'ont proposés. Tenezvous en éveil toute la nuit, sans vous laisser voir : vers deux heures du matin, après la veillée et la cérémonie funèbre, on viendra mettre le cercueil en terre, la tête au soleil levant et les pieds vers l'Occident. Si vous voulez sauver M... ne dites pas un mot, ne faites pas un geste qui puisse vous faire découvrir. On vous tuerait. À sept heures du matin, faites votre tournée comme d'habitude et, arrivé à l'endroit convenu, poussez un seul cri : Moin trouvé y ! et tirez un coup de fusil dans la direction de l'Orient ; la terre fraîchement remuée sera facile à voir. Appelez deux amis, fouillez avec le manche d'une pelle, mais pas avec la pelle, car le cercueil disparaîtrait. Vous le trouverez a cinquante centimètres de profondeur ; vous en ferez ce que vous jugerez nécessaire et vous me donnerez ce que vous jugerez que ça vaut. » Ce charpentier... jouissait dans le quartier de la réputation de vaillant sorcier et de maître quimboiseur. Je lui avais rendu plusieurs fois service. Sollicité par la famille... il avait accepté moyennant finances, et le soir il avait présidé la cérémonie funèbre à laquelle j'étais représenté par une grosse poupée bourrée ; j'étais vêtu de noir, couché sur le lit mortuaire, entouré de cierges allumés et les chants liturgiques se succédaient. Encens, eau bénite, tout y était. On passa la nuit à chanter les psaumes de la pénitence, et après chacun d'eux on buvait à la santé du mort. À la fin, je fus mis en bière, on chanta le Libera et je fus porté en terre. Mais le plus beau de l'affaire fut le réveil du quartier, le matin à sept heures, au coup de fusil tiré par (mon fils). Tout le monde est arrivé, même ceux qui avaient pris part aux cérémonies et qui croyaient fermement que le coup de fusil était le signal de 
mon départ pour l'éternité. On exhuma le cercueil, et devant le soi-disant étonnement de... (mon fils) on conseilla d'alerter la gendarmerie. Vers neuf heures j'arrivais, au grand ébahissement des badauds qui criaient : « Mi li, mi li, y pas mort ! Fonte y vaillant ! ${ }^{1}$. "

Il arrive parfois, si l'on habite près d'une croisée de chemins, qu'on aperçoive, par un beau clair de lune des hommes armés de pelles et de pioches en train de creuser un trou dans la chaussée.... Personne n'intervient tant que l'opération n'est pas terminée, et que les visiteurs nocturnes ne sont pas repartis. Le lendemain, il est souvent impossible de s'apercevoir que l'endroit a été bouleversé.

Il y a quelque quarante ans, les faubourgs de Fort-de-France étaient loin d'avoir leur extension d'aujourd'hui. Il existait, près de l'impasse Louis-Blanc, un grand terrain vague bordé d'une rangée de chambres louées à des ouvrières. L'une d'elles, une blanchisseuse, qui avait du travail en retard, s'était vue dans l'obligation de veiller fort avant dans la nuit pour le terminer. À son réveil, elle fut appelée par une voisine qui lui demanda si elle avait aperçu ce qu'il y avait sous sa fenêtre. Il s'agissait d'un beau petit cercueil de vingt centimètres environ, bien recouvert de drap noir. La foule et la police arrivèrent. On ouvrit avec un coutelas et on trouva à l'intérieur un petit corps formé de morceaux de chair agglutinés. Celui qui avait apporté le paquet comptait évidemment l'enterrer. Mais la victime ne dormait pas. L'homme avait dû renoncer à son projet et déposer son fardeau sous la fenêtre de celle qu'il visait. On eut d'ailleurs beaucoup de mal à trouver une femme pour consentir à prendre le cercueil et à le porter au commissariat. La tradition prétend que, malgré les précautions prises, elle se promenait le lendemain dans le quartier avec la main droite étonnamment enflée. $M$. Labrousse ${ }^{2}$ indique une manière de procéder qui s'apparente aux purifications par l'eau de mer. Il rappelle d'abord qu'en répandant chaque matin de l'eau salée et citronnée sur le trottoir contigu à une maison, on détruit à coup sur l'effet des quimbois qui ont pu y être déposés pendant la nuit. Il raconte ensuite comment une servante de Fort-de-France trouva un matin, à l'extrémité du caniveau par où s'évacuent les eaux ménagères à la rue, un paquet d'aspect bizarre, et qui de toute évidence y avait été volontairement introduit. Il s'agissait de deux morceaux d'assiettes creuses ficelés l'un contre l'autre et contenant un amas de viandes putréfiées et d'épices violents. Ni la bonne, ni la patronne n'osaient y toucher. On fit venir une femme au courant de toutes les questions de conjurations. "Elle demanda du pétrole, le répandit sur le parquet, de l'urine et s'y lava les mains, enleva le quimbois qu'elle porta au milieu de la cour, plongea encore ses mains dans l'urine, versa dans le caniveau de l'eau salée et citronnée. Puis elle alla mettre le feu au quimbois en allumant des journaux, après avoir prononcé une conjuration. Enfin elle annonça qu'elle reviendrait dans la soirée chercher les deux morceaux d'assiettes noircis, pour les jeter dans la mer où la purification s'achèverait ${ }^{3}$. "

Le voilà, le voilà, il n'est pas mort. F... il est vaillant. Ah ! vous, père, vous êtes « vaillant ».

Labrousse, Deux vieilles terres françaises, pp. 53-54.

Labrousse, lieux vieilles terres françaises, pp. 53-54. 
On a affaire à une forme plus classique d'envoûtement lorsqu'il s'agit d'une figurine de cire dont le cœur, par exemple, a été traversé d'une épingle. Il n'est pas exceptionnel d'en trouver dans sa literie, quand on la fait refaire. Comme tout se modernise, on remplace de plus en plus la figurine par une simple photographie. Tel jeune homme trouva un jour chez sa maîtresse son portrait ainsi "piqué ». Il en profita pour rompre, non sans avoir au préalable administré une solide correction à l'intéressée. On raconte aussi qu'un maçon, accusé d'avoir enlevé la "première pierre " d'une église, en reçut la photographie de la part du curé de l'endroit, qui le soupçonnait fort du méfait, et que, depuis lors, car l'affaire est récente, il ne vit plus, ne sort, plus, mais demeure tapi dans un coin de sa maison, comme s'il était devenu imbécile.

On admet généralement que ce sont les conjurations dans les cimetières qui donnent les meilleurs résultats, parce que faisant, appel directement aux puissances de l'au-delà et de l'enfer. Qui peut y échapper passe pour un « fort entre les forts ", comme il arriva, il y a moins de quinze ans, à un de mes amis qui habitait alors un bourg de l'intérieur. Il prenait le punch, un soir, avec quelques collègues et le directeur de son service, lorsque arriva un manœuvre payé à la journée et quelque peu " comparaison », c'est-à-dire outrecuidant. Le nouveau venu fait scandale, exige sans délai ce qu'on lui doit, puis, comme on le renvoie, part en grommelant de vagues menaces. Cela lui vaut un coup de pied bien appliqué dans les fesses. Il se retourne alors et déclare à mon ami : " Ce soir au cimetière, je mettrai trois chandelles allumées sur la tombe de la famille... (où chaque nom inscrit est suivi de la formule d-c-d) (sic), et avant huit jours « OU ke mort » (vous serez mort). » Pour arriver à cette fin, il fallait que les chandelles allumées fussent renouvelées pendant trois jours et trois nuits sans aucune interruption. Notre homme le fit d'ailleurs avec beaucoup de conscience, se vantant dans tout le bourg d'être bientôt débarrassé de son adversaire.

Or, le matin même où les trois jours prenaient fin, mon ami et l'autre furent priés tous deux d'aider au chargement d'un bac de quinze cents kilos destiné à la maison d'un collègue. On part en camion et on s'arrête dans la cour de l'usine où se trouvait le bac. À peu près au milieu de celle-ci se dressait une sorte de pilier d'un mètre de haut, auquel était fixé un étau. On installe un lit de madriers pour monter le bac de champ. Les hommes poussent. L'effort, assez prometteur au début, fléchit. Pour mieux le répartir, le chef d'équipe fait permuter mon ami avec son « quimboiseur ». Nouvelle tentative, qui aboutit au désastre. Sauve qui peut! Tous font un bond de côté. Seul le jeteur de sort, surpris, reste devant le bac qui l'entraîne et le coince sur l'étau où il s'empale. Il devait mourir un quart d'heure plus tard.

Le résultat de l'affaire c'est que mon ami, qui n'y était pour rien, eut dès lors la réputation d'être un sorcier de première force, puisqu'il avait vaincu son ennemi par ses propres armes. Personne ne pouvait admettre qu'il s'était agi d'un simple accident. Mon ami avait « engagé » le bac, placé à l'intérieur un mauvais esprit. Il savait donc exactement ce qu'il faisait en changeant de place. Lorsqu'il assista à l'enterrement de sa victime supposée, les frères du défunt le contemplaient avec une terreur non dissimulée, En revanche nombre 
d'inconnus tenaient à lui toucher la main. Cela devait leur porter bonheur et leur communiquer un peu de ce merveilleux fluide qui avait mis à mal le pauvre manœuvre, On le priait également de monter quelques instants de très nombreux chevaux, sur lesquels son pouvoir bénéfique ne manquerait pas de s'exercer. Après ce coup d'éclat, l'intéressé préféra néanmoins, pour sa tranquillité et celle de sa famille, solliciter un autre poste et déménager au plus vite.

Les charmes offensifs, c'est-à-dire ceux qui sont destinés à nuire ou à suborner, sont de toutes sortes. Il peut s'agir d'objets « arrangés » et remis en place par un domestique complice. Dans ce cas, les patrons ne peuvent plus vivre dans leur maison où, de jour et de nuit, ils sont constamment dérangés par des bruits étranges et inexplicables.

Pour se débarrasser d'un « ennemi », il n'est que de jeter dans une fosse fraîchement ouverte quelques objets qu'on lui a dérobés. Si on veut le rendre fou, on enterre sur le passage d'un convoi mortuaire une pièce de monnaie qu'on lui a subtilisée sans qu'il s'en aperçoive, et qu'on s'arrange pour lui remettre ensuite. On peut également planter un poignard sous son lit ou dans sa porte, avec accompagnement d'une main noire grossièrement dessinée.

Il a déjà été parlé des cercueils en miniature avec figurines de chair corrompue ou de matières végétales. Lorsqu'il s'agit d'un igname ou d'un autre " gros légume », il est à l'ordinaire criblé d'épingles « de mausolée ${ }^{1}$ ». Dans d'autres cas, l'on place sous le seuil de la maison visée un " charme » liquide, enfermé dans une bouteille et où entrent surtout des ingrédients venus du cimetière. On y ajoute souvent des clous trempés dans de la chair de lapin corrompue. Tout cela s'accompagne, une fois encore, de conjurations, et l'une des plus employées est celle de la lampe sur laquelle on fait brûler une formule remise par le " quimboiseur », tandis qu'elle repose sur un parchemin, parfois même un simple bout de papier, où est inscrit le nom de la victime.

Le procédé peut même servir à retrouver un voleur, dans les conditions suivantes : il faut commencer, lorsqu'on a été victime d'un larcin, par mettre trois sous - on peut supposer que les tarifs sont en hausse depuis la guerre dans le tronc des âmes du purgatoire, trois dans le tronc de saint Michel et trois dans celui de saint Antoine. Après quoi on "prépare » une lampe avec de l'« huile de roses», de l'«huile de quinquets » et de l'« huile d'amandes douces », sous laquelle on place un papier à l'adresse de "saint Michel, saint Jean et saint Georges ». Le voleur ne saurait échapper et même, si la conjuration est bien faite, il peut être maintenu sur place jusqu'à ce que, le jour venu, on puisse l'identifier et le remettre à la police. Dans d'autres cas, il est seulement obligé de venir remettre en place ce qu'il a dérobé.

1 M. R. Fortuné cite un cas à la Guadeloupe où le petit cercueil ne contenait qu'un hareng saur (Revue Guadeloupéenne, janvier 1946, p. 42). 
Les méthodes appliquées varient encore suivant le but à atteindre. Mais partout la magie intervient. S'agit-il d'une course de canots? «L'un des concurrents va distancer l'autre. Vite un œuf «monté », une calebasse d'herbes volent d'un bord à l'autre, et l'une des rames du canot trop pressé va se casser à la hauteur des tolets. Vive le quimbois ! ${ }^{1}$ » Souvent aussi on se sert des œufs «montés » et des calebasses d'herbes, ainsi que de bien d'autres choses, pour provoquer des maladies plus ou moins pernicieuses mais qui, toutes, ont la caractéristique, d'après la tradition locale, de résister obstinément aux procédés de la médecine officielle. Parmi les «faits » considérés comme authentiques, on peut citer le "gros pied » ou éléphantiasis. Il se donnerait au moyen d'un côté de soulier "travaillé » par le sorcier au cours, par exemple, d'une réparation chez le cordonnier. Il arrive même que, pour appuyer son « travail », le dit sorcier passe à plusieurs reprises devant la maison de la personne qu'il veut atteindre, en la regardant fixement chaque fois qu'il l'entrevoit. Lorsque le soulier est essayé, la maladie s'introduit. Si on le porte plus d'une journée, la jambe devient énorme et le patient peut être assuré de rouler dans tous les caniveaux de la ville ou du bourg.

À l'inverse, il m'a été affirmé qu'un cordonnier, en réparant les souliers d'une directrice d'école, y aurait trouvé, soigneusement dissimulé, un petit rectangle de papier fort artistement découpé et sur lequel étaient inscrits le nom d'un inspecteur primaire et d'un directeur d'école. En les foulant ainsi aux pieds elle se croyait assurée de les dominer.

Lorsqu'un quimbois a été enterré sous le seuil d'une maison, il provoque à l'ordinaire, raconte-t-on, des boutons qui apparaissent presque instantanément, et causent des démangeaisons tellement intolérables qu'elles peuvent conduire la victime jusqu'aux limites de la folie. Seul un autre "quimboiseur », un « Mentor », un "Fort» peut guérir ces boutons et en faire sortir la « chenille poilue » qui cause les démangeaisons.

Lèpre et tuberculose n'échappent point à la règle. Le cahier du Lorrain contient une formule de " coup de poing composé » pour donner la première. Les marins du Sud emploient à la même intention des os de "petite seiche ". La tuberculose passe pour s'attraper avec de «l'eau préparée ». On cite du nord au sud de la colonie des exemples de familles entières qui auraient ainsi disparu.

Nous avons déjà vu comment on empoisonnait sous et clous en les trempant dans des liquides immondes, à base de chairs corrompues, surtout de lapin, sans préjudice des conjurations habituelles. Si on a le malheur d'en toucher un, la main et le bras se mettent aussitôt à enfler et les médecins n'y pourraient rien, si ce n'est amputer d'urgence, avant que le mal ait gagné le reste du corps.

1 Monographie du Carbet, écrite à l'occasion du Tricentenaire par M. Branglidor, directeur d'école. 
Au Lorrain comme au Diamant, on connaît le charme à l'odeur, le quimbois qui peut être lancé à la figure de l'adversaire par la fumée d'une cigarette. On s'en sert beaucoup avec les femmes, mais à d'autres fins également, la composition de la cigarette variant dans chaque cas. Il est possible encore de provoquer la venue d'odeurs particulièrement nauséabondes ou pharmaceutiques, d'iodoforme en particulier, même s'il n'y a aucun malade dans les alentours. Parfois même un flot de sang inonde à l'improviste la maison visée.

Il est certains « faits » enfin qu'on ne croit explicables que par l'intervention d'un " esprit » au service d'un sorcier. En voici un exemple récent, où je ne supprime, une fois de plus, dans le récit qui m'en a été fait, que les noms de personnes et de lieu :

« Il est huit heures du soir. La famille... est réunie au salon, parlant de diverses banalités, lorsque soudain la fille aînée, ... âgée de vingt-cinq ans, pousse un léger cri et, portant la main à son cou, la retire ensanglantée. Stupeur de tout le monde, personne n'est entré dans la maison et les fenêtres sont fermées. D'urgence on fait appeler un médecin qui diagnostique un coup de rasoir à quelques millimètres de la carotide. La blessure pourrait être mortelle. Jusqu'ici personne n'a pu expliquer cet étrange fait... Si, pourtant, car, de guerre lasse, les parents ont dû se résigner à consulter des voyantes qui, toutes, ont déclaré ceci : "Votre fille a été attaquée par un esprit envoyé par une de ses collègues du magasin où elle travaille... » Ce drame a provoqué une immense émotion dans le quartier. » Il existe dans le Sud une sorcière qui donne à ses meilleurs clients un " couteau magique », qu'il suffit de tourner d'une certaine façon pour que l'ennemi auquel on veut s'en prendre en ressente immédiatement le coup.

Mais on ne s'attaque pas seulement aux personnes humaines. Il est normal de vouloir frapper un adversaire dans ses biens, de le faire échouer dans ses entreprises, de décimer ses troupeaux. Un brave homme du Robert entretenait, sur une presqu'île proche du bourg, un grand nombre de moutons et de cabris. Passe un boucher du Nord qui veut conclure marché avec lui. Il refuse. « Vous êtes trop piéterre, mon ami. Cela vous portera malheur. Je vous promets que vous n'attendrez même pas longtemps avant de vous en apercevoir. »

«Effectivement, le lendemain ou le surlendemain», notre homme « remarqua, au milieu de sa savane, la présence insolite de trois chiens hirsutes. Les moutons et cabrits périrent par dizaines, égorgés par ces chiens » qu'il fallut tuer à coups de fusil. C'étaient évidemment des chiens « voyés ${ }^{1}$ ".

Plus récemment, on a parlé de «vampires » dans le sud de l'île, mais une garde vigilante montée par les éleveurs de Sainte-Anne a pu «révéler la présence de meutes de chiens errants et dévorants qui, privés de nourriture par ces temps de restrictions, causent des ravages dans nos bergeries. C'est ainsi

Leray, Monographie du Vert-Pré, écrite à l'occasion du Tricentenaire. Piéterre = chiche. 
que, sur une même propriété, et en une seule journée, une douzaine de brebis et un bouc ont été trouvés morts... " ${ }^{1}$. On peut être assuré néanmoins que l'imagination populaire aura vite fait de broder sur ce thème.

\section{V. - LA DÉFENSE CONTRE LES CHARMES}

La vie serait intenable si l'on ne pouvait, dans une certaine mesure, se protéger contre des menaces de cet ordre. Un quimboiseur, heureusement, peut souvent défaire ce qu'un autre a fait, car il possède le don de "double voyance ", et connaît les contre-charmes appropriés. Il est indispensable, plus que jamais alors, de suivre exactement ses prescriptions. S'il s'agit par exemple d'une bouteille enterrée près du seuil, il faut la prendre, traverser en la portant trois rivières, puis réciter la conjuration indiquée par le sorcier avant d'essayer de la briser. On raconte au Gros Morne qu'un demi-sceptique consentit bien à passer les trois rivières, mais jugea inutile de prononcer les paroles qu'on lui avait enseignées. Il lança la bouteille de toutes ses forces contre une grosse roche. Elle rebondit comme du caoutchouc. Il s'y prit à plusieurs reprises, avec une ardeur croissante, mais en vain. Il se décida enfin à répéter la formule idoine. La bouteille se brisa au coup suivant, sans aucune difficulté. Près de Fort-de-France il s'agissait, un jour, d'un mariage que tout semblait indiquer et qui n'arrivait pas à se conclure. Les parents de la jeune fille finirent par aller consulter une quimboiseuse qui habitait à quelques kilomètres de la ville. Celle-ci n'hésita guère et déclara qu'en effet un charme avait été employé pour retarder le mariage. Il n'existait qu'un moyen de le rompre. Les parents de la jeune fille creuseraient un trou dans la cour de leur demeure, à un endroit exactement précisé. Ils y découvriraient une boîte fort lourde qu'il faudrait immédiatement aller jeter à la mer, sans l'ouvrir, ni chercher à savoir ce qu'elle contenait.

Comme il n'y a pas de doute, étant donnée la qualité des témoignages recueillis, que la boîte en question a été réellement découverte et jetée à la mer, on peut se demander, la double vue étant exclue, comment et pourquoi la quimboiseuse avait pu donner des renseignements d'une précision aussi minutieuse. Une première hypothèse consiste à admettre que la mise en place du sortilège dont il s'agissait s'exécute suivant des règles codifiées et une orientation déterminée. Cela pose d'ailleurs le problème d'une certaine uniformité de doctrine chez les sorciers et de leur appartenance à une secte organisée.

Il se peut également, et cela me paraît au fond plus vraisemblable, qu'on se soit adressé, pour favoriser le mariage, à la personne même qui avait « travaillé » pour le contrarier. Je connais un autre cas où un gendre s'était fâché avec sa belle-mère. Celle ci pour se venger, fit planter un arbre devant la maison des jeunes gens. L'homme fut réduit à l'impuissance jusqu'à ce que, sur les conseils d'un vieux « Mentor », il fît couper ras le dit arbre.

La Paix, 8 mars 1947. 


\section{VI. - RÊVES ET PRÉMONITIONS}

À défaut d'indications du quimboiseur, on croit partout à la valeur des " signes », des prémonitions et des rêves. Lorsqu'au Morne des Esses on envoie un enfant faire une commission au bourg, éloigné de plusieurs kilomètres, on lui enjoint de se presser et on ne manque pas d'ajouter : « Si, avant votre retour, une envie me prend de cracher, c'est que vous muserez, et je vous battrai. » On pense au même endroit que l'eau bénite ne peut être supportée par les menteurs. Il suffit d'en faire ingurgiter quelques gouttes à la personne soupçonnée. En cas de culpabilité son ventre enfle instantanément.

On admet encore que beaucoup d'individus ont la prémonition de leur fin. « Le grand-père du sieur Cyrus, maire du quartier du Vert-Pré dans les temps héroïques, était esclave à la Providence. Son maître lui avait confié la garde du troupeau. Il était déjà vieux lorsqu'un jour il eut le pressentiment de sa fin prochaine. Il réunit donc toutes les bêtes et en donna la charge à son fils, puis il alla trouver son maître et lui demanda de le faire admettre à l'infirmerie, car, ajouta-t-il, je vais mourir dans deux heures. Le maître le considéra. Il n'avait rien en apparence. Il le fit quand même admettre, selon son désir. Le vieillard ne s'était pas trompé. Effectivement, deux heures après, il avait expiré ${ }^{1}$. » Des faits de ce genre m'ont été confirmés par des prêtres, en particulier le chanoine Tostivint, mais avec cette restriction qu'il s'était agi à l'occasion d'empoisonnements, dont les victimes ne connaissaient que trop la rapide efficacité.

Ces prémonitions se font souvent en rêve. De là l'exceptionnelle importance qu'on leur accorde dans toutes les classes de la société, où ils apparaissent comme une transposition de faits réels qu'il s'agit, il est vrai, d'interpréter de manière correcte. Il est au matin une heure fraîche et délicieuse, qu'on appelle le « lever » à la Martinique, et où, tout en dégustant le premier café, on discute des phantasmes de la nuit et de leur signification. Mais nul ne met en doute qu'ils annoncent des événements imminents, heureux ou malheureux. Il ne semble d'ailleurs pas qu'on utilise beaucoup à cette fin les "clés des Songes » imprimées en Europe. On se laisse plutôt guider par la tradition, transmise oralement, et les explications se donnent suivant les lois d'analogie et de contraste. Il est déplorable, par exemple, d'avoir vu des enfants au berceau : toutes les combinaisons qu'on vient de monter échoueront lamentablement. Elles réussiront au contraire si c'est un géant qui est apparu pendant le sommeil. Souvent également le rêve est considéré comme une vision à distance, et il n'est pas exceptionnel qu'on fasse la dépense d'une voiture pour aller vérifier, à l'autre extrémité de l'île, si des parents ou des amis sont toujours en bonne santé et ont échappé aux dangers qu'on s'imaginait les menacer. On tient le plus grand compte aussi des avis qu'on croit avoir été

Leray, Monographie du Vert-Pré, écrite à l'occasion du Tricentenaire. 
donnés par un mort : c'est par exemple une mère, depuis longtemps décédée, qui vient toucher le bras de sa fille endormie et lui conseille de quitter immédiatement la ville ou de ne pas se marier avec tel ou tel de ses soupirants.

Il peut même s'agir d'une voix intérieure s'imposant avec une force irrésistible. J'ai entendu raconter, par ses proches, l'histoire de ce fabricant de rhum installé à Saint-Pierre qui, au matin du 8 mai 1902, assistait dans la cathédrale à l'office solennel de la première communion, lorsqu'il s'entendit ordonner distinctement, sans qu'il sût d'où cela venait, de partir sans délai pour le Morne Rouge. Il prit sa voiture, s'engagea dans la longue montée qui conduit à ce dernier bourg, et l'arrière de son équipage, au tournant proche du Petit Réduit, se trouva juste frôlé et légèrement endommagé par la nuée qui détruisit Saint-Pierre et ses vingt-neuf mille habitants. Il fut le seul survivant de sa famille, que le cataclysme avait surprise à l'église, et qu'il n'avait eu ni le temps, ni même l'idée d'emmener avec lui.

\section{VII. - LA PRÉDICTION DE L'AVENIR}

De la prémonition à la prédiction de l'avenir, le saut est vite franchi. On se sert souvent d'un objet divinatoire. Le P. Labat raconte comment un nègre sorcier, qu'il surprit, utilisait une petite idole qui répondait à ses questions. Elle venait d'annoncer, lorsque le $\mathrm{P}$. Labat entra, qu'une des négresses de l'habitation Saint-Jacques, déjà malade, mourrait dans les quatre jours, ce qui eut effectivement lieu ${ }^{1}$. Un autre Noir, ayant été convaincu de sortilèges du même ordre, fut condamné à être brûlé vif. Comme on le menait au supplice et que les assistants se moquaient de la " petite figure » qu'il faisait jadis parler et qui maintenant était rompue, il demanda à l'un des assistants de lui prêter un instant sa canne qui, après quelques conjurations, annonça d'une voix faible mais claire la date à laquelle un bateau attendu avait quitté le port d'Elseneur, celle à laquelle il arriverait et les incidents de la route. Et le P. Labat de conclure: «Je ne finirais pas si je voulais rapporter ce que je sais sur cette matière.... Il y a véritablement des gens qui ont commerce avec le diable et qui se servent de lui en bien des choses ${ }^{2}$. "

Je ne pense pas que le procédé de la petite figure soit encore très usité. On croit plutôt à l'inspiration venue d'en haut, de Dieu ou des saints, à moins que ce ne soit de l'enfer, l'opposition étant moins grande peut être qu'il ne paraît au premier abord. C'est ainsi qu'après le tremblement de terre du 21 mai 1946, l'événement est donc tout récent, on parla dans la Martinique entière d'une prédiction faite par une femme du Lorrain, et qui causa beaucoup de trouble, d'affolement même, dans le nord de lî̂le. La Paix, le journal officiel de l'évêché, écrivait, le premier juin de la même année : «Voici exactement ce qui s'est passé. La veille du séisme, une femme G. E. vint trouver le vicaire du Lorrain. Elle paraissait assez exaltée et lui déclara que quelque chose de grave se passerait bientôt, sans dire cependant ni quoi, ni quand.

Labat, Éd. Duchartre, I, p. 156.

Labat, Éd. Duchartre, I, p. 156. 
«Depuis que l'événement a eu lieu, cette personne prend l'allure d'une prophétesse et d'une visionnaire qui serait favorisée d'apparitions surnaturelles, et elle a en effet déclaré qu'autre chose de plus grave encore se passerait dans un avenir prochain. " La mise au point de La Paix ajoutait que la devineresse avait passé quelques jours dans une maison de santé au début de l'année 1946. Elle avait donc pour but d'atténuer, dans toute la mesure du possible, la portée des prédictions faites, mais elle en soulignait par ailleurs le retentissement, dont les lettres que j'ai reçues à cette époque se faisaient plus ou moins l'écho.

Nombreuses surtout sont les voyantes qui dévoilent à chacun son avenir. L'on affirme que l'une d'elles, qui habite un morne éloigné du Sud, établit d'emblée son autorité sur les clients, ou plutôt les clientes, qui se pressent à sa porte, en leur précisant ce qu'elles ont fait le jour même et ce qu'elles viennent lui demander.

Souvent encore la prédiction est conditionnelle et le sorcier indique la marche à suivre pour que l'événement souhaité se produise. L'exemple le plus typique en est ce qu'on a appelé le quimbois des trois curés, qui remonte à la guerre de 1914-1918.

Le bruit s'était alors répandu dans l'île entière que, pour débarrasser le pays des békés ou Blancs créoles, les quimboiseurs réclamaient le sacrifice de trois curés, trois jeunes filles et trois enfants ${ }^{1}$. Il est exact qu'à quelques mois d'intervalle deux prêtres furent brûlés dans leur presbytère, au Robert et au Marigot. Le second, inquiet de l'attitude hostile de ses paroissiens, avait sollicité vainement de l'évêché un autre poste quelques jours à peine avant sa mort. C'était, au dire de ceux qui l'ont connu, un homme remarquable et qui avait beaucoup d'ascendant sur les jeunes. Cela expliquerait en partie l'animosité des quimboiseurs à son égard. Enfin, un troisième prêtre aurait pu s'échapper alors que sa moustiquaire prenait feu. À la même époque, un enfant disparut dans la région du Marin, au morne Montgerald. La justice, pour une fois, consentit à s'émouvoir et interrogea de "nombreux empiriques ». Mais, ajoutait M. Legros, dont j'ai pour une large part suivi le récit, le temps a passé et on « a fini par oublier. Les ministres du culte eux-mêmes n'ont plus de gardes du corps. Un simple caniche suffit ».

1 Les trois curés devaient avoir, autant que possible, des noms commençant par les mêmes initiales que les rois mages, Melchior, Gaspard et Balthazar. 


\section{VIII. - NAISSANCE DE NOUVEAUX TABOUS, INTÉGRATION DE LA SCIENCE DANS LA MAGIE, UNIVERSALITÉ DE CELLE-CI}

Tout vient ainsi renforcer la croyance au surnaturel, à la puissance de la magie et de ceux qui la pratiquent. De nouvelles interdictions, de nouveaux tabous apparaissent, tandis que de plus anciens tombent lentement en désuétude. C'est ainsi que, dans la région au nord du Prêcheur, on ne ferait plonger personne dans un «bassin » ombragé de balisiers, depuis que, sous une touffe d'entre eux, au bassin « Bon Dié », son futur gendre, qui voulait lui offrir des " écrevisses z'habitants », en plus de la génisse déjà promise, se heurta au cadavre déjà décomposé d'un certain Sigismond Macaque de fer, qui se vantait pourtant d'être un «Fort »; et déclarait à qui voulait l'entendre que, si sa fille osait se marier sans son consentement, il viendrait chaque soir, pendant trois ans pleins, lui « tirer les orteils des pieds », qu'il fût d'ailleurs vivant ou mort.

Dans une telle atmosphère on ne fait pas grande différence entre les procédés de la magie et ceux de la science appliquée. Il n'y a pas très longtemps, avant l'électrification totale de l'île, le télégraphe et le téléphone passaient encore pour recéler des forces dont il fallait se méfier. J'ai connu d'honnêtes gens qui croyaient à la possibilité de transmettre un quimbois par ce procédé, et l'un d'eux accomplit certain jour un très haut fait. Le téléphone lui apprit qu'un incendie venait d'éclater à une quinzaine de kilomètres de son bourg: on réclamait en conséquence le renfort de la pompe municipale, aussitôt envoyée. Mais une demi-heure plus tard, nouvel appel. Il s'agissait encore d'un incendie, mais au village le plus rapproché maintenant. C'étaient donc les fils qui avaient transmis le feu et notre héros, s'armant d'une hache et aidé du voisinage, s'empressa d'abattre trois ou quatre poteaux télégraphiques et de couper les fils pour préserver sa commune. De mauvaises langues prétendent qu'au Gros Morne, dont les habitants sont célèbres dans la Martinique entière pour avoir essayé de pousser leur église, à cause d'un voisinage incommode, on trouva un jour, suspendus près de la poste, deux magnifiques souliers que leur propriétaire espérait expédier au chef-lieu par voie aérienne...

La magie arrive ainsi à dominer vraiment l'ensemble des activités humaines dans certains quartiers de l'île ou dans certaines classes de la société. On s'en ira consulter le quimboiseur et lui demander conseil à propos de tout ou presque. Amour, médecine, affaires, il n'est rien qui n'apparaisse en quelque mesure comme justiciable du surnaturel.

«Quelles que soient l'excellence de sa cause, écrit M. Thomarel, la valeur de son avocat, le plaideur ne se présentera jamais devant le juge sans avoir consulté et suivi les conseils d'un quimboiseur. En cas de succès, tout le mérite lui revient. Et même, avec le concours d'un vaillant quimboiseur, on peut se passer d'avocat, commettre les pires maladresses. 
«Si on prend un quioc (choc), c'est que la partie adverse disposait d'un meilleur quimboiseur, recruté probablement au pays de «la soie » à Dominique. Eh bien, on en cherchera un plus valeureux à Trinidad où à Barbade.

« Un juge est très disposé en votre faveur, il écoute vos explications avec bienveillance, il vous encourage du geste, du regard, tout va bien, le procès est sûrement gagné. Brusquement l'adversaire tire un mouchoir de sa poche, un violent parfum se répand dans l'air et aussitôt la physionomie du juge se fait dure, hostile. Il était tout miel, le voici maintenant tout fiel, il vous rudoie et vous renvoie brutalement à votre place.

«Ah ! Ah ! le juge a été « garé » (égaré) ${ }^{1}$. »

Une très rapide enquête m'a permis de retrouver à la Guadeloupe des faits du même ordre. Il est fréquent que les murs du Palais de Justice à Pointe-àPitre voient leur blancheur souillée par des jaunes d'œufs écrasés aux fins de quimbois. On a vu, à la médianoche, le bâtiment tout entier entouré de couverts régulièrement disposés sans que rien y manquât : assiettes, verres, fourchettes, couteaux, etc. Il s'agit, avant l'audience, d'apaiser les " esprits » hostiles par un banquet symbolique. On m'a affirmé qu'il existerait, je n'ose dire des entrepreneurs spécialisés dans la location du matériel nécessaire.

Mais deux précautions valent mieux qu'une. Il y a un moyen infaillible de mettre en fuite les «zombis » adverses, c'est d'uriner dans un coin de la salle d'audience. Il n'est pas rare encore qu'au moment de la prestation de serment les témoins hésitent à déployer la paume de leur main droite comme la loi leur en fait une obligation: c'est qu'ils y dissimulent presque toujours un objet « monté », une amulette préparée spécialement à cette occasion. Le magistrat qui me donnait ces détails avait lui-même trouvé un jour sur sa table de travail une main aux doigts recourbés qui avait été découpée dans du papier de journal, sans qu'il pût définir exactement s'il s'agissait dans l'esprit de celui qui avait fabriqué cette main d'un geste d'attaque ou de défense.

Ainsi, la magie est partout. Ce qu'on ne peut expliquer de prime abord ressort d'elle et chaque jour apporte des faits nouveaux. Un vieillard explique le plus sérieusement du monde : "J'ai soixante et onze ans, eh bien, c'est la semaine dernière qu'une chose bizarre m'a été révélée. Si moin té mô la semaine passée, moin pas té ké save » ${ }^{2}$. (Si j'étais mort la semaine passée, je n'en aurais rien su).

Thomarel, Contes et paysages de la Martinique, pp. 153, 154.

Thomarel, ibid., p. 154. 


\section{CHAPITRE V}

\section{Les sorciers et leur organisation}

\section{Retour à la table des matières}

La plupart des Martiniquais croient donc aux quimbois et les pratiquent plus ou moins. Il est des procédés de purification, de défense magique - et nous en avons cité quelques-uns - qui sont universellement répandus. D'autres ne sont accessibles qu'à des initiés, en plus petit nombre, à ceux que l'on appelle les « Forts », les « Vaillants », les " Mentors », suivant les régions de l'île. On trouve de tout parmi eux. Au plus bas de l'échelle, le simple rebouteux de campagne, puis le "magnétiseur », qui guérit par des passes, et enfin le quimboiseur proprement dit, aux ordonnances pittoresques, qui délivre des "charmes» et contrecarre ceux dont on a été la victime. Souvent le quimboiseur opère avec l'aide d'une "voyante », à laquelle on remet le " rapport », c'est-à-dire un objet appartenant à la personne visée, ou pour laquelle on consulte. Quelques passes magnétiques endorment alors cette voyante et la mettent en communication avec les « esprits » qui lui dictent ses réponses. Mais cela devient de moins en moins fréquent; ou, plutôt, les " voyantes » préfèrent opérer dans bien des cas à leur seul bénéfice. Il en est quelques-unes célèbres dans la colonie entière. Vers 1930, tous les vendredis, de nombreuses voitures s'engageaient ainsi vers le Morne des Esses et l'on eût parfois éprouvé quelque surprise en reconnaissant dans leurs occupants, non seulement de riches propriétaires, mais parfois même de hauts fonctionnaires d'origine européenne.

Dans la plupart des cas le quimbois est un «jobb», une occupation supplémentaire, qui procure souvent des revenus appréciables et dont on ne se cache guère. Que de fois n'ai-je pas admiré, sur la route de Fort-de-France à Trinité, cette simple enseigne clouée sur une barrière blanche : "Au Cristal d'Or, à la Porte Enflammée », qui ne laissait planer aucun doute sur la profession du maître de la maison. Beaucoup d'habitations ont, d'ailleurs, leur quimboiseur attitré, que le patron lui-même n'hésite pas à consulter. On cite le nom d'un "grand blanc », aujourd'hui décédé, qui aurait entretenu à lui seul une dizaine de quimboiseurs qu'il ne voyait personnellement que de temps à autre, mais qui étaient chargés de tisser autour de lui un réseau de protection efficace contre les charmes et les envoûtements de ses adversaires.

Cependant, les sorciers passent pour être particulièrement nombreux dans certains quartiers, autour de la montagne du Vauclin, vers la Glottin au Gros Morne, dans les hauteurs du Lorrain et de Sainte-Marie. Ils ne manquent pas 
non plus à la ville ni aux environs. On en trouve assez fréquemment dans le personnel domestique. J'ai vu telle bonne, originaire du Vauclin, affecter la tranquille arrogance de ceux qui «savent », qui sont initiés, et déclarer un jour à son maître que c'était elle et non pas lui qui était responsable de la bonne marche de la maison. Elle fit même venir un sorcier réputé dans tout le sud de l'île, et aisément reconnaissable au gros cabochon de verre rouge qu'il portait au doigt, pour procéder à une purification en règle avec emploi systématique de nombreuses poudres et pommades. Plus tard, d'ailleurs, elle devait manifester des intentions moins bienveillantes. On s'en aperçut parce que la femme de chambre, qui aimait beaucoup ses maîtres, voulut les quitter brusquement sans raison avouable. Ce fut une sœur aînée qui dévoila tout en racontant que la cuisinière faisait maintenant du quimbois et qu'il y avait risque de mort à demeurer à côté d'elle. Il fut alors décidé de renvoyer la sorcière, mais on n'osa pas le faire brutalement. On se contenta de la mettre théoriquement au repos complet, en lui interdisant, jusqu'à nouvel ordre, de toucher à ses fourneaux ou de faire le marché. L'intéressée comprit fort bien d'ailleurs, partit dans l'heure qui suivit, et alla se réfugier dans ses mornes d'où elle n'est plus sortie.

Existe-t-il cependant une hiérarchie, une organisation des sorciers ? Il y a lieu, semble-t-il, de répondre par l'affirmative, et tout se passe comme si les quimboiseurs étaient réellement distribués en confréries d'initiés, dont les adeptes se reconnaissent à de petits carrés d'étoffe rouge ou noire, cousus dans la chemise, et toujours au contact de la peau, ce qui n'empêche nullement d'ailleurs de porter à côté médailles et scapulaires. Ces carrés d'étoffe sont particulièrement fréquents chez les gens de la campagne, dans les mornes les plus reculés.

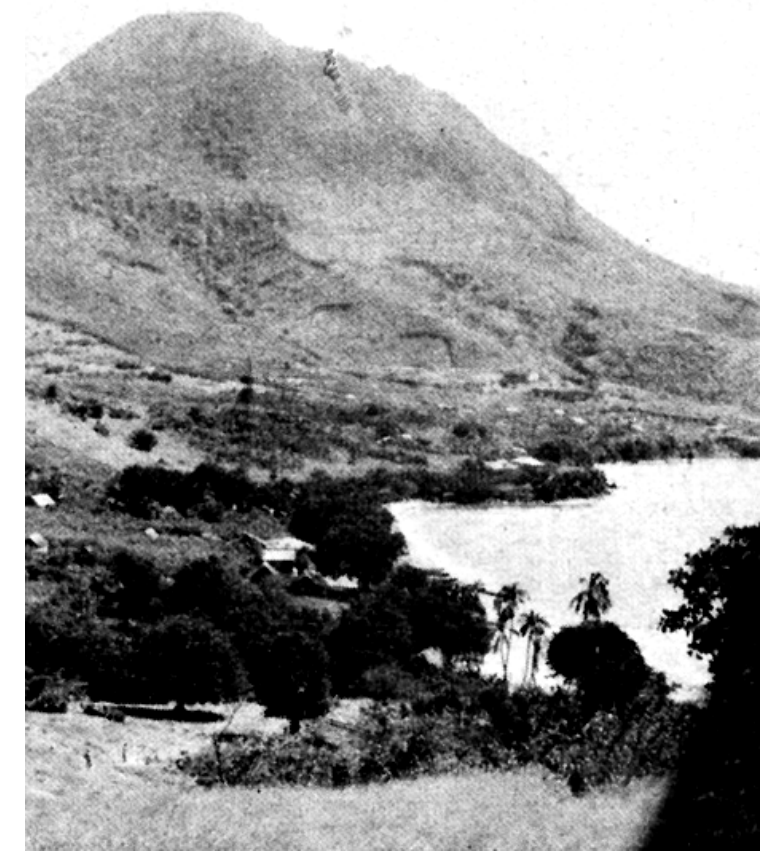

LA PETITE ANSE ET LE MORNE DU DIAMANT 


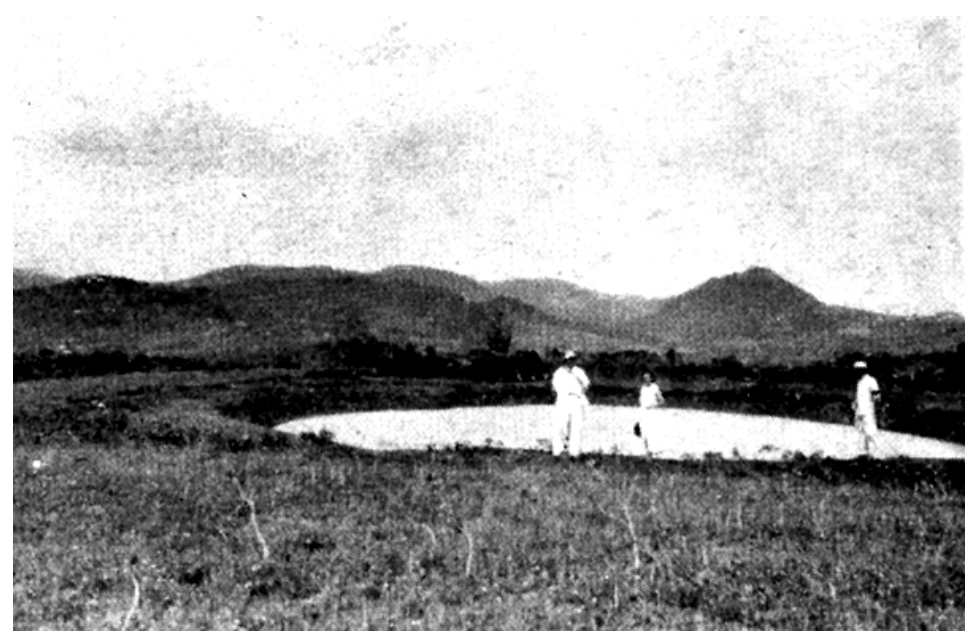

LE CAP FERRÉ ET L'EXTRÊME SUD

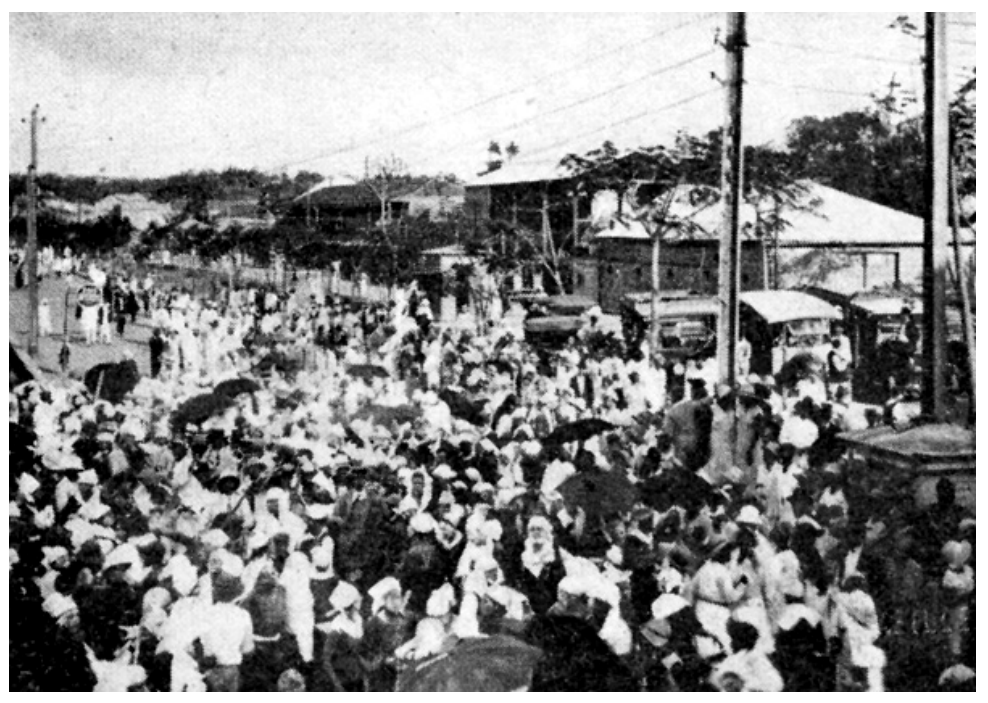

CORTÈGE DE GUIABLESSES. (Cliché Veille)

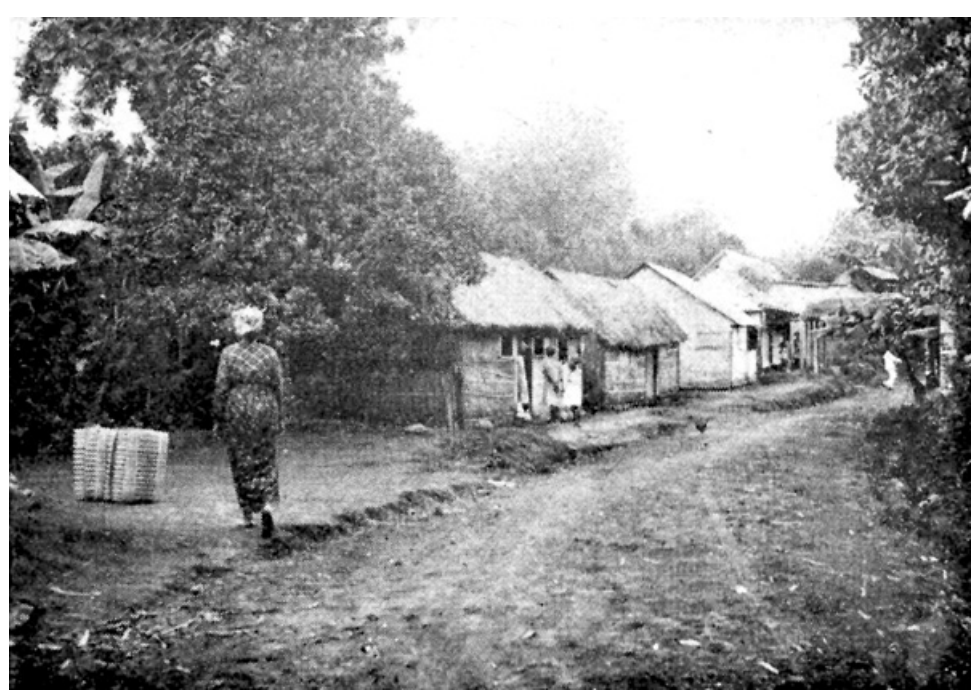

LE MORNE DES ESSES, PATRIE DES PANIERS CARAÏBES 
À beau mentir qui vient de loin. Il est encore certain que, dans l'intérieur de l'île, on accorde souvent la préférence au quimboiseur d'un quartier éloigné. Il existait au début du siècle, à Trinité, un vieillard toujours coiffé d'une casquette en peau de lapin, auquel ses voisins ne prêtaient guère attention, mais qu'on venait consulter de l'autre bout de l'île.

Ce qui tendrait encore à confirmer la réalité d'une hiérarchie au moins embryonnaire c'est l'affirmation, maintes fois répétée, qu'il existerait un « roi des sorciers » ayant juridiction sur toutes les petites Antilles, et dont on place la résidence au pays de "la soie ", c'est-à-dire à la Dominique pour les gens du Nord, tandis que ceux du Sud vont le chercher à Sainte-Lucie, mais toujours en dehors de la Martinique.

Lorsqu'on estime avoir à se plaindre d'un de ses sujets ou qu'on désire une vengeance exceptionnelle, il est indispensable d'aller le trouver en personne et de plaider sa cause devant lui. S'il accepte la requête ainsi présentée, il place l'impétrant devant trois cuvettes, la première remplie d'eau, la seconde de sang et la troisième d'un liquide noir, et lui demande quelle peine il veut infliger à son ennemi, mort, blessure ou graves ennuis. La réponse obtenue, le roi des sorciers applique la conjuration qui convient à l'une des deux cuvettes, la noire ou la rouge. Lorsqu'il en a terminé sur ce point, il ramène son client à la cuvette d'eau et lui ordonne de la franchir pour se retrouver instantanément et sans effort de l'autre côté du canal. En même temps, la vengeance sera accomplie et l'ennemi visé se retrouvera mort, gravement malade ou en proie aux pires soucis.

Les plus élevés en grade des sorciers de la Martinique connaîtraient également le procédé de la cuvette, et en profiteraient pour se transporter dans les îles voisines et y exercer leurs talents, sans crainte d'être reconnus ni poursuivis.

Autant qu'un profane puisse en juger, on distinguerait en fin de compte parmi eux de simples initiés, des maîtres et des grands maîtres. L'initiation se ferait en lisant des formules, des " oraisons », ou en les apprenant d'un maître sorcier. Il n'est pas rare que cela se passe à la Maison Centrale, c'est-à-dire à la prison, qui est un lieu de rencontre pour des gens venus des quatre coins de la colonie, et pas plus mal famé d'ailleurs que beaucoup d'autres.

\section{LES SUPERCHERIES}

Dans quelle mesure cependant doit-on croire à la sincérité des quimboiseurs ? On peut leur reprocher, de manière incontestable, de nombreuses et flagrantes supercheries. M. Legros m'en a cité quelques-unes dont il avait été témoin, tant à Tartane, qu'au Calvaire du Gros Morne et à Sainte-Anne : un comparse du sorcier, bonne langue en général, fait avouer à un brave paysan, qui croit dur comme fer à toutes ces choses, qu'il craint bien d'héberger un diable dans sa demeure. "C'est bien simple, appelez le quimboiseur X... Pour quarante francs (cela se passait avant 1914, à un moment où les ouvriers agricoles gagnaient d'un franc cinquante à deux francs par jour) 
il trouvera sûrement le quimbois chez vous et vous serez délivré. » Le paysan prie alors le comparse de bien vouloir faire la commission pour lui.

C'est justement ce que désire ce dernier, qui profite d'un moment favorable pour enterrer une ou deux fioles à des endroits qu'il marque discrètement de branchettes, avant d'aller chercher le sorcier chef. Celui-ci arrive enfin et, avec beaucoup de solennité, se livre à des "passes ", à des invocations. Puis il se promène avec une baguette posée sur deux doigts et cette baguette remue de plus en plus violemment jusqu'à ce qu'elle tombe. On « fouille » alors et on trouve la première fiole remplie d'un liquide nauséabond. On recommence pour la seconde qu'on découvre de la même manière. On entoure le sorcier, on le félicite chaudement. On l'invite à un dîner superbe et la fête dure jusqu'à minuit. « Délivrance, prospérité, plus de diables ! ${ }^{1}$ »

Le lapin blanc est une des plus terribles rencontres qu'on puisse faire de nuit. Un quimboiseur des environs du Gros Morne en possédait un empaillé et monté sur roues, jouet qu'il avait acheté dans un bazar. Il le plaçait à la nuit tombée dans sa cour proche de la grande route. Les passants attardés apercevaient l'animal et interpellaient l'intéressé : « M... Diab'là dans la cour . - Bien, je lui casse les reins. - Dépêchez vous, il entre sous votre maison.... Attendez! » Notre homme avait simplement tiré sur la ficelle et rentré son animal. Mais tout le voisinage avait aperçu le diable sous la forme d'un lapin.

Le même quimboiseur était atrocement jaloux d'un de ses voisins qui recevait, avec régularité, les visites d'une jolie fille. Il était résolu à tout pour le supplanter et pensait qu'il ne saurait mieux faire que de le rendre ridicule aux yeux de sa belle. Une nuit, pendant que les amoureux coquetaient, il plaça sous la fenêtre de la case qui les abritait un drap blanc, tendu par deux chaises à une certaine hauteur du sol. Après quoi il déclencha un infernal vacarme, entrecoupé de menaces et d'invocations à tous les grands diables de l'enfer. Placé devant la porte, il interdisait la fuite de ce côté. Restait la fenêtre, par où saute le rival abhorré qui tombe dans le drap, s'y empêtre, se croit du coup dans l'autre monde et s'évanouit. On fut obligé de le porter sur son lit et il faillit en mourir.

Un autre prétendait que ses clients étaient des possédés et, pour chasser les démons qui les torturaient, réclamait tous les matins une poule blanche qu'il fallait faire cuire suivant ses indications. Il en passait une aile ou une cuisse au patient, mangeait le reste, puis ramassait soigneusement tous les os jusqu'au plus petit, les mettait dans une terrine qu'il s'en allait jeter à la mer, dans un coin solitaire et sans jamais accepter que quelqu'un l'accompagnât.

Plus récemment, le possesseur d'un coq de combat renommé, qui valait au moins cinquante mille francs vers 1935, vit son fils aîné tomber gravement malade. Les médecins, paraît-il, n'y pouvant rien, on fit venir un « Mentor »

D'après un manuscrit inédit de $\mathrm{M}$. Legros.

Le diable est là, dans la cour. 
des hauteurs. Celui-ci opéra suivant les règles de son art, puis déclara qu'il restait, un seul moyen de sauver l'enfant, déjà presque condamné, c'était d'ouvrir en deux le fameux coq de combat et de l'appliquer tout sanglant sur la poitrine du patient pour absorber le mal. Le père hésita quelques heures, à cause de la valeur de l'animal et de l'orgueil qu'il en tirait. Il se décida pourtant. Le coq fut sacrifié suivant les rites, puis, l'opération terminée, emporté par le quimboiseur qui en fit un excellent bouillon. Il ne parut guère douteux aux témoins incrédules de l'aventure que le quimboiseur en question avait été soudoyé par un rival de pitt ${ }^{1}$, désireux d'éliminer des compétitions hebdomadaires un « coq game » particulièrement redouté.

J'ai connu, pour ma part, près de Fort-de-France, une quimboiseuse renommée qui «opérait » tous les vendredis et prescrivait comme remède essentiel de la racine de cocotier mâle, parce qu'elle possédait quelques spécimens de cet arbre sur un terrain voisin. Le mari débitait la marchandise au plus juste prix. Cette quimboiseuse entretenait d'excellentes relations avec un de ses voisins, professeur de lycée, et lui confiait sans ambages qu'elle faisait le métier de voyante et de guérisseuse sans y croire, mais pour amasser une rapide fortune. Aussi n'hésitait-elle jamais, lorsqu'elle même ou un des siens tombait malade, à envoyer chercher le médecin.

Plus nombreuses encore sont les histoires authentiques d'apparitions truquées. En 1870, lors de la révolte du Sud, on avait formé en toute hâte une milice bourgeoise au chef-lieu qui montait la garde autour des bâtiments publics. Un soir, au tribunal, la sentinelle vit une lueur rouge, comme sortie de deux yeux énormes, filer au ras de l'herbe. Étonnée, elle crie «Zombi ${ }^{2}$ ». La lumière file toujours et s'avance vers notre brave. "À la Garde, à moi ! » Le poste sort, les hommes s'alignent, épaulent leurs vieilles carabines, somment le « zombi » de s'arrêter. Celui-ci continue sa marche et passe sous le nez des vétérans qui, du coup, s'enfuient en désordre dans le poste, la plupart ayant lâché leur fusil. Porte barricadée ils attendirent l'aube, et trouvèrent alors sur l'herbe de la pelouse les restes du «zombi »: une vieille calebasse taillée en tête de mort, à l'intérieur de laquelle on avait placé une bougie, le tout enveloppé de papier rouge et monté à l'extrémité d'un bambou léger.

Telle, encore, cette véridique histoire de deux mauvais garçons qui voulaient obliger leur mère, demeurée veuve, à vendre les biens qui lui restaient pour leur permettre de « faire la bombe » tout à leur aise. Comme elle s'y refusait obstinément, ils inventèrent de se transformer en fantômes pour la rosser copieusement sans être reconnus. Ils venaient ensuite la consoler et la supplier d'apaiser le «zombi » qui la tourmentait ainsi en abandonnant les lieux.... Elle, cependant, ne comprenait pas. Alors, tous les soirs, à la même heure, le zombi recommençait : la malheureuse hurlait et ameutait le quartier, d'ailleurs friand d'assister à la scène. Les fils indignes pensèrent qu'il pouvait y avoir là une source de revenus : l'un opérait, tandis que l'autre faisait payer les

Arène où se donnent les combats de coqs.

Zombi : esprit, revenant. 
curieux qui voulaient entrer dans la cour. Tout, hélas ! a une fin. Un honnête homme finit par remarquer qu'on ne voyait jamais qu'un des fils à la fois. Il s'embusqua et surprit le fantôme au moment où, la figure voilée, et le corps drapé dans un long suaire il se préparait à « travailler les côtes » de celle qui lui avait donné le jour. Ce fut le « zombi », ce soir-là, qui prit la raclée.... Et perdit du coup le plus clair de ses revenus.

Dans un tout autre domaine j'ai connu un mari qui s'est tiré, grâce aux «zombis », d'une situation délicate. Il venait de se faire surprendre par son épouse, et en simple appareil, dans le galetas de la bonne. Mais lui, les yeux révulsés, le corps rigide, les bras tendus, suivait un « zombi » qu'il était le seul à apercevoir et qui le conduisit sur la terrasse, pendant que la jeune personne, préalablement endoctrinée, suppliait Madame de ne pas causer la mort de son époux par une intervention hors de propos.

Des procédés analogues ont été souvent employés dans ce qu'il est permis d'appeler l'escroquerie au trésor. La tradition prétend que la Martinique renferme de nombreuses jarres pleines de louis, de doublons ou de bijoux, enterrés par tel ou tel béké ${ }^{1}$ au cours d'une des nombreuses péripéties qui ont marqué l'histoire de l'île. De temps à autre, une découverte réelle vient confirmer cette croyance. On raconte qu'à la fin du XIX $\mathrm{X}^{\mathrm{e}}$ siècle, à l'habitation Valmeinière, le géreur fut réveillé en pleine nuit par six hommes masqués qui l'obligèrent à les conduire près d'un arbre écarté et là lui firent creuser la terre jusqu'à ce qu'apparût un lourd coffre qu'ils emportèrent. J'ai moi-même entendu parler de la trouvaille, faite près du Vauclin, d'un grand nombre de louis d'or. Il est donc naturel que les quimboiseurs soient souvent sollicités pour des recherches de cet ordre. Comme il leur est difficile de s'y refuser, ils se tirent d'affaire en indiquant des conditions presque impossibles à remplir. Ou bien le chercheur a commis quelque faute et le trésor s'est enfoncé de lui-même dans le sol, à moins qu'il n'ait pas su apaiser les mânes de l'esclave jadis sacrifié pour garder éternellement les bijoux et l'or du maître. C'est enfin le démon auquel on n'a pas fait une part suffisante, et dont la tête monstrueuse, phosphorescente, émergeant des cannes, a vite fait de mettre tout le monde en fuite. Ajouterai-je, enfin, qu'au témoignage de $\mathrm{M}$. Tardon, qui a raconté l'histoire en grande partie véridique d'un certain Caleb, beaucoup de quimboiseurs abusent pour des fins personnelles de la crédulité populaire?

\section{II - SINCÉRITÉ DE NOMBREUX SORCIERS}

Il ne paraît pas douteux, cependant, que bon nombre de quimboiseurs martiniquais arrivent à se persuader eux-mêmes de leur puissance surnaturelle et, pas plus que les « hommes médecine » de nombreuses populations, ne font de distinction nette entre ce qui est du domaine de la science de l'expérience, ou de la magie pure. Dans le remède accompagné de conjurations, ce qui est la règle, sont-ce ces dernières, ou les ingrédients ingurgités, qui ont l'efficacité la plus grande ? Le cahier du Lorrain contient pêle-mêle des recettes fort diverses,

Béké : Blanc créole. 
aussi bien pour guérir la vérole que pour faire parler une femme ou se rendre invisible. Il ne faut pas oublier non plus que les quimboiseurs s'adressent à une population fort impressionnable, et sur laquelle les suggestions peuvent avoir une emprise extraordinaire. M. Tardon a raconté dans une de ses nouvelles ${ }^{1}$ l'histoire entièrement véridique d'un certain Majorie, s'enfuyant nu, un coutelas à la main, sur la grève baignée de lune, parce qu'une vieille sorcière, furieuse de s'être empêtrée dans un filet de pêche, lui avait crié : "L'esprit a compté tes jours. Tu crèveras de male mort. Les requins se disputeront ton cadavre. » L'affolement grandissant, causé par cette menace, finit par pousser l'homme au pied de la falaise, "dans la bouche de la mer ", où il ne manqua pas de se noyer.

On croit facilement à des manifestations de l'au-delà. Tous les soirs, il y a quelques années seulement, dans un bourg du Sud, de mystérieuses voix semblaient tomber d'en haut. Ce ne pouvait être qu'un esprit. Le directeur d'école, consulté, proclamait gravement qu'il s'agissait «d'une voix d'outretombe réelle ». De tous les alentours, jusqu'à quinze ou vingt kilomètres de distance, on venait assister au miracle. Un sorcier renommé, qui portait trois pantalons superposés, songeait aux moyens de «faire entrer l'esprit dans son ventre ", de manière à disposer de l'oracle (Moin ka i fé esprit entrer en boudin) (boudin = ventre), jusqu'au jour où l'on s'aperçut qu'il s'agissait, d'une fillette hystérique d'une douzaine d'années, qui se postait dans la toiture d'une des plus hautes maisons du bourg.

C'est qu'au fond le ciel n'est pas loin, pas plus que l'enfer, et les bienheureux, comme les démons ou les zombis, continuent à participer à la vie d'ici bas. Il n'y a pas longtemps qu'une brave citoyenne de Fort-de-France accusait les communistes d'avoir entraîné une brouille grave entre la Vierge et son digne époux (Ou ka fé la Sainte Vierge goumé (se gourmer, se battre) épi (avec) saint Joseph). Il est vrai qu'en revanche, pendant que les dits communistes tenaient une réunion, "tout le temps Midi ka sonné » (midi a sonné tout le temps). Mais là il n'y avait plus rien de surnaturel. C'était le curé du lieu qui avait donné au sacristain les ordres en conséquence.

Cette familiarité avec les puissances d'en haut, voire d'en bas, explique, voire excuse, bien des attitudes ou des actes. On commence par obéir à sa propre impulsion. On réfléchit ou on discute ensuite. Un brave citoyen proclamait, à qui voulait l'entendre, qu'il sentait bien qu'un jour proche il ferait un mauvais coup (Moin ka senti moin ka y fai un mauvais coup ces jours ta la). Et, après cette déclaration de principe, il passait à l'église et tâtait par en dessous le tronc de l'Enfant-Jésus.

« Tronc ta la plein sous » (Le tronc est plein de sous).

«I ka taté y. » Il l'a tâté, s'écriait le peuple assemblé, comme le chœur antique.

Tardon, Bleu des îles, pp. 57-63. 
Naturellement, un beau matin, le tronc fut défoncé, notre homme arrêté. Il ne chercha nullement à nier, mais proclama avec la tranquillité d'une conscience pure : "C'était trop d'argent pour l'Enfant-Jésus, qui n'est qu'un enfant. Il était plus juste que cet argent me revint. »

D'ordinaire, les apparitions d'anges on de démons se produisent pendant le sommeil. Mais leur réalité devient indiscutable et indiscutée par les conséquences qui en résultent. Telle malade, dont les médecins désespéraient, a vu, dans son sommeil, le Christ déposer un paroissien à ses côtés. Elle trouve, en effet, son missel à portée de la main lorsqu'elle se réveille. Depuis lors elle soigne tout le voisinage en ouvrant au hasard le livre divin dont les réponses interprétées lui permettent d'indiquer les plantes et prières qui guérissent. Bien d'autres personnes, en conseillant un remède, indiquent très simplement que " cé des idées qui me viennent des saints, que je n'ai même pas vus, tout bonnement ${ }^{1}$ ».

On peut ajouter que l'habitude de parler à haute voix, même si l'on est isolé, est fort répandue. Beaucoup d'hommes et de femmes du peuple ont horreur du silence, marmonnent ou discutent sans arrêt et se prennent à écouter parfois leurs propres paroles, comme si elles venaient d'ailleurs, comme si elles étaient d'inspiration surnaturelle. Il y a, pour de nombreuses raisons, un nombre élevé d'anormaux ou de demi-anormaux à la Martinique. L'eau qu'on y boit aux repas est précédée de "punchs » quelquefois abondants. La syphilis, la lèpre, la tuberculose, la typhoïde, bien d'autres maladies encore y exercent de sérieux ravages. Fréquentes sont les crises d'hystérie chez les femmes, surtout dans la nuit du samedi au dimanche ou à la saison du Carnaval, ce qui se désigne par l'expression « tombé l'état ».

Ce sont souvent, au demeurant, des cas de folie érotique. Il n'est pas difficile de se faire raconter à la campagne, et même ailleurs, comment, au cours de certaines danses, l'excitation peut devenir assez forte pour que telle ou telle des participantes se mette à arracher brusquement ses vêtements et à les jeter au loin. C'est, aux yeux des simples, une affaire type de possession. Il en est de même pour les manifestations du delirium tremens. Il y a enfin des exemples d'extase et de vaticination. Où veut-on que se trace, dans ces conditions, une limite nette entre le réel et l'imaginaire ?

De là les extraordinaires facultés qu'on prête aux sorciers. Ils pourraient non seulement compromettre le succès d'une entreprise, ruiner un commerce, mais rendre encore un homme voleur, ivrogne ou déséquilibré, s'emparer de l'intelligence d'un enfant et l'endormir en classe, enlever un fœetus du ventre de sa mère. À l'inverse, ils ont le pouvoir de loger des " esprits » démoniaques dans le corps de leurs adversaires, qui sont alors contraints d'obéir à toutes les fantaisies de ces tourmenteurs. Les malheureux crient, se débattent, se roulent sur le sol, suivant les caprices de l'hôte incommode qu'ils abritent. M. Cadoré a raconté jadis, avec beaucoup d'esprit, l'histoire d'une certaine « Choucoune »

Zobel, Les jours immobiles, p. 163. 
qui portait en elle sept ou huit zombis ou " esprits voyés ». L'un occupait son ventre, un autre ses jambes, alternativement avec les bras, un autre son estomac. En fin de compte elle en avait partout, de toutes les grandeurs, de toutes les formes, aux exigences souvent contradictoires.

Un sorcier réputé de la Dominique, de passage à Fort-de-France, composa sur place et fit avaler à la patiente « un breuvage où il entrait de la bouse de vache, de "l'esprit des hommes » de " l'essence colibri », de l'urine d'un jeune chat et quantité d'autres ingrédients dont la vertu antimaléfique était connue de tous ». Après lui avoir fait sortir de la bouche divers animaux, dont un crapaud, un anoli ${ }^{1}$, une couleuvre, une araignée, un " chatrou ${ }^{2}$ ", un chadron noir ${ }^{3}$, le sorcier plaça autour « des reins de Choucoune, à même la peau, une ficelle à laquelle étaient attachées une patte de coq blanc et une patte de coq noir, et déclara ensuite que les zombis étaient partis ${ }^{4}{ } »$.

Il ne s'agit là, sans doute, que d'un conte, mais dont tous les éléments ont été empruntés à la réalité. Il est des logements que leurs occupants abandonnent, non seulement parce qu'ils sont hantés, mais parce que ceux qui osent y coucher seraient rossés toutes les nuits par les « esprits voyés ».

On voit l'universalité des pouvoirs attribués aux sorciers, dont ceux-ci n'usent pleinement, d'ailleurs, que dans les grandes occasions, lorsqu'un client sérieux veut "voir ses affaires » et "faire une séance ». Dans ce cas, le quimboiseur requiert toujours le concours d'une "voyante». Il « endort son sujet », lui donne le « rapport » ou objet venant de la personne en cause et le sujet endormi voit, parle et dicte. Le quimboiseur interprète et donne les ordonnances correspondantes. Mais cela n'a lieu que dans les grandes occasions. Déjà, avant guerre, pour « connaître » un ennemi et s'en débarrasser, il ne fallait pas moins, suivant les quartiers et les cas, de dix à trente mille francs. On comprend, dans ces conditions, que les quimboiseurs « séanciers » soient en général des gens fort cossus et respectés au loin.

\section{III. - LES SORCIERS ET LEURS ADVERSAIRES}

Qu'ils soient ou non sincères, les quimboiseurs tiennent à leur prestige et font tout pour le maintenir. Ils détestent particulièrement être surpris au cours de leurs exercices nocturnes et leur colère a tôt fait de s'abattre sur l'intrus. Il existe au sortir du Gros Morne, sur la route du Vert Pré, une descente assez rapide qui conduit à ce qu'on appelle le «tournant rouge), et la " Croix Jurin ». Le père d'un de mes amis passait dans ce quartier à une heure tardive, lorsqu'il aperçut, au milieu de la route, un de ses voisins, qu'il connaissait fort bien, en train de « faire la cheminée », c'est-à-dire de marcher sur les mains, les pieds en l'air, avec, en plus, un cierge allumé planté sur chacun d'eux.

Anoli : petit lézard vert.

Chatrou : pieuvre.

Chadron : oursin.

Cadoré, Choucoune, conte, avril 1921. 
- Un tel, que faites-vous là ?

- Ce ne sont pas vos affaires, M..., passez votre chemin.

Le lendemain, nouvelle rencontre. L,'homme qui avait été surpris en si étrange posture renouvela son avertissement - il ne fallait ni le reconnaître ni l'interpeller. Une autre fois, il en cuirait durement à l'imprudent.

Les sorciers domineraient sans conteste l'île entière s'ils n'avaient, dans le clergé, la majeure partie des médecins et du corps enseignant, des adversaires assez diversement redoutables, mais qui cependant progressent peu à peu.

Le prêtre, à la Martinique, sauf dans quelques très rares maisons, pénètre partout. La religion qu'il enseigne est incompatible avec le «quimbois », encore que cela ne l'empêche pas d'apparaître, à certains esprits simples, comme le détenteur d'un pouvoir magique particulièrement efficace, pouvoir qui s'étend à tous les objets du culte et surtout au Saint-Sacrement. Quand un malade est proche de l'agonie, on va chercher le curé qui, dans les mornes, est souvent obligé de monter à cheval pour porter l'Eucharistie au mourant. De nombreux cavaliers lui forment alors une escorte d'honneur. Les incroyants ne doivent pas y prendre part, sous peine de graves dangers. L'un d'eux, à SaintJoseph, voulut, dans une telle circonstance, aider à se relever un prêtre qui venait de tomber, et avec lequel il entretenait par ailleurs d'excellentes relations. Mais sa main toucha accidentellement le ciboire. La nuit même, à peu de distance, il se noyait au passage d'un torrent. Tous y virent une intervention divine.

Il en fut de même pour un incident moins tragique qui s'est déroulé il y a peu d'années. La Martinique entière a célébré, par des fêtes telles qu'on n'en avait jamais connu de semblables, le passage dans toutes ses communes de la Vierge du Grand Retour. Pour une fois, l'unanimité était réalisée et, dans la plupart des bourgs, les plus farouches communistes disputaient aux Békés (blancs créoles) l'honneur de porter la statue miraculeuse. Seuls quelques vieux " durs » résistaient. L'un d'eux parla de " Popote la Chaux » (objet fabriqué en chaux, passé à la chaux). Il n'osa cependant pas refuser sa vedette au pèlerinage. Panne brutale et prolongée au milieu de la baie de Fort-de-France. Alors toute l'assistance : «Ou voi, ou traité Popote la Chaux»: Vous voyez, vous avez traité la statue de Popote la Chaux (sous-entendu : elle vient de vous montrer sa puissance).

Je ne suis pas très certain, en fin de compte, que la diffusion de l'enseignement - plus des quatre cinquièmes des jeunes Martiniquais fréquentent l'école - entame rapidement la croyance aux sortilèges et la puissance des quimboiseurs. Il n'y a pas si loin, au fond, entre les découvertes les plus spectaculaires de notre science et les prétendus effets de la magie. Le postulat de base est le même : il y a possibilité pour l'homme d'agir sur la nature par des moyens appropriés. Ainsi l'instruction, que nous nous efforçons de dispenser largement, s'intègre-t-elle curieusement dans les vieux cadres, et perd du coup la force émancipatrice que nous eussions voulu lui prêter. Rares 
sont ceux qui ne croient pas, d'une manière ou d'une autre, à la puissance des quimboiseurs, plus rares encore sont les médecins qui osent entrer en lutte ouverte contre ces derniers, tel ce jeune docteur rentré au pays il y a quelques années et qui, d'entrée de jeu, a fait savoir aux « empiriques » du quartier où il s'est installé qu'ils auraient à laisser tranquilles les malades qu'il soignait, s'ils ne voulaient pas avoir affaire à son porte-respect, un énorme revolver qu'il porte toujours fort apparent....

\section{Woardi 25 yeaniriertg49.}

gramaires Conjergensonts

Le fochenr aut travable, pe boit louent,

qui aranse de petits pas, glisents siest satot,

ond il a mie Ses pied muts marque durents -

paralelents, la feause - coupsets de droite $a-$

gauchents, d'un trents rapide est bur prix il

revients la pointe ot du dots, et Carêsents l'erbents

- Suivant qui vastonber, tantat els ginsents sas

et la prêts, les grandents horbes frisonnets -

d'un dutude, et brusquements els a auquêts

sur un Eayours, hpilipe saretes tatents la lamets

- du droixb et la filents avee une pièrents a -

eglize, souts le ventre dans un Carnets de froit,

et mintenents, il sesféres la barbes,

$$
\text { question a espliquet }
$$

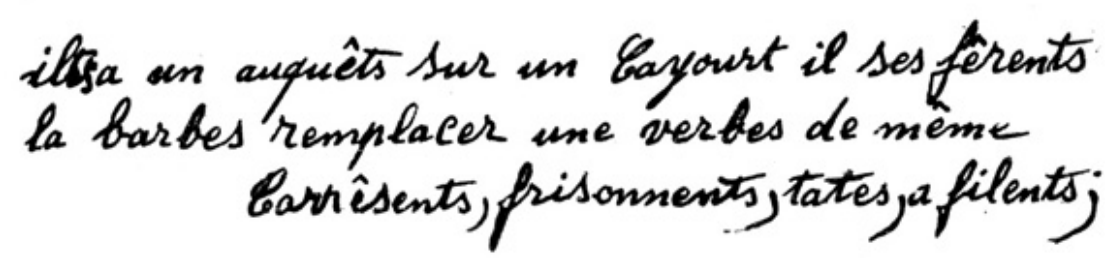

EXERCICE DE GRAMMAIRE

Mais tous n'ont pas la même liberté d'esprit et un incident récent, qui vient d'avoir son dénouement en correctionnelle, montre bien quelles sont encore à ce sujet les réactions du public, même cultivé.

Un médecin de quelque réputation lut égratigné, au cours d'une discussion violente avec une blanchisseuse. Son bras enfla fortement. Une expertise chirurgicale ne donna pas de conclusions définitives, pas plus qu'une expertise toxicologique faite à New York sur la manche de chemise déchirée. L'affaire 
vint en correctionnelle. Le journal L'Information, en date du 3 mai 1946, publiait le compte rendu suivant :

« Le docteur X ... à la barre.

« Le docteur X ... relate les faits. Il dit ses appréhensions, ses angoisses de demeurer à jamais infirme du bras gauche et de ne pouvoir désormais exercer sa profession. Un peu d'émotion parcourt l'auditoire lorsque le chirurgien indique à la cour que la pierre à serpent, au pouvoir catalyseur et absorbant, qu'il plaça sur la piqûre, y adhéra pendant plus de trente-six heures, après quoi il la plaça dans du lait, pour en extraire le poison : c'est à la propriété étrange de cette pierre qu'il dut son salut. Un léger frisson parcourt maintenant la salle. Le docteur dit ce qu'il sait des « quimbois » et des poisons à la Martinique, plantes vénéneuses, venin de crapaud, poussières des cimetières et d'ossements, etc. Il cite des faits : le chauffeur d'un camion, en panne sur la grand'route, reçoit l'aide prétendue d'un individu avec lequel il avait eu un différend ; quelques heures plus tard son bras enflait démesurément, et peu après il décédait sans possibilité de secours. Tous les jours des faits analogues peuvent être constatés dans tous les hôpitaux, en particulier dans les communes. Ainsi voit-on parfois des gens intelligents, d'excellents ouvriers, perdre peu à peu leurs capacités, leur force, leur idéal. Ils deviennent amorphes, apathiques ; ils traînent plus ou moins longtemps, pour crever un jour comme des chiens. Autant de ces cas d'intoxication lente. Ils sont ruinés aussi bien moralement que physiologiquement. »

Le texte valait d'être cité en entier, car il définit, fort clairement, le climat en l'espèce.

Il en ressort qu'une des autorités médicales de l'île croit à l'efficacité des quimbois, accompagnés évidemment de conjurations, dont il n'est pas nommément parlé, mais que suggèrent avec une suffisante netteté les poussières de cimetières et le venin de crapaud. Contre ces quimbois, la science officielle est impuissante, et cette impuissance est encore mieux soulignée par l'exemple même de l'intéressé, dont aucune analyse ne permettait de définir l'empoisonnement, qu'aucun de ses confrères n'arrivait à soulager, et qui n'a été guéri que par la "pierre noire de Trinidad". D'après les renseignements complémentaires que j'ai pu avoir, cette pierre noire, de dimensions assez réduites, apparaît légère, plate et poreuse. Elle fut rapportée à la Martinique par la femme d'un gros propriétaire terrien, qui prétend l'avoir expérimentée avec succès sur de nombreux «travailleurs ". Mais, après usage, il est indispensable de la tremper dans du lait pour qu'elle se régénère tout en se " purgeant » du venin absorbé.

On parle également dans le nord de l'île d'une pierre qui aurait des qualités identiques, et qui ne serait autre chose qu'une sorte de gros calcul trouvé dans le corps d'un serpent tué. Le P. Labat connaissait, en ce qui, le concerne, une pierre verte, issue du «limon de l'Amazone » et souveraine contre les vertiges, 
de quelque principe qu'ils viennent, et les accidents de l'épilepsie, à condition de la porter à nu contre la peau ${ }^{1}$. Quoi qu'il en soit, la médecine ainsi comprise n'est pas très loin de la magie guérisseuse, et l'on comprend mieux comment et pourquoi les quimboiseurs font de si bonnes affaires à la Martinique.

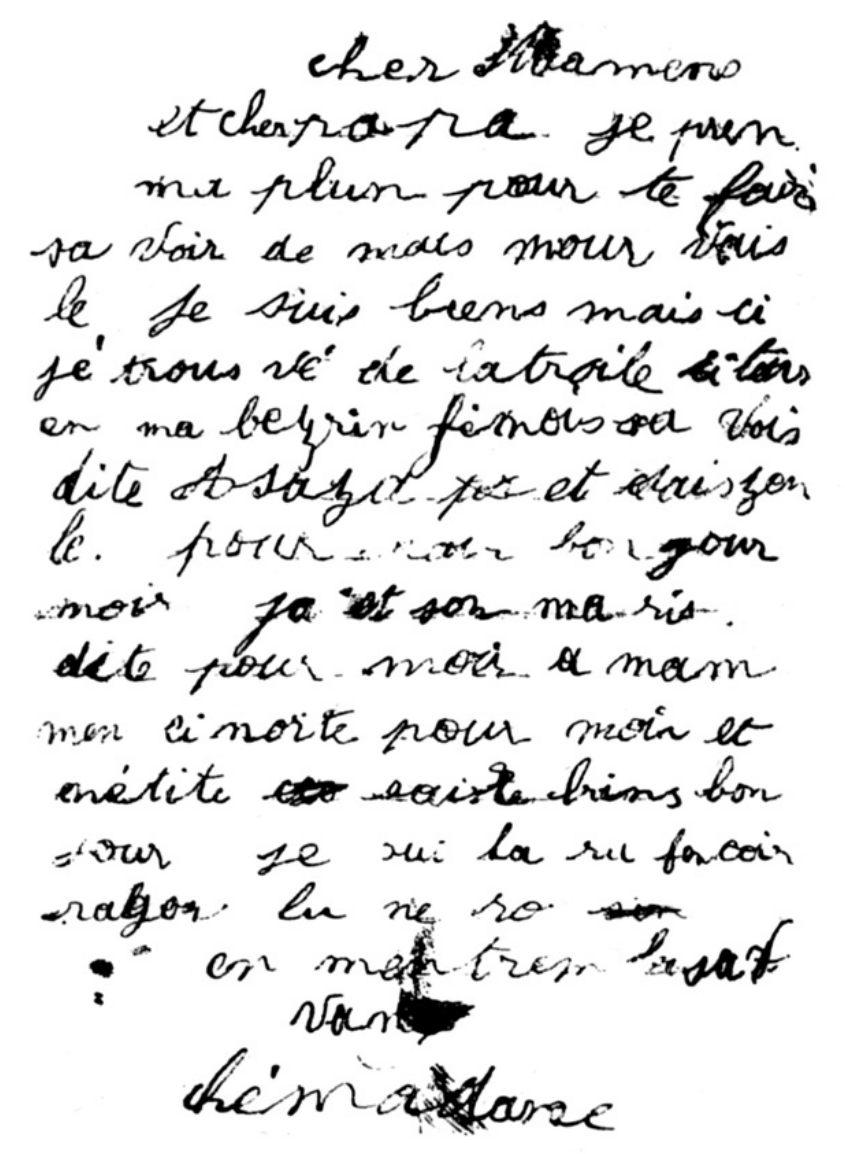

\section{LETTRE D'UNE JEUNE BONNE À SES PARENTS}

L'attitude des pharmaciens est tout aussi complexe. Il n'y a pas vingt ans existaient encore des officines tenues par des praticiens qui n'étaient jamais sortis de l'île et avaient subi un examen local. J'en ai connu quelques-uns qui en auraient remontré à plus d'un guérisseur avec leurs compositions. Il n'y a plus maintenant de pharmaciens que diplômés et ayant fait toutes leurs études en France. Beaucoup d'entre eux, cependant, consentent à exécuter les « ordonnances » des quimboiseurs, moins par esprit de lucre que pour rendre inoffensives les effroyables mixtures qu'on leur réclame. Ils délivrent donc avec beaucoup de sérieux de la poudre de perlimpinpin ou de méné vini, le bicarbonate de soude fait très bien l'affaire ; ou encore, par gouttelettes vendues fort cher, de la sueur de molocoye ${ }^{2}$, de la sueur " chattes au galop », ou encore de la «sueur en bas tété négresse ». En d'autres circonstances, on vient leur demander de la « cire de vieux mulet mâle », prise le matin, au coin de l'œil. Il y a également des essences « chassa, voltiger, ramener », etc. Un pharmacien

Labat, Éd. Duchartre, t. I, pp. 181 sq.

Molocoye : tortue de terre. 
du Sud se vit prier un jour de vendre une " plume taureau vert l'Amérique du Nord ». Il avait beau protester qu'il ne possédait pas cette denrée rare, le client insistait. En fin de compte, le praticien aperçut le vieux plumeau de sa femme. Il alla mystérieusement y arracher ce qu'on lui réclamait et le vendre vingt-cinq francs à l'intéressé, qui se confondit en remerciements. Un autre, dans des circonstances analogues, se vit réclamer de l'essence " de caca poule ». Qu'à cela ne tienne, un tour dans la cour, pour ramasser l'élément de base, un peu d'eau, une huile aromatique, et ainsi se vendit à très haut prix ce nouveau produit nécessaire à quelque quimbois.

On doit noter cependant qu'une transformation «scientiste » paraît s'être amorcée, car il n'est plus guère d'ordonnance de "Mentor » qui ne comporte des doses importantes de Dagénan, presque toujours écrit "Dargénan », et qu'on tend de plus en plus à considérer comme une panacée. Il en serait de même, m'a-t-on affirmé, dans de larges cantons d'Afrique. Il est évident qu'en de tels pays le docteur Knock eût encore plus rapidement fait fortune que dans le canton de Savoie qu'il avait choisi. En attendant, les pharmaciens font de bonnes affaires, encore que je ne croie nullement à la disparition rapide des vieilles pratiques traditionnelles que, pour ma part, j'estime capable de subsister longtemps encore. 


\section{CHAPITRE VI}

\section{Zombis, Engagés et Vaudou}

\section{I. - LA MAMAN DE L'EAU, LE LAPIN BLANC ET LE VOYAGEUR ATTARDÉ}

$\underline{\text { Retour à la table des matières }}$

L'extension même des quimbois à la Martinique suppose, aussi bien chez ceux qui les ordonnent que chez leurs patients, des croyances identiques à certaines forces surnaturelles et à leur intervention constante dans les affaires humaines. Il ne saurait être question d'essayer de réunir ces croyances, d'ailleurs contradictoires, en un corps de doctrine, pour en faire un exposé systématique, mais d'indiquer seulement quelques-unes des plus caractéristiques.

La «maman de l'eau », qui dispense ou refuse les pêches abondantes, apparaît à MM. Labrousse et Zobel comme la dernière des sirènes, à buste de femme et queue de poisson. Elle surgit la nuit près des " gommiers ${ }^{1}$ " et, si elle n'obtient pas ce qu'elle demande, « tantôt elle fait chavirer les embarcations sous le choc d'une lame, tantôt elle s'éloigne furieuse en secouant sa longue chevelure épaisse ». En fait, les pêcheurs «la satisfont toujours quand elle n'exige rien d'impossible, car sa beauté est surnaturelle, et son chant admirable les séduit à un tel point qu'ils se dépouilleraient avec joie en sa faveur de tout ce qu'ils possèdent, la suivant même où elle voudrait ${ }^{2}$ ".

Ces chants, les capitaines des navires à voile les copiaient jadis pour les apporter aux békés ou colons blancs, qui les transmettaient à leurs esclaves. Dans le Sud, dans la région du Diamant en particulier, on parle des sirènes comme d'une race disparue il y une génération à peu près ${ }^{3}$. La maman de l'eau existe toujours au contraire pour les pêcheurs de l'anse Couleuvre. C'est même une divinité redoutable, qui n'a d'ailleurs plus de queue de poisson, puisqu'on peut la rencontrer jusque sur les sentiers des mornes ou remontant vers les sources des rivières. Elle change en pierre ou en serpent, en les touchant simplement du doigt, ceux contre qui elle est irritée. C'est pourquoi on soutient dans l'extrême Nord, où ils abondent, qu'il faut bien se garder de tuer de prime

Canot pointu taillé dans le tronc d'un « gommier ».

Labrousse, pp. 77-78.

Zobel, cf. Jours immobiles. 
abord tous les serpents qu'on rencontre. On doit épargner, et c'est même une nécessité vitale, le serpent qu'on aperçoit lové, mais qui, au lieu de darder son regard, balance sa tête de droite à gauche et inversement comme dans un mouvement de dénégation. Il s'agit alors d'une "âme sœur » victime de la maman de l'eau, et qui vous supplie de passer votre chemin sans lui causer le moindre mal. Il ne reste qu'à obéir et à disparaître au plus vite, en faisant le signe de croix. Le lapin n'est pas seulement le héros d'un très grand nombre de contes où il joue un peu le rôle du renard de la tradition française. C'est aussi, et surtout lorsqu'il est blanc, une puissance malfaisante, qui prend plaisir à s'installer au milieu de la nuit à des points de passage obligés et à contraindre les voyageurs attardés à faire demi-tour. Qui essaierait de passer outre, dans un gué notamment, risquerait de s'égarer ou de se noyer.

Une autre aventure qu'on dit fréquente est celle du voyageur qui rencontre la nuit un petit enfant pleurant sur le bord de la route. Il s'arrête et l'interroge. L'enfant habite un peu plus loin et il a grand peur de rentrer seul. Le voyageur est saisi de pitié. Il offre à l'enfant de l'accompagner, mais celui-ci, au fur et à mesure qu'on avance grandit à vue d'œil et finit par atteindre une taille extraordinaire. Arrivé à destination, il exige d'être ramené à son point de départ et laisse son conducteur dans un piteux état.

\section{II. - ZOMBIS, MAISONS HANTÉES ET APPARITIONS}

Il est assez difficile de définir les zombis, terme générique, qui semble englober des types fort divers d'apparitions nocturnes et qui ne sont pas nécessairement hostiles. Dans l'ensemble, cependant, on les redoute fort et on leur prête de nombreux méfaits. Ce sont eux, par exemple, qui rendent inhabitables les maisons hantées ou même empêchent de les achever, comme telle construction depuis longtemps abandonnée sur la route de Saint-Pierre au Carbet. Il en existe aux abords mêmes du chef-lieu. Parfois un locataire plus brave, ou plus fanfaron que les autres essaie de s'y installer. Mais cela ne va pas sans inconvénients. Aucune bonne ne veut y coucher, ou même y demeurer la nuit tombée. Dans un cas type, raconté par les héros mêmes de l'aventure, les premiers jours se passèrent tranquillement jusqu'à un violent orage qui illumina tout le ciel. Au plus fort de la tempête, trois coups distincts furent frappés à la porte. Deux ou trois nuits plus tard, trois autres coups aussi nets. On vit ensuite se succéder à cadence accélérée, les accidents traditionnels en la matière : tiroirs s'ouvrant d'eux-mêmes, portes claquant par temps calme, au milieu de la nuit. Le locataire voulait tenir le coup. Sa femme et ses filles l'obligèrent à chercher une autre habitation.

La frayeur ainsi causée est à l'ordinaire des plus intenses. Telle institutrice préférait accomplir tous les matins un trajet de sept kilomètres par les mornes les plus abrupts du Sud plutôt que d'habiter le logement attenant à l'école, relativement confortable cependant, mais où elle se plaignait d'avoir chaque nuit les pieds tirés par de malicieux zombis. Peut-être, en y regardant de plus près, eût-on pu s'apercevoir que l'état de saleté du logement, les croûtes et bouteilles traînant par terre, suffisaient à justifier un infernal sabbat de rats, toujours nombreux à la Martinique. 
Les gendarmes eux-mêmes, bien qu'ils soient chargés de surveiller les quimboiseurs, n'ont pas toujours échappé à la contagion. Ceux du Marin, il y a quelque quarante ans, se plaignaient de coups régulièrement frappés à leur cuisine, lorsqu'ils étaient couchés. Ils finirent par mettre un veilleur en permanence, pour intimider le «zombi». Une nuit, cependant, le chef de brigade rentrait en toute hâte à son logement. Sa porte, en se refermant brutalement, fit claquer celle de la cuisine. C'était le zombi, et un verrou suffit pour rétablir la tranquillité.

De même un petit château, non loin de Schoelcher, abandonné depuis longtemps pour des causes analogues, finit par être réoccupé, à des conditions fort avantageuses, par un haut fonctionnaire, très décidé, avec l'aide de ses deux fils, à ne pas s'en laisser imposer. Une veille sérieuse organisée les premières semaines, une enquête discrète dans le voisinage, permirent de se rendre compte que les «zombis » n'étaient autres que des pêcheurs et contrebandiers, qui avaient trouvé l'endroit commode et faisaient ce qui était nécessaire pour chasser les intrus.

Les morts réapparaissent, sous diverses formes. Dans la région de Trinité, on affirme que, par les nuits noires, on aperçoit, sur les hauteurs entre le Gros Morne et Saint-Joseph, une vive lumière qui se déplace avec rapidité. Or, explique-t-on dans la région à qui veut l'entendre, il n'y a ni routes ni maisons sur ces crêtes, rien n'y atteste la présence de feux follets. Une tradition ancienne, à laquelle tout le monde croit, veut qu'il s'agisse du P. Labat, ou plutôt de son ombre, errant avec un fanal.

Plus nombreux encore sont les témoins d'enterrements fantastiques. Tel chauffeur du gouvernement me rapportait comment, une nuit, sur la route de Grand Rivière, à un passage encaissé, il avait été arrêté par un convoi funèbre, avec clergé, cierges et enfants de chœur, qui sortait d'une falaise pour aller se perdre dans l'autre.

De même, à la Petite Tracée, entre le Gros Morne et Trinité, une femme qui se trouvait dehors après minuit se heurta, sur le pont d'une petite rivière, à un cercueil entouré de bougies allumées, qui lui barrait la route. Chaque fois qu'elle avançait, le cercueil se mettait en travers. Elle tremblait de peur. Comme il lui fallait cependant rentrer chez elle, elle se souvint à temps du procédé traditionnel en l'espèce. Elle retroussa ses jupes par-dessus la tête et se lança en avant sans regarder le cercueil. Elle passa sans encombre et, quand elle osa enfin se retourner, le cercueil avait disparu. Un autre procédé également en usage consiste, comme nous l'avons déjà vu, à retirer ses vêtements et à les remettre à l'envers.

\section{III. - DÉMONS ET ENGAGÉS}

À côté des « zombis » et des esprits des morts, les démons jouent un rôle de premier ordre. Le diable et ses suppôts sont des personnages essentiels dans le folk-lore martiniquais. On les figure en chair et en os au moment du Carnaval où, vêtus de rouge, la tête couverte d'un masque cornu orné de petits miroirs, ils 
sont accompagnés par toute la marmaille de la ville. Mais Beljébut, Artarot, Lucifer, le Grand Ravocal, Aglamaton sont révérés dans l'île entière. Qui les offense sans raison peut s'attendre aux pires aventures. On leur attribue les disparitions mystérieuses, qu'on met toujours en rapport avec un pacte existant entre eux et la victime.

On appelle « engagés » ceux qui ont conclu un tel pacte, dont les conditions peuvent d'ailleurs varier dans certaines limites. Contre l'âme et souvent la dépouille corporelle de l'impétrant, le tout livrable à la mort, Beljébut, Artarot, le Grand Ravocal ou Aglamaton, s'engagent à le faire réussir dans une entreprise déterminée, particulièrement hasardeuse, soit même dans tout ce qu'il peut désirer, amour, honneurs et fortune.

Cela se pratique toujours, à ce qu'on raconte, et l'on entre en relations avec Lucifer, Beljébut ou tout autre démon par invocation apprise d'un autre engagé. La rencontre peut se faire chaque jour à midi, sous un grand fromager, ou sous les bambous, à minuit, le jour de la Noël. Lorsque les deux parties sont d'accord, l'engagé signe un parchemin de son sang et le remet au démon, qui le garde.

Pour les gens de la ville, d'après une tradition complémentaire, la signature du contrat s'opérerait sur un toit, et le parchemin serait alors conservé dans une bouteille placée goulot en bas sous l'arête du pignon. Si la bouteille vient à se briser accidentellement, l'« engagé » passe pour perdu et le Grand Diable peut se saisir de lui quand il le veut.

Il paraîtrait que ce genre de contrats continuerait à être pratiqué, et il serait difficile de recenser tous les «engagés » que la Martinique est censée renfermer. On explique ainsi bien des réussites. Tel gros personnage, que j'ai bien connu, aurait jadis rencontré, à minuit, sur un ponceau, tout près du Vauclin, une forme humaine qui lui aurait remis un petit sac en lui recommandant de ne jamais l'ouvrir s'il ne voulait mourir incontinent. L'apparition s'évanouit, le dernier mot à peine prononcé, mais le petit sac était là. On le conserve toujours, à ce qu'on m'a affirmé, au fond d'un coffre-fort triplement blindé, et qui passe pour recéler quelques-uns des plus grands secrets de l'histoire récente à la Martinique.

La tradition locale est naturellement toute remplie d'aventures de ce genre. L'habitation Delajus, au Carbet, est alimentée par un canal souterrain qui lui amène l'eau de la rivière en passant sous un morne élevé. Ce fut le diable qui le creusa, mais le propriétaire paya de sa vie le pacte secret et son corps fut emporté mystérieusement. Une légende analogue court sur M. de Périnelle, possesseur en son temps de la plus belle "habitation » de Saint-Pierre. Son cadavre aurait filé comme une flèche par une fenêtre, qu'on ne put jamais refermer depuis.

Il est également certain qu'il ne se passe pas d'année où l'on ne raconte que tel gros propriétaire, mort récemment, était un engagé dont le diable est venu enlever le corps, malgré la veillée, si bien qu'on a été obligé d'enterrer un tronc 
de bananier à sa place. Lorsque, par hasard, l'engagé est demeuré dans le cercueil, ce dernier se refuse à entrer au cimetière. Il recule et force les porteurs à le suivre, en leur donnant comme un choc. Il faut alors, si l'on ne veut pas que la scène se prolonge indéfiniment, avoir recours aux incantations de ceux qui « savent ». Parmi les procédés usités en cette occurrence, l'un consiste à frapper le cercueil récalcitrant à coups redoublés, un autre à le porter la tête et non les pieds en avant.

Nous avons déjà vu que, dans certains cas, le diable peut ne pas attendre la mort naturelle de sa proie. M. Thomarel a raconté l'histoire d'un ancien capitaine au cabotage qui, appelé par le « Tataoua », avec lequel il avait jadis conclu à un pacte, fut retenu une première fois par les jeunes gens de son bourg natal au moment où il allait se précipiter d'un îlet élevé dans la mer. Mais, quelques jours plus tard, profitant d'un moment d'inattention de ses surveillants, il entra dans l'eau et marcha jusqu'à ce que les vagues vinssent le recouvrir : son cadavre ne fut jamais retrouvé, malgré les recherches immédiatement entreprises.

Ne passe pas d'ailleurs qui veut un contrat avec le diable et, celui-ci une fois signé, il faut encore se faire accepter dans la confrérie présidée par Satan ou l'un de ses suppôts. L'initiation se fait à minuit, dans les grands bois. Des bruits effrayants accompagnent les premières incantations, et il n'est pas rare que le pauvre néophyte s'enfuie à toutes jambes. Il faut une âme impavide pour invoquer les puissances des ténèbres, et plus d'un, pour l'avoir fait inconsidérément, y a laissé la vie. Trois compères d'un bourg que je connais bien, et que nous appellerons P., C. et L., «bien d'accord voulurent tenter la chance de toujours gagner aux combats de coqs. Ils ne trouvèrent qu'une seule solution : avoir de la chair humaine à donner à leurs coqs. Ils résolurent de se rendre au cimetière du village pour exhumer le cadavre d'une femme enterrée la veille. P. était le chef de la bande. Bon clarinettiste, il passait aussi pour vaillant quimboiseur et sa case, avec son atmosphère fétide, ne manquait pas d'ossements humains. Les voilà donc, vers onze du soir, enjambant le mur du cimetière et se dirigeant vers la fosse fraîchement remuée. C. commence ses invocations : "Beljébut, Aglamaton et vous Lucifer, roi des Enfers, je vous ordonne de me remettre, par votre grand pouvoir, le cadavre de Sylvie, qui repose sous nos pieds. Dussent la terre et les cieux s'écrouler sur nos têtes, donnez-nous satisfaction totale pour l'œuvre que nous devons accomplir. » À ce moment, ont répété $C$. et L., la terre s'est mise à trembler avec une telle violence que nous fûmes projetés à plus de dix mètres de la fosse, et que nous prîmes nos jambes à nos cous pour repasser le mur et venir nous écraser contre la porte de la police municipale. P. les suivit quelques minutes après et, les trouvant sans parole, les porta chacun en sa demeure. Le plus lâche, L., mourut dans des transes épouvantables, trois jours après la scène. C. reprit connaissance vingt-quatre heures plus tard, et c'est lui qui, au bout de cinq jours, raconta l'odyssée. Il mourut sans avoir jamais recouvré complètement ses esprits. Quant à P., on ne le revit plus dans la commune, mais on apprit sa mort, quelque temps plus tard...» 


\section{IV. - LES « VOLANTS ». MÉFAITS DES ENGAGÉS}

Les vrais engagés ont une intrépidité plus grande. Ce sont eux qui, comme ce grand propriétaire dont nous avons déjà parlé, laissent toujours à leurs repas d'apparat une place inoccupée, servie comme les autres et réservée au démon. En échange, ils acquièrent de nombreuses facultés, dont celle de voler dans les ténèbres pour se rendre à leurs réunions, qui se tiennent de préférence dans la nuit du vendredi au samedi. On admet que les femmes montent beaucoup plus haut dans les airs que leurs confrères mâles, grâce à leurs seins dont elles se serviraient comme d'ailes. Une tradition plus détaillée, recueillie à la fois à Fort-de-France et dans le Nord, prétend que, pour obtenir ce résultat, les engagées montent au crépuscule au sommet d'une colline, où elles se mettent entièrement nues avant de s'élancer dans les airs.

La bande ailée se dirige vers le lieu convenu de réunion, où elle arrive vers minuit. Pour tout le nord de l'île, ce serait le « Bassin la Reine », qui se trouve quelque part dans le lit de la Capote. Après avoir rendu hommage au grand Diable qui préside à ces festivités, lesquelles seraient de véritables États Généraux de la sorcellerie martiniquaise, participants et participantes prennent un long bain dans la rivière, que suivent un copieux déjeuner et un bal qui dure jusque vers quatre heures du matin. Chacun alors se hâte de rentrer avant que sonne l'Angélus. On raconte de même, à Trinité, qu'une certaine nuit de juin Satan offre un grand banquet à tous ses amis et satellistes, sur un rocher situé, près de l'extrémité de la Caravelle, et que, pour cette raison, on appelle la Table du Diable. Malheur à l'imprudent qui se trouverait alors dans ces parages sans y avoir été invité.

D'après quelques récits, néanmoins, le métier de " volants » ne serait pas exempt de risques. Celui d'entre eux qui commettrait l'imprudence de passer au-dessus d'un calvaire s'abattrait immédiatement au sol. Un signe de croix fait opportunément aurait le même effet. Mais cela n'est admis que par une minorité. J'ai entendu parler de festins près d'un lieu consacré.

Une autre variante est celle des montures enchantées, dont l'exemple le plus typique qui m'ait été cité est l'histoire de Maquionna. C'était une vieille Africaine que la catastrophe de 1902 avait amenée à Sainte-Marie, et qui y vivait de la charité publique. « Un matin, grand émoi, on va dans la chambre où vivait Maquionna lui porter son café. Au grand ahurissement de la pourvoyeuse, Maquionna n'y était pas. L'alarme est donnée et déjà on craint que la malheureuse, en se rendant au rivage, n'ait été emportée par une vague. Après toutes les recherches, on entend un formidable «mi $l i$, mi $l i{ }^{1}$ " poussé par des marins pêcheurs qui se rendaient à leurs canots. "Oti, Oti li ? ${ }^{2}$ " Et tous les bras se tendaient vers l'îlet où se trouve la croix du Jubilé, et Maquionna assise au pied de cette croix. Dire l'ébahissement de la foule est

La voici, la voici.

Où est-elle, Où est-elle ? 
impossible, tant la chose ne pouvait s'expliquer. Et chacun de se poser la même question : comment a-t-elle pu faire pour y parvenir ? Allons chercher M. le Curé, seul il pourra la faire parler. En effet, aux cris de la population, le curé voulut bien voir de ses yeux si Maquionna était réellement sur l'îlet. Après que, du rivage, il l'eut aperçue, il demanda à la foule d'aller la chercher et de l'amener. En effet, on alla la prendre et on la déposa devant le curé qui n'en pouvait croire ses yeux. «Qui t'a conduite là ? lui demanda le curé. - Dépi à minuit, toutes ces mounes là vini chèché moin épi diable là. Diable là mettez nous toutes assous bels chuvals blancs épi nous prend la vole. Ces chuvals là volé épi nous assous l'îlet épi yos déposé nous en pied croix a et pi nous commencé fait la ronde. Quand y té quatre heures du matin, yos toutes pati quitté moin sans chuval, alors moin pas té peut descendre ${ }^{1}$. " Le curé, aussi hébété que la foule ne put rien dire: "Emmenez-là chez elle, la pauvre malheureuse !»

Je ne puis mettre en doute, une fois de plus, la sincérité de ce récit. Maquionna a réellement existé. Elle a été réellement retrouvée un beau matin sur l'îlet de Sainte-Marie, et il semble vraisemblable qu'elle ait été convaincue elle-même d'avoir participé au sabbat des sorciers.

\section{V. - MÉTAMORPHOSES DES « ENGAGÉS »}

Mais les engagés du degré supérieur ont des pouvoirs infiniment plus grands. Le principal est de se changer, une fois la nuit tombée, en animal de leur choix, et même, dans certains cas, prétend-on, en objet inanimé. L'opération se fait de la manière suivante. Les portes closes, le sorcier ou la sorcière se dépouille de tout vêtement et se verse sur le corps le contenu d'une petite fiole en prononçant les incantations appropriées et en se secouant de plus en plus fort, Après quelques minutes de cet exercice, la peau commence à se détacher, puis tombe tout d'une pièce. Elle est alors prestement ramassée et suspendue derrière la porte de la chambre. L'engagé, mué en fourmi, passe par le trou de la serrure ou la petite fente sous la porte. Une fois dehors, il prend la forme qui lui plaît et vaque à ses affaires. Troubler le sommeil des gens, effrayer les noctambules, monter les animaux domestiques, les porcs en particulier, les empêcher de grossir, sont les moindres de ses méfaits. Mais il faut, comme les volants ordinaires, qu'il soit rentré avant l'aube. Cela ne va pas sans incidents, à l'occasion. Les sorciers, lorsqu'ils agissent sous forme animale et que leur peau se trouve suspendue an clou derrière leur porte fermée, essaient toujours de défendre celle-ci par d'effroyables conjurations. Il arrive parfois, néanmoins, que des sorciers ennemis, particulièrement experts, arrivent à briser ces conjurations et à entrer dans la case pendant l'absence du propriétaire. L'un des plus mauvais tours qu'ils puissent jouer à celui-ci est de passer l'intérieur de sa peau au gros sel. Lorsque l'intéressé rentre à potron-

À minuit tous ces gens-là vinrent me chercher accompagnés du diable. Le diable nous plaça tous sur de beaux chevaux blancs et nous prîmes notre vol. Les chevaux volèrent avec nous jusqu'à l'îlet et nous déposèrent au pied de la croix. Et puis nous commençâmes à faire la ronde. À quatre heures du matin, ils partirent tous sans me laisser de cheval, et alors il me fut impossible de descendre. 
minet et s'empresse de réendosser sa défroque humaine, il endure d'horribles souffrances et pousse des hurlements qui ameutent le voisinage.

Cela peut aller plus loin encore. Il m'a été raconté qu'à Basse-Pointe, une " engagée » de couleur était parvenue à entrer dans l'intimité d'une Blanche créole, qu'elle initia successivement au vol à voile, puis aux transmutations nocturnes. La confiance la plus absolue semblait régner entre les deux femmes. Un soir de sabbat, la première se plaignit amèrement d'un malaise qui l'empêchait de se rendre à la réunion habituelle. Elle pria donc son amie, la Blanche, de vouloir bien l'excuser. L'autre sans méfiance, se dépouilla de sa peau suivant le rite et partit ; c'était ce que voulait la femme de couleur, qui se dénude aussitôt, se dépouille à son tour et prend l'enveloppe de l'absente en mettant la sienne à sa place. C'était un moyen peu banal de « passer la ligne ». La créole, à son retour, s'introduisit sans méfiance dans la défroque suspendue au clou, et s'aperçut trop tard qu'elle n'était plus d'une blancheur immaculée. Il en résulta, comme on pense, maintes disputes et contestations.

L'histoire aurait été répandue par un gamin d'une quinzaine d'années qui s'était vanté auprès de ses camarades, dont l'un au moins fut mon élève, de connaître tous les secrets des notables de la commune. On ajoutait même qu'il avait fait retenir le curé au presbytère par un de ses complices sous divers prétextes, pendant que, revêtu d'une vieille soutane, il confessait, à sa façon, les dévotes de l'endroit.

Sous leur forme animale, les engagés peuvent d'ailleurs commettre les pires méfaits. M. Labrousse a conté l'histoire de l'araignée buveuse de sang ${ }^{1}$. Tous les matins, à son réveil, une femme trouvait des taches de sang sur ses draps, tandis qu'elle ressentait comme une piqûre à l'épaule. La proche voyante, consultée, lui apprit que c'était une de ses voisines qui se changeait ainsi en bête pour l'épuiser peu à peu. Dans d'autres cas, l'engagé se transforme en vermine grouillante pour infester les boucauts de morue ou de viande salée de l'épicerie voisine. Ou, mué en serpent, il pique à mort ses adversaires pour avoir la joie d'assister à leur enterrement, à moins que, devenu mouton, il n'entraîne un troupeau entier vers les précipices de la montagne.

En fait, les engagés passent pour être nombreux et pour l'avoir toujours été. Le Carbet garde par exemple le souvenir de $\mathrm{M}^{\text {me }}$ Roy, qui montait à reculons, sur un cheval fougueux, le morne qui porte son nom. À Case-Pilote, on parle encore de $\mathbf{M}^{\text {me }}$ de Saint-Amour, qui ne fréquentait personne, haïssait le voisinage et ne se plaisait qu'à faire le mal. Quand elle rencontrait un bébé, elle trouvait moyen d'introduire un doigt dans la petite bouche pour tâter les dents, et l'enfant mourait le lendemain. Un épicier ouvrait-il un baril de viande salée en sa présence, elle en réclamait le plus beau morceau, et si on avait le front de le lui refuser, le baril, en quelques heures, grouillait de vers et il fallait jeter son contenu. Accusée des pires méfaits, elle devait finir sur l'échafaud. Le vent ayant emporté son foulard comme elle y montait, elle le réclama, car elle

Labrousse, Deux vieilles terres françaises, p. 43. 
craignait de prendre froid. De fait, après sa mort on la revit dans tous les lieux où elle avait vécu. Sa maison tomba de vétusté, car personne n'osait y habiter. Un cavalier assura l'avoir aperçue, sans aucun vêtement, et les cheveux en flammes, en train de laver dans la rivière de Bellefontaine. Ce brave avait tourné bride sans autre explication. Le soir, aux veillées, on la voyait parfois traverser l'assemblée, aller d'une pièce à l'autre. La nuit également elle arrêtait les passants et, pendant longtemps, à Case-Pilote, on n'osa voyager tard, de peur de la rencontrer.

J'ai quelques raisons de connaître certain directeur d'établissement scolaire qui passa pour être un très authentique engagé aux yeux d'une partie de ses subordonnés. On l'avait reconnu sous la forme classique d'un chien noir, en faisant regarder l'animal par une femme renversée, la tête entre les jambes. Au demeurant, le personnage était suspect depuis longtemps et telles fouilles qu'il avait entreprises sur deux ou trois points de la colonie ne pouvaient s'expliquer que par la recherche d'un trésor avec l'aide de Beljébut, Artarot ou Aglamaton. On le voyait donc rôder tous les soirs sous sa forme seconde autour des cuisines, et cette surveillance constante était fort gênante. Aussi essaya-t-on sur lui tous les procédés classiques d'exorcisme. Il y résista brillamment. Il passa pour un "Mentor », un fort entre les forts, et n'en fut pas médiocrement fier. Les résultats ne manquèrent d'ailleurs pas de pittoresque. Un pauvre chien des rues pelé, galeux et tondu devint en quelques semaines gras et luisant à souhait. Il circulait librement dans la maison et nul ne contestait les beaux morceaux au " patron » ainsi déguisé. Un garçon " faisant le mur », un beau soir, trouva l'animal installé sur son arrière-train, qui le regardait de ses yeux luisants. Il en tomba de frayeur à la renverse et faillit se rompre le cou : il en fut quitte, heureusement, pour quelques jours d'hôpital.

À la vérité, l'imagination populaire travaille de manière constante suivant l'occasion du moment. On a aperçu, par exemple, un «ti (petit) veau » attaché à côté d'une vache. On lui a trouvé un drôle d'air, un front presque humain, c'est la partie la plus reconnaissable en principe, car elle garde l'empreinte du baptême. Par une sorte de symbolisme immédiat et instinctif on s'imagine voir dans le «ti veau » en question l'enfant né hors mariage d'une femme que son amant avait fort maltraitée.

\section{VI. - LES « DÉSENGAGEMENTS »}

Peut-on, cependant, mettre à la raison les «gens gagés » ou même les arracher à l'empire du démon ? Cela dépend de qui entreprend l'affaire, et des conditions dans lesquelles elle est entreprise. Le premier point est de s'assurer qu'on est bien en face d'un suppôt de Satan, et là-dessus les avis diffèrent. Suivant les uns, rien, au premier abord, ne distingue la nuit un animal " gagé » d'un autre. On ne peut le reconnaître, comme il a déjà été dit, qu'en se renversant pour le regarder et en se plaçant la tête entre les jambes. Une autre tradition prétend au contraire que, même devenu chien, lapin, serpent ou cheval, l'engagé conserve une partie de son visage d'homme. Il est naturellement invulnérable aux procédés ordinaires. On parle dans la Martinique entière du cheval blanc à trois pattes que peu ont vu, mais dont 
beaucoup ont entendu l'infernal et caractéristique galop. Il ne faut pas essayer de l'arrêter ou de tirer sur lui. La balle, dans ce dernier cas, ne manquerait pas de rebondir sur l'assaillant. Si extraordinaire que cela puisse paraître, il est des « Majors » ou des « Mentors » qui finissent par se croire eux-mêmes à peu près invulnérables, et s'offrent par bravade à essuyer le feu d'un adversaire. Cela a réussi plus d'une fois, l'autre tremblant de peur et visant mal. Il est arrivé cependant que l'affaire tournât mal pour le fanfaron. On raconte aussi des histoires de duels où l'un des participants, soigné avec les onguents et conjurations d'ordinaire réservés aux coqs de combat, vit l'épée de son adversaire plier et rompre sur sa peau, devenue plus dure que le cuir d'un rhinocéros.

Mais il n'est pas de règle sans exception. Il existe des "Forts » plus puissants que les engagés et qui savent préparer les armes destinées à les blesser et aussi à les désengager. Il existerait des spécialistes de ce genre d'opérations à la montagne du Vauclin, à la Glottin et au Morne des Esses.

On connaît d'ailleurs de nombreuses variantes sur ce thème. Dans le cas de l'araignée buveuse de sang, la victime avait pu se venger elle-même, et casser trois pattes à son ennemie d'un coup de serviette bien appliqué. Le lendemain, l'engagée apparaissait avec la main droite emmaillotée et trois doigts en moins.

On se sert le plus souvent d'un fleuret démoucheté passé à l'eau bénite et sur lequel les conjurations convenables ont été prononcées. Le principe est alors que toute blessure faite à l'animal doit se retrouver sur l'homme et l'immobiliser les jours suivants, sans qu'il consente à fournir des explications plausibles. On vise de préférence l'attache des membres ou le front entre les deux yeux. C'est le remède qui avait été essayé sur l'universitaire nocturnement transmué en chien. On l'avait piqué à l'arrière-train. Il eût dû rester au lit le lendemain ou tout au moins boiter fortement. C'est parce que rien de tout cela n'arriva qu'il se fit, sans le vouloir ni s'en sans douter, une réputation de très vaillant quimboiseur.

On obtient également de bons résultats en flagellant l'engagé sous sa forme animale avec des branches de cerisier (pays) ${ }^{1}$, d'acacia ou de bois moudongue $^{2}$. Les coups donnés avec ce dernier passent pour infliger une douleur horrible et particulièrement longue à s'atténuer.

Il est généralement admis que l'engagé «piqué » dans les règles ou « flagellé » doit reprendre plus ou moins vite, sinon instantanément, la forme humaine. Il le fait obligatoirement avant de mourir. Le « séancier » qui prépare un " désengagement» prévient toujours la personne qui le consulte des suites probables de l'opération, et lui demande si elle aura le courage de blesser ou de tuer volontairement son adversaire sous la forme d'un chien, d'un chat, ou d'un rat. " Même si c'est votre mère, vous piquerez ? " L'heure la plus favorable

Cerisier pays : Malpighia.

Bois moudongue : probablement Clusia Rosea L. 
pour ce genre de travail est le vendredi à minuit. La bête menacée, et sentant déjà la pointe du fer, retrouve parfois une voix humaine pour supplier qu'on l'épargne. «C'est moi, un tel, votre parent, votre ami. Ne me tuez pas. » Le lendemain ou le surlendemain, on apprend dans le quartier qu'il a été blessé plus ou moins grièvement. S'il survit, il ne peut plus se métamorphoser, perd du coup toute malfaisance et se réconcilie souvent avec l'Église. S'il est touché mortellement, le «désengagement » le contraint à confesser publiquement ses méfaits avant de rendre l'âme. Si étrange encore que cela puisse paraître, il y a eu plusieurs de ces confessions au cours des dernières années. La famille s'efforce alors de les arrêter au plus vite et même, comme le cas s'est produit, en offrant au malade un bouillon destiné à hâter son passage dans l'autre monde. De telles pratiques témoignent à tout le moins de la profondeur de cette croyance aux engagés et de la grande suggestibilité d'une partie de la population.

Il peut arriver d'ailleurs qu'on se trompe sur l'identité «animale » de l'engagé. Récemment, dans un bourg que je connais bien, des collègues et sa famille étaient persuadés qu'une jeune fonctionnaire, fort avenante d'ailleurs, pratiquait la transmutation nocturne, et, tous les goûts étant dans la nature, qu'elle se plaisait à patauger, sous l'aspect d'une cane au beau plumage, dans toutes les mares de l'endroit. On résolut de la sauver. Le volatile fut délicatement " piqué » à l'aile, capturé et porté dans son lit présumé, tandis que la famille anxieuse se pressait dans la chambre pour assister au retour à la figure humaine. L'intéressée, qui, à d'autres fins, était allée faire une petite sortie nocturne, tomba en rentrant sur ce remue-ménage et n'en fut pas autrement flattée.

Rien cependant, dans la vie courante, ne distingue un engagé d'un autre homme. Je n'ai trouvé qu'un ou deux exemples de la croyance opposée. Lors de l'établissement, par exemple, de l'école laïque, en 1882, quelques curés avaient fulminé contre les nouveaux établissements et leurs maîtres. Une femme de Saint-Joseph interrogea son fils après la première classe. "Comment est-ce fait, un laïc ? Porte-t-il des cornes et une queue ? - Non, maman, seulement il n'a pas de doigts aux mains et ses pieds sont crochus. » Le hasard avait voulu que l'instituteur nommé à ce poste fût infirme de la main droite, ce qui ne l'empêchait d'ailleurs pas d'écrire.

On admet en revanche qu'un engagé qui ne s'est pas réconcilié avec 1'Église avant de mourir chasse le curé au milieu d'un extraordinaire flot d'imprécations. Il expire ensuite la face tournée vers le sol, et on l'enterre, si le diable n'a pas pris possession du cadavre, sans « levée de corps » ni « croix portée ».

\section{VII. - LE VAUDOU}

Il est cependant un culte, celui du Vaudou, qui a jadis été pratiqué dans toutes les Antilles. On peut se demander dans quelle mesure il en reste des vestiges à la Martinique. On connaît la définition qu'en donne Moreau de SaintMéry : Vaudou signifierait un être tout-puissant et surnaturel, dont dépend la vie à la surface du globe. Il se manifesterait sous la forme d'un serpent non 
venimeux. Son culte est rendu sous l'autorité d'un grand prêtre et d'une grande prêtresse, le « papa-loi » et la "maman-loi », appelés quelquefois aussi le roi et la reine. Les réunions, secrètes et nocturnes, ouvertes aux seuls initiés, débutent par l'adoration du Vaudou. Il existait à Haïti, vers 1880, "deux sectes de fidèles pratiquant le vaudou: ceux qui adorent uniquement dans leurs cérémonies le sang et la chair des coqs blancs et des chèvres sans tache, et ceux qui, pour leurs dévotions, non seulement se servent des objets qui précèdent, mais, dans les grandes occasions, ont recours à la chair et au sang des « chèvres sans cornes ", c'est-à-dire des victimes humaines ${ }^{1}$ ".

M.-R. Fortuné a cité pour la Guadeloupe ${ }^{2}$ un exemple récent, où une victime humaine faillit être sacrifiée pour la recherche d'un trésor. Elle parvint à s'échapper in extremis. L'affaire, ayant eu son dénouement en cours d'assises, fut alors connue dans ses détails. En ce qui concerne la Martinique, on peut admettre que ce genre de pratiques n'existe plus. La dernière manifestation que j'en connaisse est le fameux « quimbois des trois curés », déjà cité, qui devait débarrasser l'île de tous les blancs.

Il semble pourtant qu'il subsiste quelques survivances sporadiques, mais heureusement très atténuées, de telles pratiques, comme en témoigne l'article suivant de La Paix : " On nous rapporte de Sainte-Luce, y est-il écrit ${ }^{3}$, qu'un bébé de dix-huit mois, qui avait été enlevé, a été retrouvé dans les bois de l'habitation Volcar par une brave femme, alertée par les cris de l'enfant.

«Le pauvre petit était tout ensanglanté par de très nombreuses éraflures qu'il portait sur tout le corps.

« Le bruit court que c'est l'œuvre diabolique d'un jeune sorcier bien connu dans cette commune.

« De semblables faits nous avaient été signalés dernièrement en d'autres quartiers. Que les mères de famille veillent bien sur leurs enfants, et nous espérons que l'Administration saura prendre les mesures qui s'imposent pour empêcher le retour de pareils procédés. »

Il est vraisemblable également que certains sacrifices d'animaux, de coqs ou poules de couleur blanche ou noire en particulier, ne sont pas sans rapport avec les rites du Vaudou, encore qu'on en retrouve de très nombreux exemples ailleurs. On peut admettre de même que ces morceaux d'étoffe rouge, brune ou noire cousus à l'intérieur de la chemise et en contact direct avec la peau, dont nous avons déjà parlé, correspondent à des confréries dont les réunions se font à l'ordinaire la nuit, à la lueur des torches et plus souvent d'un grand feu. Il en brûle souvent, dans la montagne du Vauclin, vers le Chamflore, le Carabin et le Morne des Esses, qui ne sont ni des feux de charbonniers, ni des incendies de

Sir Spencer, Saint John Haïti ou la République noire, Londres, 1881, cité par R. Fortuné, Revue Guadeloupéenne, décembre 1945, p. 38.

R. Fortuné, Revue Guadeloupéenne, p. 41 (janvier-février 1946).

La Paix, 5 octobre 1946. 
cannes, ni des signaux de contrebandiers. J'ai de nombreux témoignages concordants qui les attribuent à des assemblées placées sous le signe du mystère. "Un soir, écrit un de mes correspondants, nous revenions d'un mariage. Il était exactement minuit : un temps superbe, mais sans clair de lune. Nous étions six... Arrivés à un tournant de la route... Nous nous arrêtons tous en même temps, comme mus par un même ressort et nous avons devant nous un spectacle qui nous glace d'épouvante. À cinq cents mètres de nous, dans la savane, un véritable bal de feu bat son plein. Nous voyons distinctement deux rangées de flambeaux se faisant face, comme les danseurs d'un ballet venus se rencontrer en cadence au milieu de la savane, tournoyer pendant douze secondes et se retirer en ordre, comme obéissant à un signal. Nous avons contemplé ce spectacle, qui nous atterrait pourtant et nous clouait sur place. Le ballet recommençait à intervalles réguliers, et les feux semblaient s'embrasser, se soulever, s'étreindre puis se repousser, pour se regrouper et recommencer le ballet. Nous fûmes bien obligés de nous ressaisir et de rentrer chez nous, ne sachant comment expliquer ce phénomène, qui ne pouvait être attribué aux feux follets, l'endroit n'ayant jamais été l'asile des morts, encore moins aux engagées, que l'histoire n'a jamais fait apparaître aussi nombreuses dans leurs réunions au pied des fromagers géants : l'endroit en est totalement dépourvu. Quand, le lendemain nous nous sommes rendus sur les lieux, nous n'avons rien vu d'anormal... » D'autres m'ont parlé de la ronde des lutins autour d'un feu rouge, qu'on ne peut apercevoir qu'une seule fois dans sa vie.

\section{VIII. - ORIGINES DE LA MAGIE ACTUELLEMENT PRATIQUÉE À LA MARTINIQUE}

Le problème du Vaudou et de ses survivances éventuelles pose sous sa forme particulière, celui des origines qu'on peut attribuer à la magie, aux « quimbois » et aux croyances irrationnelles qui les accompagnent. Il ne saurait être question, dans le cadre de cette brève étude, d'élucider les diverses sources de cet ensemble, - il y faudrait des années de travaux comparatifs, - mais d'indiquer seulement quelques directions de recherches, quelques hypothèses de travail, d'après les faits connus.

Il est un premier point à mettre en lumière, le folk-lore martiniquais n'est pas spécifiquement différent de celui des îles voisines, et rentre dans un ensemble plus vaste qui paraît s'étendre de la Guyane aux Petites Antilles et à Haïti, où il commence à être bien étudié, et même dans une mesure plus restreinte, jusqu'à la Louisiane et la Nouvelle-Orléans. À cette uniformité relative correspond la réputation, déjà mentionnée dans toutes les Petites Antilles, des quimboiseurs de la Dominique et de Sainte-Lucie, voire de Trinidad et de la Barbade. On en connaît qui voyagent d'île en île pour exercer leur profession.

D'autre part, à la Martinique même, les premiers colons et leurs esclaves noirs ont été en relations beaucoup plus intimes qu'on ne l'admet communément avec les populations indiennes. Jusqu'en 1720, les recensements 
permettent de suivre des groupes de Caraïbes dispersés dans les diverses habitations. Il est incontestable qu'ils ont transmis aux nouveaux arrivés un certain nombre de techniques encore en usage, pour la vannerie en particulier on fabrique toujours des paniers dits caraïbes, analogues à ceux qu'ont pu connaître les PP. Dutertre et Labat - la poterie et la pêche. Il est vraisemblable, dans ces conditions, qu'ils ont aussi transmis un certain nombre de leurs croyances. Il est probable, par exemple, qu'on peut leur attribuer l'exceptionnelle importance du lapin dans la tradition locale. C'est une histoire largement répandue en effet à travers toute l'Amérique, que celle du héros plus ou moins civilisateur qui est en même temps un fourbe et un tricheur de première force. Il s'agit « du corbeau sur la côte du Pacifique Nord, du Coyote dans les montagnes de l'Ouest et du lapin dans la région des forêts orientales », la plus rapprochée par conséquent de la zone caraïbe. Ce qu'il y a de particulier dans le caractère de ces personnages, c'est que, s'ils apportent d'un côté l'ordre civilisateur, «ils s'abaissent par ailleurs aux tours les plus vils qu'on puisse concevoir, ou passent fréquemment pour les plus naïves des dupes ». C'est un « des traits les plus caractéristiques de la mythologie du Nouveau Monde ${ }^{1}$ ». Ainsi le « compé Lapin » de la tradition créole a-t-il de nobles ancêtres, dont il s'efforce de ne pas se montrer trop indigne.

Un troisième trait caractéristique de la magie contemporaine à la Martinique, c'est l'usage qui y est fait de tout ce qui vient du cimetière, de la chair ou des ossements des morts. Au témoignage du P. Breton, pour parler au « diable » (c'est le terme qu'il emploie), il faut l'intercession d'un « boyé », d'autres disent un " piaie », et, ce terme est encore en usage à la Guadeloupe. Cependant, "plusieurs n'en ont pas besoin », car, "fouillant la terre où ils savent qu'il y a quelqu'un d'enterré, ils en tirent des os ou du poil du trépassé, le mettent dans une calebasse qu'ils bouchent de coton, et les diables leur parlent par ces os ou cheveux...».

«Voire, avec ces os ils font toutes sortes de charmes pour se venger de leurs ennemis. Les uns prennent le reste du repas de leur ennemi et le mettent auprès de ces os de mort que nous avons dits, les ensorcellent, les autres y mettent du sang de leur plaie ${ }^{2}$. »

Les cas de possession abondent d'ailleurs, car « les diables entrent même dans les corps des hommes pour parler par leur bouche ${ }^{3}$ ». " Quand les malades sont guéris, ajoute le P. Breton, ils font un festin au Boïé, qui appelle aussi quelquefois son diable à la fête. Et le Boïé et le Maître Gonin, s'il y est, noircissent le malade de genipa pour conclusion de la farce. » Rappelons simplement que dans certains repas, nous l'avons déjà souligné, on continue à mettre le couvert du diable, convive invisible, mais présent et servi au même litre que les autres.

Clark Wissler, The American Indian, p. 212.

P. R. Breton, Relation de l'île de la Guadeloupe, Éd. Rennard, p. 52.

P. R. Breton, ibid., p. 51. 
Les éléments d'origine africaine sont nombreux et évidents. On peut y comprendre tout ce qui, de près ou de loin, se rapporte au Vaudou et à ses formes même les plus atténuées, les seules qui aient chance de subsister présentement à la Martinique. Beaucoup d'histoires d'engagés, avec leurs transmutations multiples sous forme animale, sont aussi proches de la tradition noire que du loup-garou de nos provinces. Il est certain également qu'une large partie des récits faits aux veillées ont une origine analogue. "Compé » Éléphant, Compé Lion ou Crocodile n'existent pas à la Martinique. "Compé » Tigre est là pour rappeler les rapports nombreux avec l'Inde et l'Extrême-Orient au cours du $\mathrm{XIX}^{\mathrm{e}}$ siècle. Les Chinois ont apporté leurs recettes à base d'holoturies, leur «trépang ». Les descendants des "coolies » hindous amenés depuis 1852 se sont convertis au catholicisme. Cela ne les empêche pas de continuer à pratiquer leurs anciens cultes. À l'occasion de la fête de Siva, ils élisent un grand prêtre parmi eux, dans certains coins du Nord. Les cérémonies durent neuf jours. Les étrangers peuvent y assister pendant huit. Le neuvième on les renvoie, et d'aucuns prétendent qu'il y a alors orgie sacrée.

Le sacrifice du mouton continue à se faire de manière assez courante. " Conduit sur le parvis du temple, l'animal est enivré d'encens. Un jeune Indien (il faut entendre Hindou), de vie irréprochable, d'un coup de coutelas tranche la tête de l'animal. Cette cérémonie accomplie au son des tambours s’achève au milieu des cris de joie et des acclamations frénétiques. Parfois, le sacrificateur monte et se promène sans danger sur la lame d'un coutelas aiguisé ${ }^{1}$. »

Il s'agit dans ce cas de cérémonies exceptionnelles et localisées dans un groupe d'importation récente. Rites et pratiques de la magie martiniquaise se couvrent à l'ordinaire d'apparences chrétiennes. Cela se conçoit facilement. Les premiers évangélistes des îles n'ont jamais essayé de mettre en doute la puissance des sorciers. Ils se sont contentés de la rapporter au démon et à ses suppôts. Le P. Labat, fort explicite à cet égard, raconte de nombreux prodiges dont lui-même ou certains de ses confrères, dont il cite les noms, auraient été les témoins, et cela avec un luxe remarquable de détails et de précisions. C'est un enfant capable de faire pleuvoir par ciel bleu, avec l'aide de trois oranges ; un sorcier obtenant des réponses claires et pertinentes d'une idole; une négresse transformant par vengeance en parchemin desséché le cœur et les entrailles de ses ennemis. "Il est constant, écrit-il des Caraïbes, qu'ils sont souvent maltraités par le diable. Cela n'est point arrivé pendant que j'étais dans leurs carbets, et c'est une chose avérée que la présence d'un chrétien les délivre des persécutions de l'esprit malin. Ils ont encore un remède assuré contre ses violences, quand un chrétien ne peut pas demeurer avec eux dans le carbet, c'est de le prier de faire une croix de bois et de la placer en quelque endroit de la maison ${ }^{2}$. »

Normands, Bretons ou gens d'Aquitaine ont naturellement apporté avec eux les croyances de leur pays d'origine : cercueils rencontrés la nuit entourés de

Monographie inédite de Basse-Pointe, 1935.

Labat, Éd. Duchartre, II, p. 134. 
bougies allumées, enterrements mystérieux sortant d'une falaise et absorbés par l'autre, saints protecteurs non seulement de l'âme et du corps, mais aussi des champs et des biens. Qu'il y ait, tant de petites chapelles à la Martinique, de niches ornées d'une Vierge devant laquelle brûle une lumière toujours entretenue, est évidemment l'indice d'une piété très profonde, en même temps qu'une protection assurée contre la foudre qui ne saurait tomber, assure-t-on, dans un rayon de douze à quinze mètres, Il faut tenir compte encore d'un vieux fond de magie universelle. Au total, s'il me fallait essayer de définir l'état actuel de la sorcellerie et de la magie à la Martinique, j'admettrais assez volontiers qu'elles sont pour les deux tiers environ d'origine européenne, un tiers viendrait d'Afrique, tandis que se maintiendraient quelques survivances indiennes. Mais le trait dominant en est de manière incontestable un syncrétisme toujours actif.

Toutes proportions gardées, et malgré la prédominance extérieurement absolue du catholicisme, le milieu martiniquais a réagi et continue de réagir à la façon du paganisme antique. Il peut y avoir des forces, sinon des dieux inconnus. Pourquoi se refuser à des rites nouveaux qui n'excluent en aucune manière les anciens, et dont on peut, espérer une action supplémentaire sur le monde invisible?

\section{IX. - SYNCRÉTISME ET « CLIMAT MAGIQUE »}

Aussi se montre-t-on fort disposé, dans ce domaine, à accueillir les innovations venues d'ailleurs. Nous avons déjà marqué comment les quimboiseurs expliquaient leurs échecs par l'intervention d'un confrère plus puissant venu d'une île voisine. Depuis vingt-cinq ans, on assiste à un élargissement de la magie martiniquaise sous l'influence de livres spécialisés édités à l'extérieur, comme le "Grand » et le " Petit Albert» ou le recueil du "pseudo abbé Julio». Les diseurs de bonne aventure à prétentions scientifiques trouvent toujours des clients, et plus d'une jeune fille, pour avoir l'illusion d'un beau mariage, leur verse chaque mois une dîme appréciable. D'autres s'adonnent à l'astrologie, et il n'est pas jusqu'à tel honorable membre du corps médical qui n'ait éprouvé le besoin de faire tirer l'horoscope d'un de ses enfants une demi-heure après sa naissance, comme de faire assurer par les étoiles les plus importants de ses diagnostics. Il fut également un bureau officiel où, plusieurs années durant, on s'occupa beaucoup plus des signes du zodiaque et de leurs rapports avec l'humanité souffrante que du courrier administratif.

Il y a ainsi comme un " climat magique » qui se maintient dans l'île entière, et donne parfois une tonalité assez curieuse à la vie qu'on y mène. Il faut reconnaître que le décor s'y prête. L'homme est écrasé par l'ardeur trop verticale du soleil de midi. C'est l'heure des pactes avec Satan et celle où apparaît, sur les routes poudreuses, l'aguichante silhouette de la " guiablesse », qui entraîne ses galants vers les précipices de la montagne. Rien n'est plus impressionnant encore, plus physiquement angoissant que la tombée de la nuit en pleine forêt, dans le vacarme assourdissant des «cabris bois" et les mouvantes phosphorescences des premières lucioles. Un rai de lune à travers 
les bananiers simule un bras menaçant qui s'avance, ombres et lumières alternées dessinent un être étrange qui barre le passage.

Tout concourt alors à renforcer l'impression première, y compris les mauvais plaisants qui promènent des calebasses allumées pour faire croire aux esprits, mais avec une sorte de mauvaise conscience qui les amène parfois à se prendre eux-mêmes à leur propre jeu. Naguère encore, il n'était pas rare qu'un cavalier rentrant chez lui un soir de fête, une fois la nuit tombée, rencontrât des hommes couchés tout de leur long et contrefaisant les morts. Puis, leur victime à bonne portée, ils se dressaient en hurlant, saisissaient les rênes et faisaient faire volte-face au cheval. Cela faisait un nouveau tour porté par tous au compte des « zombis ».

Au début de 1950 la Martinique entière s'est intéressée à « l'Homme sans tête », auquel le "groupe folklorique martiniquais » vient de consacrer une de ses «biguines ». L'« Homme sans tête » existe réellement. De l'enquête à laquelle un de mes amis a bien voulu se livrer, il s'agit d'un joyeux paillard, qui, pour ne pas être reconnu dans son morne lorsqu'il allait rejoindre ses bonnes amies, avait inventé de sortir la face masquée par un grand sac, que maintenait raide une planchette posée sur le crâne. Dans la nuit opaque, cela formait une apparition effrayante devant laquelle tout le monde prenait la fuite, jusqu'au jour où quelques citoyens moins crédules voulurent en avoir le cœur net et découvrirent la supercherie. Beaucoup cependant continuent à craindre le prétendu monstre et n'osent plus sortir la nuit...

Il n'est pas, comme nous l'avons vu, jusqu'aux applications de la science qui ne s'intègrent en pareil cas dans la magie : une brave femme du quartier Belley m'expédia jadis une longue lettre dont on trouvera les passages essentiels aux annexes, pour se plaindre en termes véhéments d'un instituteur qui, passant tous les jours en automobile devant sa case, en profitait pour lui « jeter la foudre » avec cette diabolique machine.

Une telle crédulité s'exerce dans tous les domaines, accepte pour un temps les bruits les plus incontrôlables. Au début de la dernière guerre, on vit débarquer un beau matin sur la savane, à Fort-de-France, des «bitacos », ou habitants des hauteurs, venus assister à l'exécution par fusillade d'un personnage que la seule consonance de son nom leur avait fait prendre pour un espion. Les vieilles "das » racontent aux enfants dont elles ont la charge les plus sombres et étranges histoires, et beaucoup de leurs jeunes auditeurs y croient ensuite toute leur vie. Rares, bien rares en vérité sont les maisons où ne pénètrent pas croyances et pratiques irrationnelles et plus ou moins teintées de magie. L'on finit, malgré soi, par en être obsédé.

À tel point que les histoires de zombis ou de revenants peuvent à l'occasion servir d'excuse absolutoire devant les tribunaux : «Il y avait cette session, écrivait en 1935 un journal local, des vols et des cambriolages qui ont été sévèrement réprimés, et un gros détournement de deniers publics dont le coupable a été acquitté... On peut prêcher les économies, sabrer et tailler les traitements, les pensions, les titres et les subventions. Cela ne sert de rien si l'on 
acquitte ceux qui mangent la grenouille, mènent joyeuse vie avec l'argent des contribuables et déshonorent encore leur pays en racontant des histoires à dormir debout de fantômes, d'esprits frappeurs et voleurs, de disparitions mystérieuses dans des coffres fermés ${ }^{1}$. "

Le patriotisme de clocher s'insurge contre de telles constatations. On rappelle les rebouteux des campagnes métropolitaines, leurs prescriptions bizarres, les fantômes qui hantent nos vieux châteaux. « En certains points de la Bretagne, affirme-t-on, la croyance au surnaturel est encore plus forte qu'à la Martinique ${ }^{2}$. » L'argument n'est pas sans valeur et mérite d'être rappelé.

Il y a quelques années encore, je l'eusse véhémentement contesté. J'avais alors la conviction profonde qu'il existait dans la métropole des milieux nombreux et étendus absolument exempts de toute contamination magique. Je serais beaucoup moins affirmatif aujourd'hui. Le dernier carré rationaliste fait peau de chagrin. Il est peu, très peu de journaux où l'on ne publie, chaque matin, l'horoscope du jour ou de la semaine. Les fakirs, voyants et voyantes de tout poil font une tapageuse publicité et n'ont jamais eu davantage de clients. Nous n'avons pas à rechercher ici dans quelle mesure de tels faits sont révélateurs d'un affaiblissement continu des croyances traditionnelles qui, du moins, opposaient un barrage à l'invasion de toutes ces pratiques. Il reste un fait certain : la crédulité humaine, de nos jours, apparaît plus incommensurable que jamais.

En même temps, les moyens actuels de diffusion de la pensée favorisent sans aucun doute une large tendance à l'uniformisation dans ce domaine comme dans beaucoup d'autres. Nous en avons rencontré plusieurs exemples au cours de cette étude. J'ai été frappé, lors de mon dernier voyage, par le nombre des copies manuscrites du Grand et du Petit Albert qui circulaient. J'en possède une qui vient d'une de ces "geôles » qui sont, pour beaucoup de braves gens, un lieu de rendez-vous, de palabres, et où l'on apprend beaucoup de choses, lesquelles se dispersent ensuite dans le pays entier. Le fameux Beauregard, bandit pittoresque abattu durant mon dernier séjour après avoir tenu, plusieurs années durant, ce qu'on pourrait pompeusement appeler le maquis martiniquais, portait un de ces textes sur lui. Le vieux folk-lore, la magie traditionnelle, dont j'ai essayé de fixer un moment, seraient donc en voie d'affaiblissement rapide, de disparition.

Peut-être, mais peut-être seulement, et pour renaître aussitôt de leurs cendres, comme le Phénix de la fable. Car il existe toujours, à la Martinique, un climat magique, c'est-à-dire un ensemble de conditions favorables à la naissance et au développement de légendes et de pratiques irrationnelles. Il y a une prédisposition profonde à accepter le merveilleux comme un fait de la vie courante, les «miracles de la science » étant assimilés aux hauts faits des quimboiseurs. Les veillées mortuaires, avec leurs récits qui se prolongent à la

La Paix, 16 juillet 1935.

V. Scvère, Séance du Conseil général du 3 juin 1903, C. R., p. 54. 
lueur de quelques clignotantes bougies dans la nuit hostile, les contes des «das» aux tout-petits, mille incidents de la vie courante concourent à entretenir et renforcer ce climat. L'usage intensif de l'alcool aboutit sans mal à la « possession démoniaque » qui oblige le patient ou la patiente à tenir dans la rue, à haute voix, des propos incohérents, à moins qu'il ne procure, au contraire, le don de double voyance. J'ai encore connu deux honnêtes citoyens, fort cossus au demeurant, qui, de passage à Londres, avaient banqueté joyeusement, si joyeusement qu'à la sortie ils se mirent, suivant leur expression même, à "pousser une beuglante de première ". Surgit un policeman qui s'adresse à eux dans un français irréprochable, les embarque dans une voiture et les ramène paternellement à leur hôtel. Sur quoi le lendemain, le plus jeune, qui n'avait aucune connaissance de langues étrangères, confiait à l'aîné : «F... moin saoul hier. Moin ka comprendr' Anglais. » Ajoutons les discours de toutes sortes - il y en a d'épiques qui durent des heures et où l'orateur déjà « chargé » achève de se griser au son de ses propres paroles -, les contes et les chansons du Carnaval, les improvisations sur accompagnement de mandoline, qui m'ont fait parfois songer aux mélopées soutenues par le kantele que j'avais connues, au début de ma carrière, vers les confins de la Carélie finnoise.

Il y a aussi cette étonnante puissance de déformation, de transformation, dont il faut sans doute chercher l'une des causes les plus agissantes dans une prononciation dont les $r$ sont absents et une graphie - le mot d'orthographe sonnerait faux - d'une ahurissante fantaisie. D'une assonance naît une affabulation, une vérité provisoire qui tend à devenir définitive, même et surtout si cela ne signifie rien. Un politicien avec lequel, en des temps anciens, j'avais eu maille à partir, ne cessait de gémir, au début de la dernière guerre, sur l'irrémédiable décadence des usages et des mœurs : "Frenq' siècl' la changé. Jusqu'à l'abbé qui ka monté en cher pour yo juré bonda maman la France ${ }^{1}$. » En fait, le brave curé de ce que j'appellerai le Morne Jaune, pour faire pendant au Morne Gris de R. Tardon, avait vivement conseillé à ses paroissiens de prendre des bons d'armement pour notre mère la France.

La parole écrite est plus extraordinaire encore. On trouvera aux annexes quelques-uns des textes authentiques dont je détiens les originaux. Deux surtout me paraissent mériter d'être signalés: la lettre d'une jeune bonne en place à Fort-de-France, qui écrit à ses parents pour leur faire savoir qu'elle va bien, et plus encore ce magnifique exercice de "Grammaires conjugensonts » (conjugaison) qu'il serait impossible d'inventer : ceux-ci sont reproduits en facsimilé dans les hors-texte.

Il en résulte des transpositions, souvent peu conscientes, des déformations qui augmentent de copie en copie, d'interprétation en interprétation. Sera-t-il permis d'ajouter que, dans les formules à base végétale, le passage est singulièrement facilité par l'existence, dans la flore antillaise, d'un très grand nombre de noms vernaculaires qui rappellent ceux de la métropole ? Il y a des

Frenqu' : juron grossier - qui ka monté : qui est monté pour jurer par le «bonda ». Bonda : bas-ventre. 
lilas, des cerisiers, des pruniers "pays ». On y connaît une verveine, une mauve, etc.

Je suis, en 1949, tombé à un mauvais moment où il venait d'y avoir, dans la magie antillaise, une injection massive et récente d'éléments européens. Je demeure persuadé qu'ils auront tôt fait de fondre au soleil tropical ou d'être entraînés par un verbalisme torrentiel, considéré comme magiquement efficace bien avant que les surréalistes en aient découvert les vertus littéraires. À y regarder de plus près, il en est sans doute ainsi depuis fort longtemps. Il n'y a qu'à voir l'importance jouée par le parchemin vierge, les fils de couleur et ces formules qui, probablement latines à l'origine, ne sont plus maintenant que macaroniques. Déjà, pour le Cahier de quimbois du Lorrain, les copies qui circulent actuellement à la Martinique comportent d'importantes variantes. Je n'ai pas de doute que ce petit livre, qui sera très certainement lu et commenté aux Isles, verra à son tour la plupart de ses formules recopiées, transformées et essayées... Ainsi se manifeste un syncrétisme original, pittoresque, toujours vivant, qui maintient à la Martinique son climat magique et continue à en faire, dans les palmes bruissantes et les fleurs, ce doux pays des revenants à la nostalgique attirance que chantait déjà Lafcadio Hearn. 


\section{ANNEXES}

\section{Cahier de Quimbois}

\section{Retour à la table des matières}

Le cahier de quimbois reproduit ici m'a été communiqué par le $P$. Delawarde, qui l'avait en sa possession depuis 1932. Il avait été confisqué dans une descente de justice au Lorrain vers 1930. Il commence à être connu à la Martinique, et quatre au moins de mes amis m'en ont envoyé des traductions qui présentent des variantes. Un certain M. R. Gaillard, qu'on m'a dit être un auteur a succès, a publié l'une de ces traductions, sans aucun commentaire, plus d'un an après la soutenance de mes thèses. J'eusse aimé qu'il voulût bien indiquer ses sources. Cela n'a en soi que peu d'importance : je tenais seulement à marquer combien les droits d'antériorité du P. Delawarde, et partant les miens, sont hors de conteste. On trouvera donc ci-dessous le texte original, avec en notes les quelques indications et commentaires nécessaires à l'intelligence de l'ensemble.

\section{Pour vous clouer ${ }^{1}$ dans une place :}

Vous coupez les ongles de vos gros oteilles ${ }^{2}$ et les ongles de vos gros pouces, vous les mettez tremper dans une petite tasse neuve dans un peu d'eau bénite vous prendrez trois épingles de mosolé avec trois épingles de cercueille que vous entrelasser ${ }^{3}$.

Les ongles dans une petite bousse ${ }^{4}$ que vous allez envelopper avec un morceau drap neuf. Puis un vendredi à trois heures au fond dans un établissement déposez là dans un loin ${ }^{5}$ pour que personne ne la voie pas mais tachez de l'arroser avec de la lavane double rouge ${ }^{6}$ tous les premiers vendredis du mois. Tâchez de faire dire messe trois francs ${ }^{7}$ pour les âmes du purgatoire pour conserver votre place.

Clouer : fixer.

Oteilles : orteils.

Épingles de mosolé (mausolée) : épingles à tête noire utilisées dans les cimetières. Épingles de cercueil : épingles qui servent à maintenir le drap noir dont le cercueil est enveloppé.

Bousse : bourse.

Loin : coin.

Lavane double rouge : lavande double rouge, nom donné à une essence de lavande vendue à la colonie, le rouge symbolisant les nègres.

Prix d'avant 1914. Ceci, comme les 10 centimes d'alcali ou d'acide phénique indiqués plus loin, montre l'ancienneté relative du document et le maintien des traditions en la matière. 


\section{Coup de point composé ${ }^{1}$}

Vous prendrez un crapeaulade ${ }^{2}$ vous prendrez son fiel et son foie vous les mettrez dans un coco en cuillère ${ }^{3}$ avec 10 centimes alcali 10 centimes acide phénique ${ }^{4}$ une cuillerée d'eau de même coco une cuilleré laitte ${ }^{5}$ d'une vache puis vous rebouchez le coco vous le laissez à la trompe ${ }^{6}$ durant sept jours avant le servire. Quand la personne recevait le coup il serait lade ${ }^{7}$.

\section{Compte ${ }^{8}$ pour guérir la personne :}

Vous mettez dans une bouteille un peu d'eau de mer, trois feuilles monthe ${ }^{9}$ glaciale, trois cuillerée d'eau bénite trois groines sel à monger ${ }^{10}$ un peu d'esprit de tofia ${ }^{11}$ pour frictionner la personne dans l'endroit où il a reçu le coup.

Coup de poing composé.

Crapaud ladre. Cet animal a été introduit à la Martinique en 1848.

Coco non encore arrivé à maturité, contenant de l'eau et sur les parois une couche d'amande tendre que les enfants mangent avec une cuiller.

4 Nous avons déjà souligné que les «quimbois » comprenaient souvent des produits pharmaceutiques ou des parfums. De là les demandes plus ou moins extraordinaires faites aux praticiens, à moins que le sorcier lui-même ou un de ses acolytes ne se charge de procurer les ingrédients prescrits. Je reproduis ci-après, à titre de comparaison, la longue nomenclature de médicaments étranges trouvée chez une sorcière de la Guadeloupe surnommée Mignonne et publiée par M. R. Fortuné (Revue Guadeloupéenne, janvier 1946, p. 40 :

« 25 chandelles, 25 pois de santerre (sic), 50 gr. bromure, 50 gr. morphine, 15 gr. parégorique, 5 fr. eau d'anun (sic), 25 gr. hémétique, 1 flacon ce que femme veut, 1 flacon héliotrope blanc, 1 flacon pompéa, 1 flacon trèfle incarna, 1 flacon alcool de menthe, 1 flacon fleur d'oranger, 5 paquets poudre de soleil, 5 paquets poudre brillant, 5 paquets poudre aimée, 5 paquets poudre amour, 5 paquets poudre de victoire, 5 paquets poudre de garance, 10 paquets précipité rouge et blanc, 5 paquets poudre inquitable, 5 paquets poudre indispensable, 5 paquets attirance, 5 paquets accostables, 5 paquets ramenantes, 5 paquets veut et veut pas, $10 \mathrm{fr}$. oubli de paillette, 5 paquets poudre divine, 5 paquets poudre d'or, 10 paquets esprit de tous les hommes. »

« Eau divine, eau de mélisse, eau menée vini, eau de victoire, eau de toutes choses, eau de maître pierre, eau de carme, eau d'éclair, eau de céleste, eau de Lubin, eau méné nous, essence blanchir, lavande blanc et rouge, essence acacia, essence verveine, essence rosa, essence patchouli, essence méné vini, eau babel, eau de samseance, beaume commandeur, beaume de vie, reine des fleurs, reine des femmes, brise de mai, essence d'iris, lait d'iris, fleur de soleil, essence de jasmin, beaume de Judée. »

« 3 petites poupées garçons, 2 petites poupées fillettes, 1 petite glace de 3 faces, 4 fr. épingles à attacher, $3 \mathrm{fr}$. clou dorée (sic), $3 \mathrm{fr}$. clou à pompe, 1 pelote fil rouge, $5 \mathrm{fr}$. 10 rubans différents, 10 paquets poudre d'iris, 15 fr. un parchemin vierge, carmé rose, 1 boîte poudre d'iris rose, 1 savon toilette rêve d'or, 25 muscades, 10 paquets cannelles. »

"Composition pour la lampe : une tête de pavot, lavande blanc et rouge, beaume tranquille, eau de carme, éther voyageur, miel douce (sic), 2 fr. sucre cassé. »

Laitte : lait.

Trompe : trempe.

La personne qui recevrait le coup deviendrait ladre, c'est-à-dire lépreuse.

Compte : contre, d'où contrepoison.

Monthe menthe.

Trois grains de sel de table, de « sel à manger ».

11 Littéralement, esprit de tafia : rhum blanc. 
Compte pour servir vous-même ${ }^{1}$ :

Vous prendrez une cuillerée l'huile d'olive, une cuillerée l'huile parinacristie, une cuillerée l'huile quinqué ${ }^{2}$ une cuillerée l'eau bénité 10 centimes sovon pays pour frotter vos moins avant et après que vous servez votre trovoil ${ }^{3}$

\section{Compte poison pour foire souter un vere ${ }^{4}$ :}

Vous mettez dans une fiole ici cent l'huile d'étère ${ }^{5}$ trois cors ${ }^{6}$ d'ails un peu jus oronge douce ${ }^{7}$ morceau écorce filao ${ }^{8}$ piler un peu de ravine arada ${ }^{9}$ pour mettre le jus dedans. Quand vous allez dons festin dons vos mains mettez sept gouttes et soisie le verre si il est empoisonner il seroit briser ${ }^{10}$.

\section{Pour foire parler une femme au sommeil ${ }^{11}$ :}

Vous prendrez 3 bronches de son cheveux ${ }^{12}$, vous prendrez une grenouille, vous achetez une glace sombe ${ }^{13}$ sur son nom, vous prendrez un morceau de son linge taché ${ }^{14}$, pour entrelacée ${ }^{15}$ la grenouille et les cheveux sur la glace vous achetez une boujie, vous surveillez quand elle doit dormir vous mettez les objets au bat de sa tête ${ }^{16}$ puis vous allumez la boujie vous une telle racontez moi se qui ces passé à mon absence et ne la laissé pas dormire plus qu'une heure de temps puis éteindre la boujie et retirez les objets et vous la réveillez immédiatement ${ }^{17}$.

Contre-poison pour vous-même, c'est-à-dire pour celui qui donne le coup de poing composé.

Huile à quinquets, c'est-à-dire huile à brûler.

310 cent. savon du pays pour frotter vos mains avant et après que vous servez votre travail, c'est-à-dire que vous donnez le coup de poing.

Contre-poison pour faire sauter (éclater) un verre.

Étère éther.

Cors gousses.

Oronge douce : orange douce.

Filao : Casuarina Kumph., arbre originaire de Madagacar.

9 Ravine arada : racine d'arada ou Arrada. Cette racine exhale une odeur forte qui rappelle celle de l'ail. On la trouve dans toutes les pharmacies sous le nom de racine pipi, car elle est diurétique.

10 Saisissez le verre : s'il est empoisonné il se brisera.

11 Au sommeil : endormie.

12 Littéralement, trois branches de sa chevelure : trois de ses cheveux.

13 Sombe : sombre : plaque de verre avec une couche de peinture noire.

${ }^{14}$ Par le sang menstruel.

15 Le morceau de linge sert à envelopper la grenouille et les cheveux.

16 Sous sa nuque.

17 Il m'a été remis en 1949 un cahier manuscrit intitulé Secrets de Magie Noir.

Les secrets merveilleux du Grand et du Petit Albert. Le grand grimoire et la clavicule et, le « Secret de la Magie Noir Dévoilé ».

Je ne crois pas devoir le reproduire, parce qu'il n'apporte rien de spécifiquement nouveau au point de vue martiniquais. On y trouve cependant, page 8 , une formule beaucoup plus simple, mais quelque peu apparentée à celle ici développée, « pour faire dire à une fille ce quelle cache, padan (pendant), quelle dort, mettez lui le cœur d'un crap. (crapaud) sur la mamelle gauche, elle dira tous ses secrets ». 


\section{Pour déchormer une personne que vou avez chormer ${ }^{1}$ :}

Vous prendrez 3 feuilles menthe glaciole, vous achetez 10 cent. corne cerfs en poudre vous prendrez 3 feuilles oronge sur ${ }^{2}$, vous la foite bouillir vous mettez dedons trois goutes eau de Cologne 3 goutes eau bénite vous allez la doucire ${ }^{3}$ avec du sirop raffiner mais il faut que vous foites le thé ${ }^{4}$ un vendredi matin vous buvez et donner à la personne une tasse aussi si vous l'ovez donner une charme ${ }^{5}$ pour qu'elle devient folle elle seroit guérir ou si c'est une autre homme qu'il le foit de même ${ }^{6}$ elle seroit guérir.

\section{Pour poison :}

Vous irez, dons un pied de citron vous prendrez un morceau dans un citron dans la nuite ${ }^{7}$ sur le nom de la personne vous prenez le morceau de citron et la puger dons un ponche ${ }^{8}$ en disant au grand Lucifere au grand Beljébite au grand Ravocal ${ }^{9}$ foite qu'une telle va foire un soulord un voleur un vogobon foire ce qu'il ne doit pas foire ${ }^{10}$.

\section{Chorme :}

Vous prenez un sonssure ${ }^{11}$ vous la déposez sur votre côté gauche pour retirer votre sang vous le prenez et le méterz sécher au soleil quond il sera sèche vous le prendrez et le moitre ${ }^{12}$ dans un petit pot en terre vou prendrez un pied d'herbe chorpentier vous le mettrez dans le pot sons casser la racine ni les bronches ${ }^{13}$ vous amorez ${ }^{14}$ la gueulle du pot avec un morceau de linge bien propre vous cherchez l'endroit que vous trouvez un ta de fumier pendant 10 jours. Au bout de ces 10 jours vous irez la prendre vous y trouverez un ver dedons vous prendrez le ver en le mettant dans une tasse et vous le mettez sécher au soleil quand il sera sèche vous le rendrez en poudre ${ }^{15}$ et le mettrez dans une fiole en ajoutant neuf goutes de la sueure de votre front du côté

Chormer, dechormer : charmer, décharmer.

Orange sûre.

Doucire : sucrer ; le sirop raffiner signifie du sirop fait avec du sucre raffiné.

Thé : le terme de thé désigne de très nombreuses infusions ou même décoctions.

Si vous lui avez donné un charme.

Si c'est un autre homme qui aurait fait de même (qui avait donné le charme).

Dans la nuit.

Purger dans un ponche : purger dans un punch, c'est-à-dire presser le morceau de citron et en faire tomber le jus dans un punch.

Lucifer, Belzébuth, le Grand Ravocal.

10 Soulord : soulard; vogobon : vagabond.

Sonssure : sangsue.

Moitre : mettre.

13 Sans casser la racine ni les branches. L'herbe du Charpentier, ou à charpentier (Dianthera pectoralis), est très employée localement. On emploie l'infusion simple contre les maux d'estomac, mélangée à du sirop contre les maladies de poitrine, tandis que les feuilles macérées avec du sel passent pour guérir les blessures.

14 Amorez : obturez, fermez.

15 Vous le réduirez en poudre. 
gauche en ajoutant dans la tasse l'huile divers et 25 centimes huile Cazalemi ${ }^{1}$ de la vous mettez six gouttes la poudre en mettant trois prises de la cigarette ${ }^{2}$ et vous n'ovez qu'à donner 3 coups de fumer ${ }^{3}$ à la figure de la personne et elle sera chormée.

\section{Pour guérir la vérole :}

Vous achetez un petit pote ${ }^{4}$ en terre vous metterez dedans racine grois bois ${ }^{5}$, racine corosole ${ }^{6}$ sur racine guimauve une corosole sur moturilé coupée en 3 morceaux ${ }^{7}$ morceau pote blanc ${ }^{8}$ puis vous lovez ${ }^{9}$ la Verge avec d'l'eau boriqué 10 centimes extrait de satine ${ }^{10}$ que vous achetez puis 10 cent essence de menthe glaciale vous mettez tout cela dans une bouteille pour lové la Verge et remplisser la bouteille avec l'eau de rivière à meusur ${ }^{11}$ qu'elle se réduit remplissez la avec 6 même article.

\section{Pour avoir chonce pour le travail ${ }^{12}$ :}

Vous irez dans une boutique ofeuve ${ }^{13}$ vous ferez foire pour vous une alliance double à couverture vous le ferez graver pour vous C.P.T., vous surveillez le jour qu'une personne est à la gonnie ${ }^{14}$ mois un homme vous la faurez la bague dans la bouche ${ }^{15}$ aussitôt qu'il trépasse. Il faut dire en prenant la bague mort j'ai pris ton dernier soupirs de la vous prendrez la bague vous le mettez à l'indesse ${ }^{16}$ de la main droite puis vous allez donner la bague à une jeune fille mais le jour où elle va se communier d'embrasser trois la bague pour vous ${ }^{17}$ en disant mort mort mort la créature de Dieu m'encharge ${ }^{18}$ de la bague il m'a promis de faire une femme pour vous ${ }^{19}$ mais si vous être comminiante vous pouvez la foire vous même. Il faut que ce travail entre vous et la jeune

\footnotetext{
1 Huile divers : huiles de diverses espèces, huile Cazalemi, probablement une huile siccative, employée pour les vernis.

Mettez-y aussi 6 gouttes de la poudre obtenue et trois prises de cendre de cigarettes.

3 Fumer ? fumée. Il est évident que la cigarette doit être fabriquée avec du tabac et une partie du produit destiné à « charmer »

Pote : pot.

Racine gros bois sans doute racine de Kaïmitier noir (gros bouis à la Martinique Chrysophyllum caeruleum Jacq.).

Corosole : corosol : Anona muricata L.

Un corosol sur à moitié mûr, coupé en trois morceaux.

Pote blanc : pot blanc, de faïence ou de porcelaine.

Lovez lavez.

Satine : saturne.

Meusur : mesure.

Pour avoir de la chance quand on cherche du travail.

Ofeuve : orfèvre, bijoutier.

La gonnie : l'agonie.

Vous lui fourrez la bague dans la bouche.

Indesse : index.

Vous chargez la jeune fille d'embrasser trois fois la bague pour vous.

M'encharge : me charge.

Variante du P. Delawarde : Elle m'a promis de faire une messe pour vous.
} 
fille ${ }^{1}$ quand elle vous remettra la bague vous la mettez dans une petite tosse ${ }^{2}$ à couverture en ajoutant 25 cent. vif argent un peu d'eau rouge, un peu d'essens vous irez enterrer la tosse durant trois jours en disons ${ }^{3}$ mort mort mort je ne vous oublirait pas la promesse que je vous avez faite donner la chonce à ma bague autant pour le trovail que pour la fortune. Le jour de sobat ${ }^{4}$ vous apporterez la tosse avec vous au pied d'un pied de fougère en vous accompagnant d'une drap blanc avec un peu de la cire sortant dans les yeux vieux mulet avec une glace mois ayez soin ce jour là de ne pas aller à la femme quand vous arriverez au bat du pied de fougère vere onze heures trois quart dans la nuit vous vous coucherez face en bas en vous envelopent la tasse sur votre estomac avec la bague en disont. Prince des infernales altudoros ${ }^{5}$. Altudoros je prétends que por votre pouvoir que vous mettez la bague pour moi dans l'indexe ${ }^{6}$ là il ne faut pas avoir de frayeur : vous entendrez un grand bruit où un grand crit de là il ne faut pas regarder il décendra ${ }^{7}$ son poyemente ${ }^{8}$ vous lui direz de prendre la bague la tosse et le drap en disant ceci vous vous réveillez ${ }^{9}$ quand vous voulez prendre quelque trovoille ${ }^{10}$ vous n'avez qu'à mettre la bague dans la main droite dons l'index mois la face qui est gravée C.P.T. ${ }^{11}$ vous frappez trois fois à la porte de la personne. Il ne vous refusera de trovoille.

Les jours heureux :

$\begin{array}{ll}3-10-27-31 & \text { janvier. } \\ 5-8-18 & \text { février. } \\ 3-9-12-14-16 & \text { mars. } \\ 5-19 & \text { avril. } \\ 1-2-4-6-9-14 & \text { mai. } \\ 3-5-7-9-12-23 & \text { juin. } \\ 2-6-10-23-30 & \text { juillet. } \\ 5-7-10-14-19 & \text { out. } \\ 6-10-13-19-30 & \text { septembre. } \\ 13-16-22-31 & \text { octobre. } \\ 3-19-23-30 & \text { novembre. } \\ 10-20-29 & \text { décembre. }\end{array}$

Le copiste du cahier tiré du Grand et du Petit Albert avait reproduit, sur une feuille détachée, une liste très proche des jours heureux, mais à laquelle

\footnotetext{
Il faut que ce « travail » reste secret entre la jeune fille et vous, que d'autres n'en aient pas connaissance.

Tosse : tasse.

En disant.

Sobat : sabbat.

Signifie sans doute hauteurs ou plutôt profondeurs infernales.

Je prétends que par votre pouvoir vous mettiez cette bague à mon index.

Il réclamera son paiement.

Paiement.

Vous vous réveillez : vous vous relevez.

Travail.

Les lettres C.P.T. doivent toucher la chari.
} 
s'ajoutait celle, ci-dessous reproduite également, des jours malheureux. L'une et l'autre de ces listes apparaissent d'origine évidemment européenne.

Table des jours heureux et malheureux :

Jours heureux

Le 3.10.27.31

Le 7.8 et 18

3.9.12.19

5 et le 17

1.2.4.6.9.14

8.5.7.9.12.23

3.6. 10.23 .30

5.7.10.14.29

6.10.13.18.30

13.16.25.31

3.13.23.30

Le 10.20. le 29
Mois

Janvier

Février

Mars

Avril

Mai

Juin

Juillet

Août

Septembre

Octobre

Novembre

Décembre
Jours malheureux

Le 13 et le 25

2.10 .17 et 22

13.19.23.28

18.20.29.30

10.17 et le 26

Le 4 et le 20

Le 5.13 .27 et 27 ( $\mathrm{sic}$ ).

2.13.27 et 31

13.16.18.19.

Le 3.9 et le 27

Le 16 et le 25 .

Le 15.28 et 31

\section{Oraison Saint Joseph :}

Ô Dieu qui fournis tous les autres anges a fait choix de St Gabriel pour annoncer les mystères de sa sointe Incarnation faites dans votre volonté qu'après avoir célébrer sa fête sur la terre nous gonterons ${ }^{1}$ dans le ciel les effets de sa protection vous qui étant Dieu, délivrez moi de tout danger Ainsi soit il Lectis Danicles Ph Prophète St Joseph ${ }^{2}$. Délivrez moi.

\section{Une chonce pour toute chose ${ }^{3}$}

Vous vous procurez une bages ${ }^{4}$ soit en or ou en argent quand vous verrez qu'on a tué une Serpent vous prendrez la tête de ce serpent, puis vous fourrez la bague dans la geule ${ }^{5}$ dans la tête du serpent, puis vous allez enterré la tête de ce serpent ave la bague dans la gueule dans un endroit que la bague ne va pas ${ }^{6}$ vous cherchez une personne qui a une vâche qui donne du lait vous prendrez un condition avec la personne ${ }^{7}$ pour qu'il vous donne vingt un chaupine tous les matins ${ }^{8}$. Arrivez jusqu'à vingt jours, vous allez arroser la tête du serpent avec

\footnotetext{
Gonterons : goûterons.

Formules inintelligibles. Peut-être Danicles ferait-il songer au prophète Daniel.

Une chance pour toute chose.

Bages bague.

Geule gueule.

Formule peu claire. Les traductions portent : un endroit où personne ne va.

Vous vous entendrez avec cette personne.

Vingt et une chopines à raison d'une chaque matin.
} 
une chaupine de lait, mois vous payez la personne qui vous donne du lait vingt polvants ${ }^{1}$ l'autre pobouts qui rester vous ne la payez pas, de là au bout de vingt jours, vous allez voir que du champignon va lever dans l'endroit que vous arrosez avec la lait sur la tête du serpent. De là quand vous verrez cela vous allez acheter une assiette neuf le dernier pobants du lait qui est resté vous le videz dans l'assiette puis vous allez prendre la bôgue et, le champignon qui est sur la tête du serpent que vous avez arrosée vous le mettez dans l'assiette du lait. De la aussitôt de finir le bien laver, vous prenez cette champignon et la bague vous le mettez dans un petit bourse vous le donnez à un accolique ${ }^{2}$, vous dites à l'accolique de le bénir pour vous au moment de la consécration mais vous donnez un fronc ${ }^{3}$ à l'accolique pour lui pour le bénir pour vous. quand il finirait de la bénir pour vous il vous l'apportera. vous le prenez, vous le mettez dans votre droite ${ }^{4}$ puis vous prenez la champignon vous les encadrez ${ }^{5}$ bien dons un morceau chomois ${ }^{6}$ vous le mettez chez vous au fond de votre mole ${ }^{7}$. Si vous foites comme on vous indiquerer vous serez bien réussi ${ }^{8}$.

\section{Voici la manière pour envoyer quelqu'un voler :}

Vous cherchez de connaître le nom de baptême de la personne. Quand vous connaissez le nom de son baptême vous achetez un sou papier avec un gobelet neufs vous couper une feuille papier toute ronde la largeur du geulle goublet ${ }^{9}$. Vous le tournée gueulle embas. Vous écrire le nom de baptême de la personne sur le rond de ce papier vous prenez un morceau de terre sortout sur une fosse dans le cimetière ${ }^{10}$, vous déposez cette terre dons le gobelet vous achetez 50 centimes prescipité ${ }^{11}$ à la pharmacie vous acheté dix centimes l'huile parmacristie, dix centimes l'huile quinqué, dix centimes l'huile soldats ${ }^{12}$ dix centimes l'huile d'amonde, dix centimes l'huile d'olive, dix centimes miel d'Angleterre un peu l'huile poisson vous mettez... (manque la fin de la formule).

\section{Charme à l'odeur :}

Pobant, flacon servant de mesure (flacon importé de France contenant des olives, etc., autrefois). Il y en avait de divers modèles. Il contenait environ un demi-litre (note du P. Delawarde).

2 Accolique : acolyte. Le P. Delawarde interprète ainsi ce passage : donnez celle-ci à un acolyte pour qu'il la tienne au moment de la consécration, elle sera ainsi bénite.

Fronc : franc.

Droite mis ici pour doigt, il s'agit de la bague.

Vous l'enveloppez.

Dans un morceau de peau de chamois.

Mole : malle.

Si vous faites comme on vous a indiqué, vous réussirez bien dans vos entreprises.

À la largeur de l'ouverture du gobelet.

Un morceau de terre dépassant sur une fosse dans le cimetière.

De « précipité », formule vague et qui peut recouvrir divers produits.

12 Parmacristie : ricin, huile soldats : huile extraite en principe du Bernard-l'Ermite, surnommé « soldat » en créole. 
Vous achetez 50 centimes escensse mouceline mètre salivre le motin avec personne pendant trois jours ${ }^{1}$.

La crosse au bas de votre bras gauche ${ }^{2}$, la crosse dans milieu de votre tête, la crosse au bas de votre pied droit, puis vous laissez la composition à la trompe ${ }^{3}$ pendant sept jours de la vous achetez une mouchoir sur le nom de la personne et vous possez ${ }^{4}$ au vent de la personne pour qu'elle puisse expirer ${ }^{5}$ cette odeur, elle serait à vous.

\section{Pour faire venir une femme chez vous :}

Vous allez dons une boutique un vendredi matin avont que la boutique soit ouverte. Aussitôt qu'elle serait ouverte vous achetez 10 centimes d'asoie couleur ${ }^{6}$ entrez dons une autre boutique vous achetez une père de couvert ${ }^{7}$ sur le nom de la personne aller dons une autre boutique achetez deux muscades un femelle et un mal sur le nom de la personne en disant une telle j'achète votre esprit et je le poyerai ${ }^{8}$. Puis aller chez vous entrelasser la fourchette sur la cuillère mettez les muscades dans la cuillère tout entrelassant, vous dites une telle de la même manière que la fouchette se trouve dans la cuillère c'est de même que je voudrais me trouver avec vous. vous servez ce travoil un mercredi à midi puis le vendredi à la même heure vous dessentrelasser. vous loissez votre maitresse ${ }^{9}$ et à 3 heures au son du trépos ${ }^{10}$ de notre Seigneur apporter la paire de couverture pour la femme ${ }^{11}$ elle viendroit chez vous plus vite que possible ${ }^{12}$.

\section{Pour prendre une place :}

Vous envoyez achetter par une femme une peigne vous lo mettez à la trompe ${ }^{13}$ dans une assiette creuse vous allez à la pharmacie vous achetez 25 centimes lavande double rouge 25 centimes escensse $\mathrm{I}^{\mathrm{me}}$ la crasse de cuisse que

1 L'essence mousseline est employée aux quimbois, la fin de la formule signifie : mettez-y de votre salive le matin pendant trois jours, avant d'avoir vu personne.

La crasse au bas de votre bras gauche.

Trompe : trempe.

Possez : passez.

Expirer : respirer.

De soie de couleur. Deux des textes traduits que je possède ajoutent ici: ajoutez 10 centimes de soie de la couleur de votre peau (noire, jaune ou blanche, le noir pouvant être remplacé symboliquement par le rouge).

Une père de couvert : une paire, c'est-à-dire un couvert comprenant fourchette et cuiller.

Poyerai : payerai.

Vous laissez votre maîtresse : vous vous débarrassez de votre maîtresse en titre.

Trépos : trépas.

Vous portez le couvert à la femme (que vous désirez).

12 Elle viendra chez vous le plus vite qu'il lui sera possible. À propos des graines de muscade dont il est question dans ce quimbois, le P. Delawarde fait remarquer que la graine mâle plonge dans l'eau tandis que la graine femelle surnage.

13 À la trempe. 
vous lovez la cuisse avec l'escensse menthe glociale ${ }^{1}$. Mélangez avec l'escensse des jeunes garçons pour le laisser tromper avec 10 centiment graine l'âne ${ }^{2}$ laisser à la trampe durant trois jours au bout de ces troisième jour. vous allez demonder votre place ${ }^{3}$ avont d'aller peignez vous bien avec le peigne, portez avec lui ${ }^{4}$ hoter votre chapeau, vous serrez conter obtenir votre place ${ }^{5}$.

Pour déplacer ${ }^{6}$ quelqu'un ou quelqu'une dans un endroit ou dans une place quelconque :

Vous n'avez qu'à aller chercher un vonvon ${ }^{7}$ si cet une personne ou ci cet deux dons le même endroit, vous n'avez qu'à chercher deux vonvons dans la même bronche ${ }^{8}$ et vous les prendrez sur le nom de ce deux individus sur son nom ${ }^{9}$ et vous dites un tel un tel je vous prends et vous déplace ici et c'est moi qui vous commende après la volonté de Dieu : Je ne veux vous voire ici d'après l'ordre du Seigneur Jésus Christs parce que vous ovez rovi ${ }^{10}$ ma nourriture et telle ${ }^{11}$ de ma famille allez vous réfugier ailleurs, Dieu vous conduit pour le bien ou mal, de la vous enfermez les deux vonvons ensemble et vous dites disputez vous entre vous même et Dieu fera le reste si c'est un lundi vous le conservez trois jours de chez vous ${ }^{12}$ à chaque jour frappez le pot en nomment les noms de ces individus motin et soir ovont l'angélus. La mer, lompe et neuvoine ${ }^{13}$ et vous dites les ômes ${ }^{14}$ chossez ${ }^{15}$ les pour moi par votre prière et je vais vous récompenssez.

\section{Oraison :}

Deux bois mangnoque pour conserver une place ${ }^{16}$ un petit croix foite avec acasias, une chopine seil ${ }^{17}$ une chopine sabre ${ }^{18}$ un petit bonce ${ }^{19}$ pour mettre

\footnotetext{
$1 \quad$ L'essence $\mathrm{I}^{\mathrm{eme}}$ est l'essence de première qualité, la suite de la phrase veut dire : la crasse de cuisse obtenue en lavant celle-ci avec l'essence de menthe glaciale.

Probablement l'ieux bourrique : Mucuna urens.

Demonder : demander.

Porter avec lui : emportez le peigne.

Vous serrez conter obtenir votre place : vous pouvez compter, être assuré d'obtenir la place. Déplacer faire sortir d'une place.

Vonvon sorte de gros bourdon.

Bronche : branche.

Vous les prendrez sur le nom (au nom) de ces deux individus en répétant celui de chacun d'eux.

10 Vous avez rovi : vous avez ravi.

Telle : celle.

Vous le conservez trois jours chez vous.

La mer ; lompe signifie peut-être allumer une lampe ; neuvoine : neuvaine.

Les ômes : les âmes, désigne dans ce cas les âmes du Purgatoire.

Chossez : chassez.

Deux bois magiques pour conserver une place.

Seil : sel.

Sabre : sable.

19 Bonce bourse.
} 
une petite croix, foite en écose ${ }^{1}$ acasions pour enturés de vent la pote de la personne ${ }^{2}$.

\section{L'Oraison pour le Combat :}

Alphosuda Malter Orat

Panatra ponotra Coniais ostrol

Conaio apheuis gorgamde Veniat

Serobout quand vous frapper le coup, je dis je vous becté

Régina gagna Voi la une manière pour cueux opère coune L'oncien le nonnee Jersil ${ }^{3}$.

\section{Secret du bôton du bon voyageur ${ }^{4}$ :}

Vous cuillerez le lendemain de la Toussoin ${ }^{5}$ une forte branche de sureau dont vous ferez un bôton que vous approprierez à votre move ${ }^{6}$. Vous la creuserez en otout ${ }^{7}$ la moëlle qui est dedans après l'avoir garni le bout d'un bas ${ }^{8}$ d'une virole de fer, vous mettez au fond du bôton les deux yeux d'une jeune bœufs, la longue ${ }^{9}$ et le cœur d'un chien trois lézards verts, trois cœurs d'hirondelle et que tout cela soit sécher au soleil entre deux papiers, les ayonts auparavant soupoudrés de fine poudre de salpêtre et vous mettez par dessus tout cela dans le boton sept feuilles de vervoines ${ }^{10}$ cueilli la veille de St JeanBaptiste.

Contre poison pour boire chez vous avant que vous sortez pour allez n'importe qu'elle endroit :

Vous achetez un cornet poudre de cerf vous prenez un peu feuille du poid engaule blonc ${ }^{11}$ vous pillez ${ }^{12}$ les feuilles des poids engaule bien fin vous prenez trois morceaux racines accasial blanc ${ }^{13}$ vous vous procurez un gros

Écose : écorce. Acasions : acacia.

Pour enterrer devant la porte de la personne.

La plupart des mots sont absolument incompréhensibles. Malter orat est probablement pour Mater oral ; viennent ensuite des onomatopées correspondant peut-être au bruit du combat. Conaio ou Coniais s'apparentent peut-être à cogner, gorgam doit désigner la gorge. La dernière phrase signifie : Voilà une manière pour ceux qui opèrent comme l'ancien nommé Jersil. « Jersil se serait servi de narcotique (on n'a jamais eu de précisions) pour voler et violer. Jugé vers 1906, il fut condamné aux travaux forcés à perpétuité. » (Note du P. Delawarde.)

Secret du bâton du bon voyageur.

Toussoin : Toussaint.

Move : mouvement, par conséquent ici à votre taille.

Otout : ôtant.

D'un bas : d'en bas.

Longue : langue.

Verveines : verveine (Heliotropium parviflorum L.).

Pois d'Angole blanc (Gajanus Indicus Spreng.).

Pillez : pilez.

Accasial : acacia. Acacia blanc : Acacia paniculata W. ou Amourette. 
patate blanc sotir dans le sable du bord de mer ${ }^{1}$, vous gragez ${ }^{2}$ cette potote sur une petite grage vous prenez l'eau de cette potote, vous jetez la racine vous mettez toutes ces compositions ensemble dans une bouteille pour foire une seule ${ }^{3}$ vous ajoutez la dedons une misse ${ }^{4}$ l'huile d'olive, vous ajoutez encore dedans une roquille cognac avant que vous portez chez vous ${ }^{5}$ pour aller n'importe quel endroit vous n'avez qu'à prendre une cuillerée la dedons pour boire de la vous serez à l'abri de poison que vous buvez ${ }^{6}$.

\section{Charmes pour les femmes :}

Poudre commondoire ${ }^{7}$.

Essence coulibri poudre coutorie deux cois foulant duférents ${ }^{8}$.

\section{Pour se faire aimer :}

L'herbe neuf chemin, Ite Concordia ${ }^{9}$ je te ramasse au nom de Jeheva pour que tu m'attache l'amitié... d'une telle ${ }^{10}$ il faut jeter la dite herbe sur la personne que vous voudriez en avoir ${ }^{11}$ excepter en jetant la dite herbe ${ }^{12}$ il faut la personne dire ${ }^{13}$ ces cinq paroles trois fois Allis Alla. Bac. Kirobac Retroga matou.

\section{Pour se rendre invisible :}

Vous prenez un chat noir, vous la tuer, mois il ne faut pas la brûler il faut l'écorcher. Vous achetez un miroir, un brisquet une pierre d'agathe d'aimant et de l'amadou ${ }^{14}$, vous vous procurez un pot neuf, obsevez il faut aller au cour de

Une grosse patate blanche sortie (poussée) dans le sable du bord de mer.

Gragez : râpez.

Vous mélangez toutes ces compositions dans une seule bouteille.

Misse : muisse ou demi-roquille, la roquille valant un quart de litre.

Avant de partir de chez vous.

Vous serez à l'abri du poison que l'on vous fera boire.

Poudre commondoire: probablement poudre commandoire, qui commande, le P. Delawarde interprète poudre du commandeur.

8 Essence de colibri, poudre de cantharide, le P. Delawarde interprète les quatre derniers mots : deux bois foulant différents...

9 L'herbe neuve du chemin de sainte Concordia (P. Delawarde) ; on peut admettre aussi la formule de mauvais latin Ite Concordia ce qui donnerait: l'herbe neuve du chemin, Ite Concordia, je te ramasse.

10 Au nom de Jeheva : déformation de Jehova.

En avoir : avoir.

Cependant en jetant la dite herbe.

13 Il faut que la personne dise.

14 Brisquet : briquet pierre d'agathe d'aimant : les deux termes sont inconciliables, il existe à la Martinique de la magnétite dans les sables du bord de mer, et des jaspes et calcédoines, la pierre d'agathe d'aimant serait alors tout simplement un morceau de calcédoine servant à battre le briquet. 
minuit ${ }^{1}$ dans une fontoine prendre de l'eau pour cuir la viande et quel bruit vous entendriez ${ }^{2}$ il ne faut pas bouger ni regarder derrière vous.

Maintenant il faut vous procurer du chorbon de lourier ou de coudrier ${ }^{3}$ pour cuir la viande vingt quatre heures observer il fout ${ }^{4}$ la tenir couvert durant le Vingt quatre heures avec la moin ${ }^{5}$ gauche sur la couverture après avoir bouillir vous déchausserez toute la viande sur les os en prononçant ces cinq paroles quad, tibi, do nihil, amplices sous la perdre aucune os ${ }^{6}$, après quoi vous vous regarderez dans le miroir et mettre les os un à un dons les dents du côté gauche ${ }^{7}$ en prononçant les paroles suivantes Pater in manus jusqu'à tout il arrive le bon ${ }^{8}$ en prononçant toujours les mêmes paroles sitôt vous le verrez plus ${ }^{9}$ dans le miroir vous portez à reculons ${ }^{10}$.

\section{Lampe éternelle :}

Huile avone double ${ }^{11}$, houile du russin ${ }^{12}$, houile du rose, houile Jérusalem, houile les sept dants ${ }^{13}$, houile du St Esprit, houile la menthe glaciale, sierge lachendeloire de moi de moi de Marie ${ }^{14}$, vous irez dans le semitierre ${ }^{15}$ vous comptez sept fosse vous lui implorez vos besoins ${ }^{16}$ vous prendrez un peu de terre dans le milieu de ce fosse allumé la un peu le cierge la place du marché ${ }^{17}$,

Au cour de minuit : au coup de minuit.

Quelque bruit que vous puissiez entendre.

Charbon de laurier ou de coudrier. Ce dernier arbuste n'existe pas à la Martinique, mais " on utilise le goyavier, plante qui se plie comme le coudrier et dont on peut faire des baguettes ». (Note du P. Delawarde.)

Fout : faut.

Moin : main

Sous la perde aucune os: sans perdre aucun os. Les formules de latin macaronique qui précèdent n'ont aucun sens suivi.

Mettez les os, un à un, entre vos dents, du côté gauche de votre mâchoire.

Jusqu'au moment où arrive le bon (jusqu'à ce que la chose se réalise).

Aussitôt que vous ne verrez plus votre image dans le miroir.

10 Vous partez à reculons. Deux brèves remarques : les prières de l'Église sont ici employées à des fins peu canoniques et considérées comme efficientes en elles-mêmes : Pater in manus. D'autre part, il arrive fréquemment dans les mornes que les chats, surtout noirs ou tachetés de blanc, soient enlevés par des voisins peu scrupuleux, qui les consomment à des fins à la fois alimentaires et magiques. Il est incontestable que beaucoup donneraient cher, maintenant encore, pour avoir la faculté de se déguiser, comme on dit, en courant d'air. J'ai surtout retenu le cas d'un personnage qui tenait à tout prix à cette faculté pour remplacer, auprès d'une certaine Hortensia, son amant en titre, pourtant balayeur de première classe. Il possédait, et ses héritiers possèdent peut-être encore, un cahier de recettes de plus de cent pages, sur lequel il y aurait quelque intérêt à pouvoir mettre la main.

11 Huile de lavande double.

12 Huile de ricin.

13 Huile des sept dons.

14 Un cierge de la Chandeleur du mois de mai de Marie, ce qui doit sans doute s'interpréter : un cierge de la Chandeleur et un cierge du mois de mai.

15 Semitierre : cimetière.

16 Vous lui implorez vos besoins : vous vous adressez au mort qui se trouve dans la septième fosse, et dans votre prière vous lui exposez vos besoins.

17 Il ne faut pas tenir compte de la ponctuation mise au hasard. La phrase semble signifier: prenez un peu de terre au milieu de la fosse, allumez au même endroit le cierge. 
vous prendrez terre devant lamérie ${ }^{1}$, un peu de terre devant le palais la Justice ${ }^{2}$ un peu de terre dans le milieu de la grande rue. Vous prendrez un gros colbosse ${ }^{3}$ vous le coupez en deux vous prendrez la moitié vous le nettoyer bien propre pour mettre un dans noivoine ${ }^{4}$ et l'autre moitié vous le crottez ${ }^{5}$ et le mettez dans un coin de votre chambre fosse en bas ${ }^{6}$, vous prendrez un peu eau de Vendredi St, un pied balloi doux ${ }^{7}$, un pied menmisa ${ }^{8}$, après la volonté du Seigneur, un pied poule ${ }^{9}$ à l'honneur du St Pierre de Paradis et vite St Pierre ces vous qui donne ${ }^{10}$ le pouvoir de lié dans le cièle et lié sur la terre avec tout le mondes ${ }^{11}$ et vous prendrez les trois pieds arbes vous le pillerez ${ }^{12}$ pour prendre le jus pour foire eau de neuvoine et vous le mettez dans le coin avec une choupine l'huile amone double ${ }^{13}$, ayez bien soin de mettre toutes les terres au fond de la lampe et une petite canarie neuf ${ }^{14}$.

\section{Si une femme vous a laisséz pour la reprendre :}

Vous allez au marché vous achetez une petite canarie neuve environ sept sous sur le nom de la personne. De la vous achetez mois sous le nom de la personne ${ }^{15}$ vous allez dans trois boutiques diférentes vous achetez dans la première 50 cent l'huile d'olive dans la $2^{\text {me }} 50$ cent l'huile du riçin dans la troisième 50 cent l'huile quinqué mois achetez toujours sur le nom de la femme vous allez à la rivière vous prendrez un peu d'eau dans un courant ${ }^{16}$ sur son nom vous achetez une boite de mèche ${ }^{17}$ vous mettez l'eau au fonde de la petite canarie et mettez les huiles. alumez votre lampe avec une alumette en disant : une telle j'allume cette lempe ces ton coeur que j'allume ${ }^{18}$ c'est pour foire ce que je veux avec ton esprit et je prétends que tu viendras me trouver d'après la

Sur la place du marché, vous prendrez un peu de terre devant la mairie.

Le Palais de Justice : il ressort de ces deux déterminations que la formule a été composée dans un bourg où la mairie est en face de la place du marché et où il $\mathrm{y}$ a un «Palais de Justice », c'est-à-dire au moins une Justice de Paix : il s'agit donc d'un chef-lieu de canton.

Colbosse : calebasse.

Pour que l'une des moitiés serve à une neuvaine (on y versera un liquide approprié).

Crottez : ici grattez.

Fosse en bas : face en bas.

Balai doux : Scoparis dulcis L., herbe très employée dans la pharmacopée locale. On se sert de ses tisanes contre les maux d'estomac, les maux de gorge et toutes sortes d'indispositions.

8 Menmisa : mimosa. Il s'agit probablement de la sensitive : Mimosa pudica L., dont la racine est très employée à tous usages.

9 Pied Poule Eleusine Indica Gaertn. Les racines sont employées comme calmants. Cette plante pousse facilement sur les emplacements d'anciens fours à charbon. On prétend qu'on est sûr de trouver du charbon de bois dans ses racines le 24 juin. Les autres jours, on risquerait d'avoir affaire à un esprit malin. Cf. Thomarel, Contes et paysages, p. 154.

10 Vite pour dites : dites « Saint Pierre c'est vous qui donnez ».

11 Avec tout le monde : le pouvoir de lier de saint Pierre s'exerce sur tous sans exception.

Pillerez : pilerez.

13 Amone double : amande double.

14 Ayez bien soin de mettre toutes les terres, au fond de la lampe et un petit canari (pot en terre) neuf, c'est-à-dire au fond de la lampe faite avec un petit canari neuf.

15 Sous est mis ici pour sur.

16 Courant : endroit où une rivière coule rapidement.

17 Mèche : il s'agit ici de mèches à veilleuses flottant sur l'huile.

18 C'est ton cœur que j'allume. 
du grand Rofocal et l'esprit enfermer ${ }^{1}$. La lampe pourrait rester trois jours allumer et durant ce temps l'esprit de la femme sera précipiter $^{2}$ et quand la lampe commence à s'étinde elle viendra chez vous sertennement ${ }^{3}$.

Tel se présente le cahier de quimboiseur pris au Lorrain il y a une vingtaine d'années : nous n'y ajouterons que quelques commentaires.

Il est écrit non en créole, mais en français, très corrompu d'ailleurs. On a parfois l'impression que certaines au moins des formules avaient été rédigées à l'origine dans une langue correcte, qui s'est altérée de copie en copie. Il est assez curieux de constater côte à côte des mots ou des expressions relativement difficiles convenablement orthographiés tandis que d'autres sont entièrement défigurés. Les formules magiques proprement dites demeurent en grande partie incompréhensibles. Peut être y pourrait-on soupçonner quelques essais d'harmonie imitative, comme dans l'oraison pour le combat. Leur allure, à l'occasion, de latin macaronique n'exclut pas à l'origine une plaisanterie de lettré, prise au sérieux par ses victimes.

On peut remarquer également que la plupart des plantes citées au passage sont fort employées dans l'«apothiké créole », la pharmacopée locale, et jouissent de qualités certaines reconnues depuis longtemps par les botanistes et les médecins : le sorcier a toujours été aussi un guérisseur.

Quant aux conclusions d'ensemble qu'on pourrait tirer de ce document, elles rejoindraient de toute évidence celles auxquelles nous a déjà conduits l'étude générale de la magie martiniquaise. Sur vingt-huit formules il en est sept, soit exactement le quart, qui concernent l'art de charmer ou décharmer, dont cinq visent spécialement à subjuguer les femmes et à les amener chez soi. Comme on ne trouve nulle trace dans le même recueil de philtre destiné aux hommes, on peut admettre que la clientèle du sorcier auquel il a été confisqué était exclusivement masculine.

Viennent ensuite, à égalité, les affaires d'empoisonnement et de chance au travail. À côté d'un procédé pour donner la lèpre et d'un autre " pour poison », quatre autres ont une vertu protectrice. Leur seule existence témoigne d'ailleurs combien demeure ancrée dans les campagnes martiniquaises la croyance aux empoisonnements et aux dangers que peut faire courir un "punch » pris en mauvaise compagnie. Cinq recettes concernent la chance, soit générale, soit particulière. Il s'agit de se " clouer » dans une bonne place. Une autre permet de se débarrasser des concurrents gênants. Puis viennent les oraisons, dont une à saint Joseph, que l'on regarde à la Martinique comme le plus grand saint du Paradis, et l'autre pour le combat. Enfin, toute une série de secrets pour guérir la vérole, fort répandue, envoyer quelqu'un voler, faire parler une femme en sommeil, avoir une lampe qui ne s'éteigne jamais, se procurer le bâton du bon

D'après la du grand Rofocal : d'après la volonté du grand Rofocal (autre forme de Ravocal) et de l'esprit enfermer : infernal.

Précipité : tellement troublé qu'elle ne sera plus maîtresse d'elle-même.

Étinde : éteindre. Sertennement : certainement. 
voyageur, le plus beau de tous permettant de se rendre invisible. Rien en revanche sur l'Anticri, les esprits « voyés », les zombis, les engagés. Cela seul marque les limites du document, qui ne correspond donc qu'à un aspect pittoresque, mais nettement délimité et restreint de la magie martiniquaise.

Formule de «bains consolidé » accompagnant le Cahier extrait du Grand et du Petit Albert, mais d'une autre écriture :

\section{Bain consolidée :}

1 pied à poule (Eleusina Indica Gaerth.),

1 feuille lavande du champ ;

3 feuilles reforts (raifort),

3 pied dandaillet (racine d'Arada),

1 pied agomant,

1 branche lilas en fleurs,

3 fleurs mal papagne (papaye),

1 branche patte choulie,

9 feuilles vigne noir, (trèfle),

1 paquets racine vetivert.

\section{3}

Ajoutez alcalie Ether, assa foetida, bay-rhum, baingnez 3 fois dans le même bain lumière pour les âmes et les saints. 


\section{Larsenale (sic) des Sorciers}

$\underline{\text { Retour à la table des matières }}$

\begin{tabular}{ccccccccc}
\multicolumn{1}{c}{} & $\mathrm{A}$ & & & \\
& & $\mathrm{A}$ & $\mathrm{B}$ & & & \\
& $\mathrm{A}$ & $\mathrm{B}$ & $\mathrm{R}$ & $\mathrm{A}$ & & \\
$\mathrm{A}$ & $\mathrm{B}$ & $\mathrm{R}$ & $\mathrm{A}$ & $\mathrm{C}$ & \\
$\mathrm{A}$ & $\mathrm{B}$ & $\mathrm{R}$ & $\mathrm{A}$ & $\mathrm{C}$ & $\mathrm{A}$ \\
$\mathrm{B}$ & $\mathrm{R}$ & $\mathrm{A}$ & $\mathrm{C}$ & $\mathrm{A}$ & $\mathrm{D}$
\end{tabular}

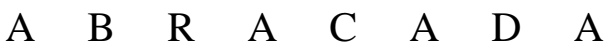

$\begin{array}{llllllllllllllll}A & B & R & A & C & A & D & A & B\end{array}$

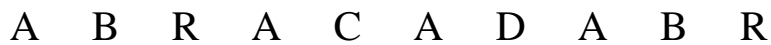

$\begin{array}{llllllllllll}\text { A } & B & R & A & C & A & D & A & B & R & A\end{array}$

Les talismans d'amour ou scapilaires (scapulaires)

Formule accompagnant les extraits du Grand et du Petit Albert, sur un bout de feuille déchirée, mais signée par le possesseur du cahier. 


\section{Correspondances}

\section{$\underline{\text { Retour à la table des matières }}$}

Lettre adressée de Sainte-Luce, le 21 juillet 1938, au Chef du Service de l'Instruction Publique à Fort de France :

Je viens vous donner ma déposition. Veuve de puis 9 ans avec deux enfants sur ma peauvrasion ${ }^{1}$ seul mais de puis 4 ans on me donne un petit secour tout les mois par le couvenement ${ }^{2} 30$ francs C'est avec cette argent que je payérér ${ }^{3}$ une chambre car je ne ${ }^{4}$ pas de logement Mon mari est mort à Guadeloupe, 3 mois après la mort de mon mari une personne me fait des visions ${ }^{5}$ la personne me poserèr une botte à la tête ${ }^{6}$, on a dit une fludre qui sans flutrais ${ }^{7}$ à Paris quand ces grossiserais ${ }^{8}$ et la personne sait lacherer un mauvais ames ${ }^{9}$ encore apres moi auquel qui me pousuivais partout ${ }^{10}$ j'entant une voie qui me diserais des betise et je ne voie personne. durant les 9 ans il y a un ans on méfarrer ${ }^{11}$, on me fait tomberér evanenuie avec les éfards ${ }^{12}$, enfin je déclare à la justice au Couvenement que je ne plus la force de surtorter encore ${ }^{13}$ Car il y a 9 anné que je marcherèr dans la foudre ${ }^{14}$ une pauvre Veuve je crois que c'est moi, ... qui est la plus foufrante ${ }^{15}$ de la Martinique.

Il y a un an que une personne qui s'apele... qui me farrer ${ }^{16}$ et sa fenie qui s'apéle...

... Il y a encore... qui me donne de la foudre qui me farrèr et il me surveil avec son revolverre en main il vient juis au ${ }^{17} \ldots$ au troisieme kilomaitre pour me

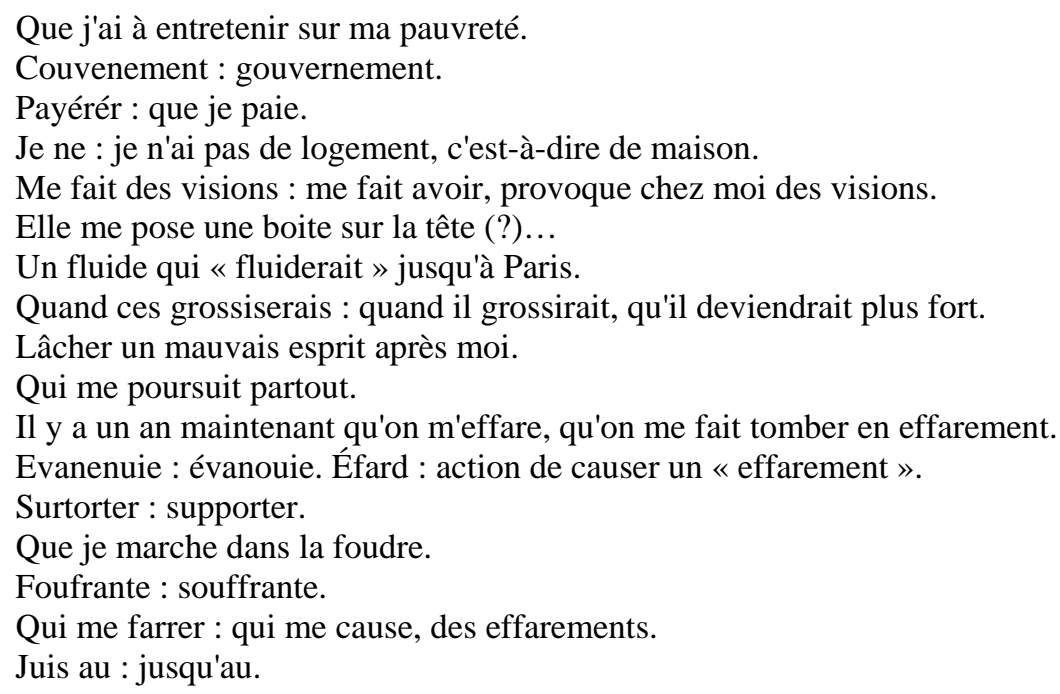


donnér de la foudre dons son hoto ${ }^{1}$ il viens me donner la foudre toutes le jour et il me surveil toute la nuit pour me donner de la foudre et avec son revolvèr en main et on me donner des ingers nouveaux en penses ${ }^{2}$ il y a encore hoto de... qui me donne de la foudre enquantitér dans son hoto en passans au quartier car j'étais au bourg il y a un mois que je suis a la campagne et tout les resanton cette foudre ${ }^{3}$ et on me donne des enguelement encore me disant que j'ai des bon clilant ${ }^{4}$.

Ce matin 20 Juillet je suis si couver ${ }^{5}$ de la foudre de la fumè je ne écrire a la ligne Monsieur ${ }^{6}$.

Veuillez m'exuser car je népas du tout du tout Orthographe tent que on méfarér ${ }^{7}$ on m'a donnu un sur non les éfard... ${ }^{8}$

Lettre de charation d'amour pour jeune homme :

Mademoiselle

Je vous prie pardonnez mon audace Joses vous Ecrire mais lisez Ma lettre sans crainte elle neprimera que mon recpet pour vous Cest lexuse que Jenvoque pour obtenir votre mansuetude Jait subi le chame qui de degage de vous au point quein sentiment nouveu un trouble extreme ont envahi mon cœur et depui ce jours je nai plu le calme des anciens jours Je ne vi plus est passe mes nuits anrîvé De vour ne vour de trounez pas de vois au la vie perdra tout son prix Mon sort est entre de vos main Je nen doute pas vous asez reçu d'autre hommage d'autre decharation plus décharnatoires auqun plus sincere Mon trouble minterdit toute perfection de style Jexprime male mes pences mais vours jugerez si vous voulez bien me mieux connaître que vours navez pas d'adorateur plus sincere et plus pasionné que moi Je vous en trourerai devouement le plus tendre et consacrerais ma vie a la votre Je manque aux regle de la correction en osant vous écrire ainsi pardonnez moi en faveur de ma franchise soyez sinsible a ma prière ayez pitié de mon

\section{A Mours}

Il s'agit évidemment d'une lettre recopiée à l'origine dans un manuel quelconque du parfait secrétaire et, j'insiste, recopiée avec soin. Il n'en est que plus intéressant de voir les déformations déjà profondes que le texte original a subies: pas de ponctuation, mots réunis ou séparés au hasard, déclaration

\footnotetext{
Hoto : automobile

Signifie peut-être ; il introduit des ingrédients, des éléments nouveaux dans ma pensée (?).

Tous ressentent cette foudre.

On me donne des « engueulements », on me fait des reproches en me disant que j'ai de bons clients (pour me donner la foudre).

Je suis si couverte par la foudre.

Et par la fumée que je ne (puis) écrire à la ligne.

On m'a tant « effarée ».

Qu'on m'a donné, un surnom : l'effarée.
} 
devenu « de charnation » d'où les décharnations décharnatoires, "pences » au lieu de pensées. Ainsi naissent les confusions et plus tard les mythes...

Texte recueilli en 1949.

Lettre d'amour, authentique, et dont je possède 1'original :

\section{Le 5 Marse 1948}

Mademoiselle, J'ai le plésir de vous faire obtenir Une désièmes lettes pours vous faire savoirs ques jér déjas Dépensé, Dix-setp plume troi car ; pour faire Contre Quelque Chose ; de même que le soleil Ecjeptes Sa premièr Rayons de lumière sur le Montagne de Sinaï ; Mademoiselle ; La vie sais les désairte Et la femme est une Charmeaus pour traversé les désairte il faut Monter sur le Charmeaus Sans vous la femmes je ne puis vivre, Est que vous alez Considéré ma lette, Mademoiselle M.... Ne regarde pas ; petit ous frier ; L'homme qui jémie sur ses poins, acablanc de préjugez de ta la presomptions cé l'homme qui cousant capables,

\section{Mon refrain Damour}

Vivre dans tes bras

Et la mort m'endormira Dans tes bras

Pense et liser ces most vous moubliras jamais

Et le ciel est a nous de nous aimer pour toujours

Mon guide et mon témoin je trouve que c'est I vous, Le dieu est juste

Voulan uniquement penser et plaire à vous

Ma langue au point du jour mur nuir sur vous

Souvent je crierai le douce non ce vous

Et je prendrai mai repas dans vos yeux en vous voyants

Dans mes pleurs je ferai mes soupirs pour vous

Et mes transports d'amour serons dan la joie pour vous

Réponse

$$
\mathrm{X}
$$

Deux courtes remarques. L'auteur de la lettre a déjà dépensé, dix-sept plumes trois quarts pour faire Contre quelque chose, ce qui est avouer nettement l'emploi de conjurations. La lettre elle-même et les prétendus vers qui l'accompagnent renferment des formules à prétentions magiques avec ce rappel du Sinaï, du désert, du Dieu juste qui correspondent à la diffusion récente de manuels d'origine européenne ou haïtienne.

La majeure partie de la lettre est facile à comprendre il suffit presque de la lire à haute voix et de se souvenir que le créole ne prononce pas les $r$. La fin semble signifier que la demoiselle, à qui ce chef-d'œuvre est adressé, ne doit pas regarder au fait que son amoureux n'est qu'un petit ouvrier (ous frier). Car l'homme qui gémit sur son mal, accablé par l'audace de sa présomption et les préjugés qu'il redoute chez sa bien-aimée, est tout de même celui qu'on sent capable de les surmonter. 
Les vers, qui semblent avoir été copiés également dans un recueil, ne présentent que deux légères difficultés : I a été mis pour en, d'autre part, « mur nuir » veut dire tout simplement murmure...

Mardi 25 Janvier 1949

$$
\text { gramaires Conjugensonts }{ }^{1}
$$

Le focheur aut travalle, je le voit' LOUENT qui avans de petits pas, GLISENTS s'est sabot, Ous il a mie ses pied nuts marque DURENTS PARALÊLENTS, la feaux coupets de droite a CAUCHENTS, d'un trents rapide est sur prix il revients la pointe et du dots, et CARÊNTS l'erbenssuivant qui vas tomber, tantôt els grinsents sas et la prêts, les grandens d'erbes frisonnets - d'un dutude, et brusquement els a auquêts sur un Cayvours, hpilipe sarêtes talents la lam ets - du droixts et la filents avec une pièrents a-églizé, souts le ventre dans un Cornets de broit, et mintenents, il sesfères labarbes,

\section{Question a espliquet}

ilsa un auquêts sur un Cayourt il ses fêrent la barbes remplacer une verbes de même

Carrêsents, frissonnents, tates, a filents ;

Il s'agit ici, en principe, d'une dictée française suivie de questions. J'ai reproduit, sans rien y changer, le texte que j'ai entre les mains. J'avoue n'avoir pu le comprendre dans son entier. Il ne s'agit plus de "créole », mais de déformations en partie imprévisibles. Voici, pour les Edipe que ce travail de déchiffrement amuserait, quelques indications: il s'agit d'un faucheur au travail, louent : loin ; mie mis ; trents : train ; la pointe : l'appointe ; du dutude d'habitude (?) ; auquêts : choqué ; hpilipe : Philippe ; pièrent à églizé : pierre à aiguiser...

Textes adressés Par Mme Clémence Vve Lernot en 1929 à la «mission volcanique » chargée de surveiller le réveil de la Pelée.

I. - Texte dactylographié :

\section{ANCIEN TESTAMENT}

En ces jours s'assemblèrent près de Moïse et d'Aaron les Fils d'Israël et d'un ton plein de révolte ils crièrent Donne nous de l'eau nous voulons boire. Moïse et Aaron après avoir congédié cette multitude se prosternèrent le front contre terre devant l'Arche d'Alliance et crièrent au Seigneur ces paroles : Seigneur

\footnotetext{
Voir fac-similé dans les hors-texte.
} 
Dieu, entends la clameur de ce peuple, ouvre-lui le trésor de ta pitié en lui donnant une source d'eau vive, afin qu'étant rassasié, cesse leur murmure et que brille à leurs yeux la Gloire du Seigneur. Rendons Graces à Dieu. Moïse frappa le rocher deux fois avec sa baguette mystérieuse et prophétisa deux bois : la Croix sur laquelle le sang de Jésus devait jaillir pour le péché du monde. Moi petite créature, après avoir rendu grace à Dieu de ce qu'il m'exorce ${ }^{1}$, j'ai le pouvoir de frapper la terre par trois fois et d'éteindre le feu s'il y en a encore qui vient dans le volcan.

Clémence Vve LERNOT.

\section{II. - Bénédiction des Saints}

(citée intégralement dans le texte de, l'étude d'ensemble, pp. 61-62).

$$
\text { III. - Le Génie divin (imprimé). }
$$

Ma langue n'est point comme la plume du savant écrivain, mais Dieu déposa une grâce particulière sur les lèvres de sa petite servante. Je suis obligée en toute conscience de faire connaître mon pouvoir.

Dans une personne qui professe la science divine, il faut remarquer trois choses : la foi, le savoir, le don de Dieu.

La foi. - Le verbe s'est fait chair et il habite parmi nous. Dieu est avec nous comme il était dans la barque avec les apôtres en danger. Voici la science sublime sans limite devant laquelle les autres sciences ne sont que faiblesse. Nous, les serviteurs de Dieu, nous sommes les héritiers de la puissance du Christ. Voici le testament : En vérité, en vérité, je vous le dis, celui qui croit en moi fera lui aussi toutes les œuvres que je fais, et il fera même de plus grandes, Jean, XIV, 12.

« Tout est possible à celui qui croit (Marc, IX, 22).

En science divine, un volcan est inoffensif. »

Dès le début des éruptions j'ai dit il n'y aura pas de grand danger si l'on veut de moi. J'ai confié à mon Directeur, un curé chanoine, que je sais arrêter le volcan, étant sûr de ma parole après 20 ans d'expérience. il m'a d'onné l'ordre de l'arrêter. Pour arrêter un volcan qui menace gravement il faut une heure de travail. c'est ce que je fis le 21 décembre dernier. J'aurai dû y travailler trois fois dans une journée et cela pendant 9 jours. J'ai exercé seulement 6 fois dans l'intervalle de trois mois, et sans le secours de quiconque parce que l'on ne s'intéresse pas de moi.

Si on veut anéantir un volcan qui gêne absolument, le minimum de travail est de neuf jours, le maximum de 27 . Au bout de ce délai l'activité ne se

\footnotetext{
Exorce : exauce.
} 
renouvelle jamais plus, il faut y exercer de temps en temps avec des secrets que j'aurai pu donner pour après ma vie.

Et toi Mont Pelée, que j'appelle Mont Saint Janvier, tu n'es pas un gros joujou, et de ma bouche peuvent sortir contre toi des glaives à double tranchant.

Le Savoir. - Les premières paroles pour arrêter le volcan sont: "Père Éternel, montrez la force de votre bras à l'égard de vos petits qui sont à la Martinique; Seigneur Dieu, Fils, la force de votre bras s'est toujours merveilleusement signalée ; par cette même force nous anéantirons le volcan dans le plus bref délai, nous le voulons.

On est porté à dire que c'est Dieu qui a envoyé le feu dans le volcan : non, c'est lui qui l'arrête, au contraire. Le créateur est le directeur des éléments, aucun astre n'a jamais manqué au rendez-vous, et il les empêche de tomber sur nous. II y eut, sous Louis XIV, un cardinal qui était également géologue en science divine ; il avait exorcisé le Vésuve et obtenu de merveilleux résultats en y travaillant plusieurs fois. La France l'avait bien compris ; l'Italie l'a cru sorcier, mais le pape l'a approuvé parce qu'il sait que Dieu est le maître, et peut tout faire par sa seule volonté.

Je suis d'accord avec le cardinal, à part quelques rares exceptions, ce sont les mauvais esprits qui prennent possession du feu souterrain pour troubler les règles de la nature comme ils se sont révoltés dans le ciel en présence de Dieu lui-même. Nous ne prions pas assez, c'est pourquoi ils sont venus légion habiter le sein de la montagne, à nous les serviteurs de Dieu de les y déloger.

Il y avait jadis un archevêque géologue en science divine qui a laissé son œuvre dans laquelle j'ai puisé ma philosophie, alimentée par les dons que j'ai reçus de Dieu, et je considère un volcan en éruption comme un réchaud de feu.

Quand une personne sait commander un volcan et lui faire obéir immédiatement, sauver la vie à tout un peuple, elle sait travailler sans se croire de ce chef supérieure à quiconque.

Le don de Dieu. - À la Martinique, nous sommes un peuple privilégié. Dieu a choisi parmi nous une petite créature, et par elle il travaille, parce que c'est Dieu seul qui peut faire de telles merveilles. Et nous serons sauvés. En haut les cœurs. Nous les élevons vers le Seigneur, Rendons Grâce à Dieu pour chanter, humblement prosternés : Saint, Saint, Saint est le Seigneur Dieu Sabbaoth : les cieux et la Terre sont pleins de votre gloire : hosannah au plus haut des cieux. Béni soit celui qui vint au nom du Seigneur. Hosannah au plus haut des cieux.

Nous voulons vivre dans l'amour du Père Éternel et dans l'espoir de le voir face à face pendant toute l'éternité. Ainsi soit-il !

Clémence Vve LERNOT. 
Conte recueilli dans la région du Marin, au cours d'une veillée mortuaire :

\section{COMPÈRE LAPIN ET COMPÈRE ÉLÉPHANT ${ }^{1}$}

Compère éléphant revient de la pêche, son panier plein de poissons. Il croise compère lapin.

- Tu as fait bonne pêche, mon ami, donne-moi un peu de poissons.

- Tu n'en auras pas, rétorque compère éléphant, et il passe fièrement son chemin.

- Tu me le paieras, riposte lapin intérieurement.

À quelques temps de là, compère éléphant, portant une pèche merveilleuse, s'en retourne chez lui. La charge alourdit sa marche pesante.

Près d'un manguier qui ombrage le sentier ${ }^{2}$, il remarque un lapin allongé et rigide comme un cadavre.

- Pauvre ami ! et, méditant tristement, il poursuit sa route.

Trois pas plus loin, un lapin pareil est étendu tout roide et il a failli le heurter.

- Étrange coïncidence ! murmure compère éléphant. Encore un de mes amis qui meurt de la même façon.

À peine sa réflexion terminée, voilà un troisième lapin gisant, pareil aux deux premiers. Tous mes amis périssent ainsi, se dit-il, et, l'intérêt l'emportant sur sa pitié, il pense que trois lapins ajoutés à sa pêche seraient bienvenus dans sa cuisine. Il dépose sa charge au bord du chemin, avec le troisième lapin dessus, puis s'en retourne chercher les deux autres. Mais la route s'allonge, s'allonge... et de lapin point...

Il se décide à abandonner les deux lapins pour apporter chez lui le produit de sa pêche. Harassé de fatigue, il retrouve enfin son panier, mais vide, et, tandis qu'il se désole et essaie de comprendre, du haut d'un flamboyant, voilà lapin qui lui crie : «Que ton poisson était bon, mon cher ${ }^{3}$ ! »

1 Le terme de compère (compé) est très employé à la Martinique depuis les débuts de la colonisation. C'est ainsi que les Caraïbes dénommaient toujours les Européens avec lesquels ils s'entendaient.

À noter que le manguier a été introduit sous la Révolution.

3 Monographie du Marin, écrite à l'occasion du Tricentenaire en collaboration par Mme Saint-Cyr, directrice de l'école des filles, et M. Régis, directeur de l'école des garçons. 


\section{BIBLIOGRAPHIE SOMMAIRE}

\section{$\underline{\text { Retour à la table des matières }}$}

I. - Documents non imprimés :

DELAWARDE (R. P.). - Quimbois Martiniquais. Étude dactylographiée, $25 \mathrm{pp}$.

Monographies des communes et quartiers de la Martinique composées par les directeurs et directrices d'école à l'occasion du Tricentenaire (1935), inédites, conservées à Fort-de-France dans les archives du service de l'Instruction Publique.

II - Études imprimées.

Les Caraïbes de la Guadeloupe, 1635-1656, d'après les relations du R P. Breton, par l'abbé J. RENNARD. Paris, Ficker, 1929, in-8, 182 pp.

R. FORTUNÉ. - Quelques croyances populaires. Revue Guadeloupéenne (Basse-Terre), novembre-décembre 1945, pp. 37-42 ; janvier-février 1946, pp. 39-43.

R. P. LABAT. - Voyage aux Isles de l'Amérique. Duchartre, Paris, 1931, 2 vol. in-8 ${ }^{\circ}$, I, XVI-366 pp. ; II, 478 pp.

PAUL LABROUSSE. - Deux vieilles terres françaises: Martinique et Guadeloupe. Chez l'auteur à Colombes (vers 1935), in-8º 2, 191 pp.

L. NAY-REINE. - Fo-Yal. Imprimerie Bezaudin, Fort-de-France, 1935, in-8², 4+78+XXXVIII+18+6+8+ $29 \mathrm{pp}$

RAPHAËL TARDON. - Bleu des Îles, récits martiniquais. Paris, Fasquelle, 1946, in-8 209 pp.

A. THOMAREL. - Contes et Paysages de la Martinique. Imprimerie Antillaise, Fort-de-France, 1930, in-4º, $160 \mathrm{pp}$.

CLARCK WISSLER. - The American Indian. New-York, 2e édition, 1922, in$8^{\circ}$ XXI-474 pp. 